Prepared in cooperation with the U.S. Army Corps of Engineers' Upper Mississippi River Restoration Program, Long Term Resource Monitoring element

\title{
General Classification Handbook for Floodplain Vegetation in Large River Systems
}

Techniques and Methods 2-AI Version 2.0, November 2015

\section{U.S. Departiment of the interior}

\section{U.S. Geological Survey}

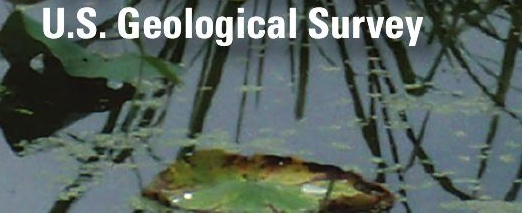

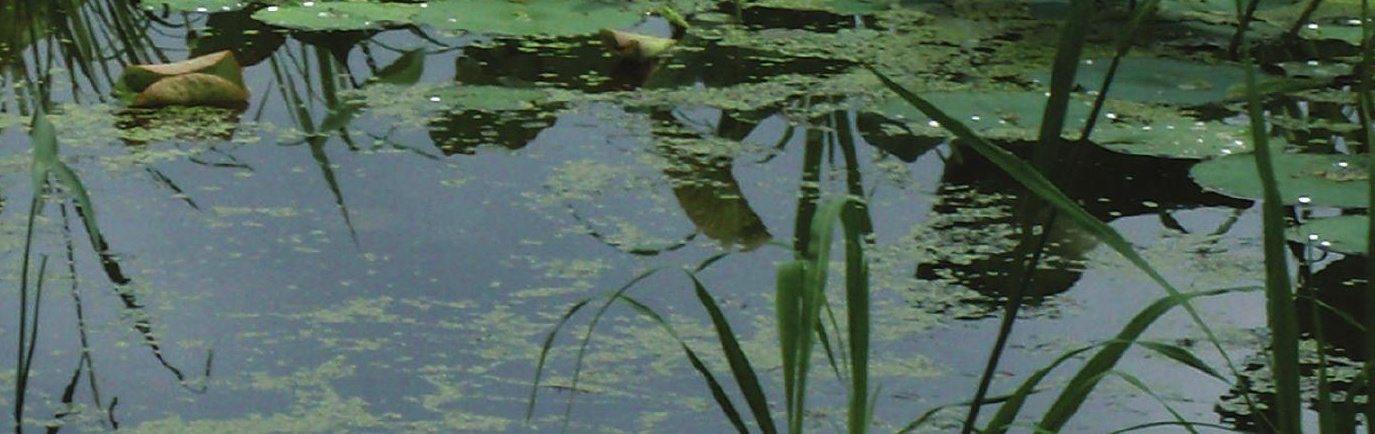


Cover photo and all other photographs. Taken by USGS or partner-agency employees, unless otherwise noted. 


\section{General Classification Handbook for Floodplain Vegetation in Large River Systems}

By Jennifer J. Dieck, Janis Ruhser, Erin Hoy, and Larry R. Robinson

Upper Midwest Environmental Sciences Center, prepared in cooperation with the U.S. Army Corps of Engineers' Upper Mississippi River Restoration Program, Long Term Resource Monitoring element

Techniques and Methods 2-A1

Version 2.0, November 2015 


\title{
U.S. Department of the Interior SALLY JEWELL, Secretary
}

\section{U.S. Geological Survey Suzette M. Kimball, Acting Director}

\author{
U.S. Geological Survey, Reston, Virginia: 2015 \\ First release: 2004 \\ Revised: November 2015 (ver. 2.0)
}

\begin{abstract}
For more information on the USGS - the Federal source for science about the Earth, its natural and living resources, natural hazards, and the environment-visit http://www.usgs.gov or call 1-888-ASK-USGS.

For an overview of USGS information products, including maps, imagery, and publications, visit http://www.usgs.gov/pubprod/.
\end{abstract}

Any use of trade, firm, or product names is for descriptive purposes only and does not imply endorsement by the U.S. Government.

Although this information product, for the most part, is in the public domain, it also may contain copyrighted materials as noted in the text. Permission to reproduce copyrighted items must be secured from the copyright owner.

Suggested citation:

Dieck, J.J., Ruhser, Janis, Hoy, Erin, and Robinson, L.R., 2015, General classification handbook for floodplain vegetation in large river systems (ver. 2.0, November 2015): U.S. Geological Survey Techniques and Methods, book 2, chap. A1, 51 p., http://dx.doi.org/10.3133/tm2A1.

ISSN 2328-7047 (print)

ISSN 2328-7055 (online) 


\section{Preface}

This series of manuals on Techniques and Methods (TM) describes approved scientific and datacollection procedures and standard methods for planning and executing studies and laboratory analyses. The material is grouped under major subject headings called "books" and further subdivided into sections and chapters. Section A of book 2 is on the collection of environmental data in biological science. The unit of publication, the chapter, is limited to a narrow field of subject matter. These publications are subject to revision because of experience in use or because of advancement in knowledge, techniques, or equipment, and this format permits flexibility in revision and publication as the need arises. Chapter A1 of book 2 (TM 2-A1) is the General Classification Handbook for Floodplain Vegetation in Large River Systems. The original version of this chapter was published in 2004. New and improved technologies and methods have resulted in this revised second edition of the General Classification Handbook for Floodplain Vegetation in Large River Systems. This edition supersedes the 2004 edition. This revised second edition of "General classification handbook for floodplain vegetation in large river systems" is published online at http://dx.doi.org/10.3133/tm2A1. 



\section{Contents}

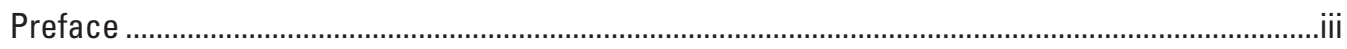

Contents

Abstract

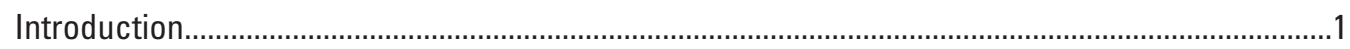

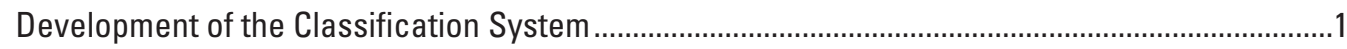

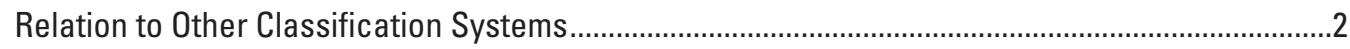

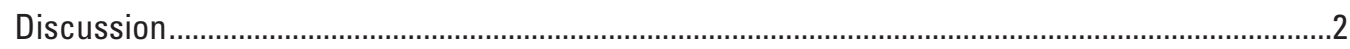

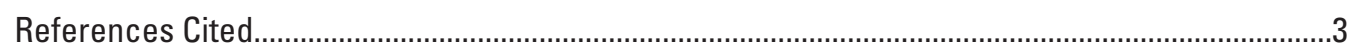

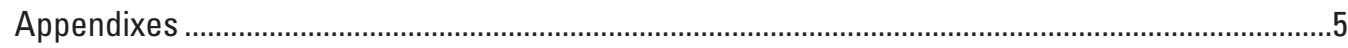

Appendix 1. Using the General Wetland Vegetation Classification System To Describe and Monitor Vegetation ………..............................................................................................

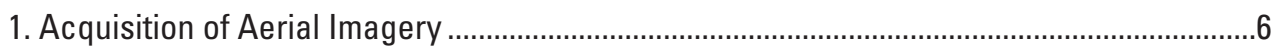

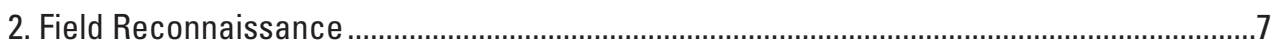

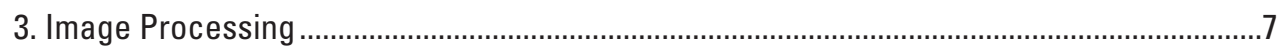

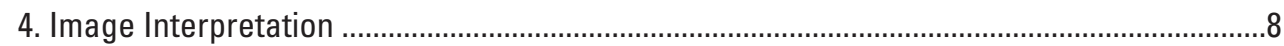

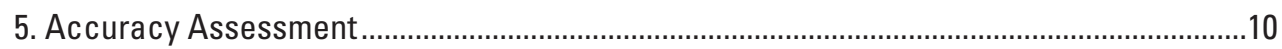

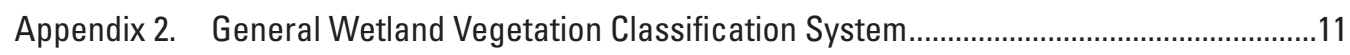

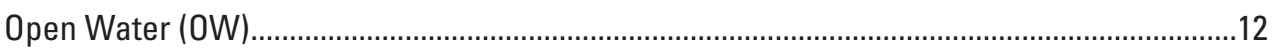

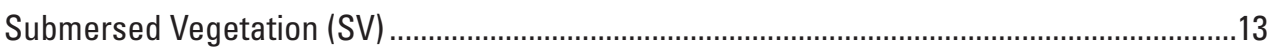

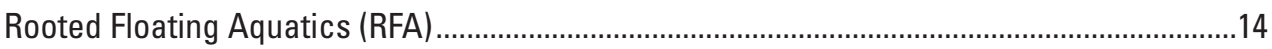

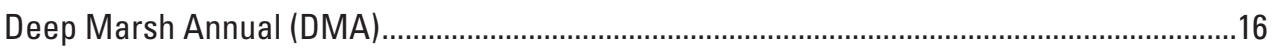

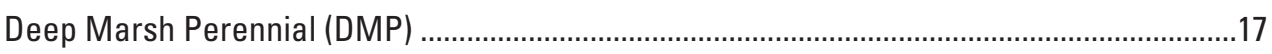

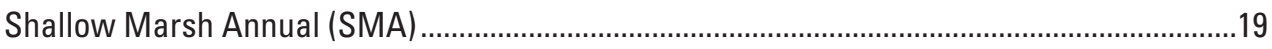

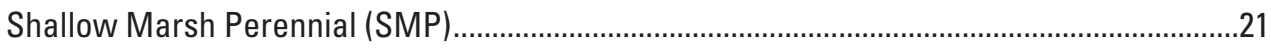

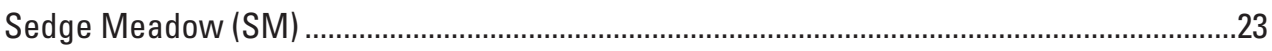

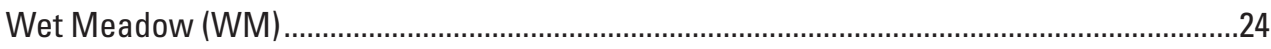

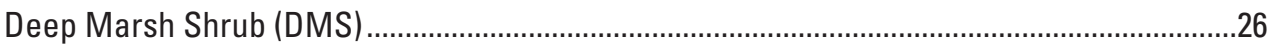

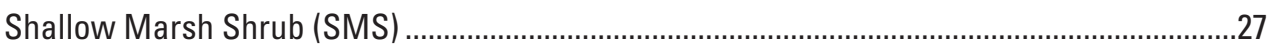

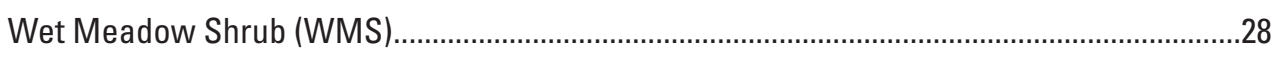

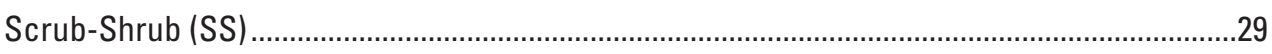

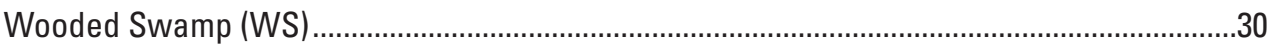

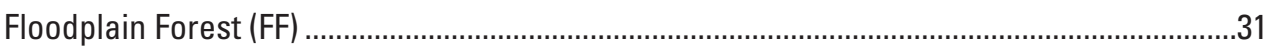

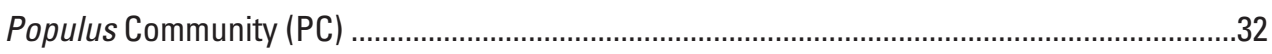

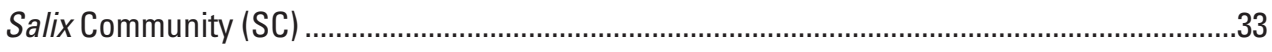

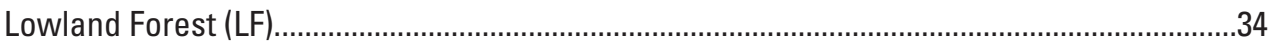

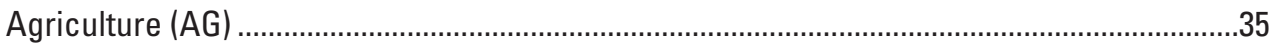

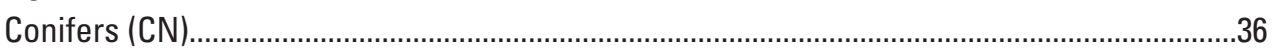

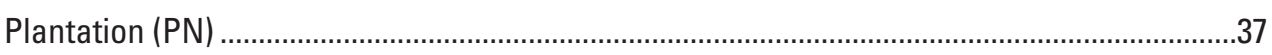

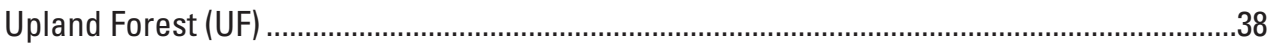

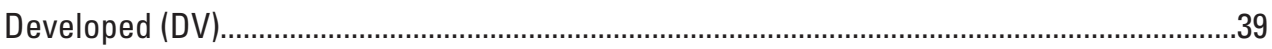

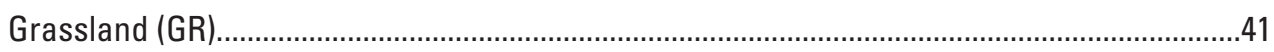

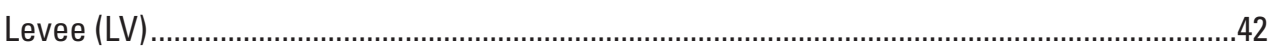

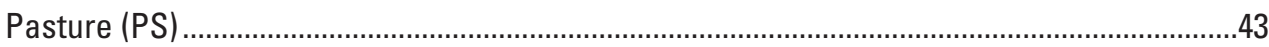


Appendix 2. Continued

Roadside (RD).

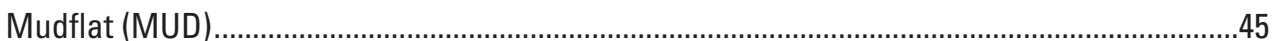

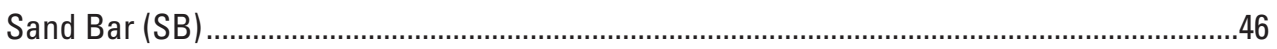

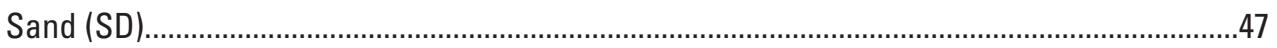

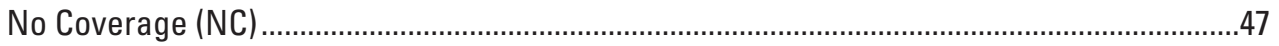

Appendix 3. Classification Key for the General Wetland VegetationClassification System ........48

Appendix 4. Representative Genera and Species and the Map Classes With Which

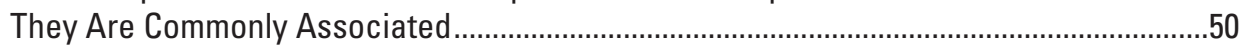

Appendix 5. Example Accuracy Assessment Contingency Table ...............................................51

\section{Figures}

1-1. Photographic comparison of $(A)$, low-resolution color-infrared (CIR) imagery with $0.4 \mathrm{~meter} / \mathrm{pixel}$, and $(B)$, high-resolution CIR imagery with 0.2 meter/pixel..............6

1-2. Photographic example of a flight plan on the Illinois River, shown in Google Earth.........6

1-3. Photograph showing field reconnaissance being performed by use of a ruggedized tablet computer..

1-4. Aerial photographic depiction of two different minimum mapping unit sizes (1 hectare and 0.4 hectare)

1-5. Photograph of a three-dimensional (3D) workstation used for image interpretation .......8

1-6. Depiction of the interpreted vegetation data layer, shown in Google Earth......................8

\section{Tables}

1-2. The 31 map classes, together with their respective codes, hydrologic regimes, and modifiers

2-1. The 31 map classes, together with their respective codes, and possible density and height modifiers

\section{Conversion Factors}

International System of Units to Inch/Pound

\begin{tabular}{lcll}
\hline & Multiply & By & \multicolumn{1}{c}{ To obtain } \\
\hline & Length & & \\
\hline centimeter $(\mathrm{cm})$ & 0.3937 & inch (in.) & \\
meter $(\mathrm{m})$ & 3.281 & foot (ft) & \\
meter $(\mathrm{m})$ & 1.094 & yard (yd) & \\
\hline & Area & & \\
\hline hectare (ha) & 2.471 & acre & \\
\hline
\end{tabular}




\section{Abbreviations}

$<\quad$ less than

$>\quad$ greater than 



\title{
General Classification Handbook for Floodplain Vegetation in Large River Systems
}

\author{
By Jennifer J. Dieck, Janis Ruhser, Erin Hoy, and Larry R. Robinson
}

\begin{abstract}
This handbook describes the General Wetland Vegetation Classification System developed as part of the U.S. Army Corps of Engineers' Upper Mississippi River Restoration (UMRR) Program, Long Term Resource Monitoring (LTRM) element. The UMRR is a cooperative effort between the U.S. Army Corps of Engineers, U.S. Geological Survey, U.S. Fish and Wildlife Service, and the states of Illinois, Iowa, Minnesota, Missouri, and Wisconsin. The classification system consists of 31 general map classes and has been used to create systemic vegetation data layers throughout the diverse Upper Mississippi River System (UMRS), which includes the commercially navigable reaches of the Mississippi River from Minneapolis, Minnesota, in the north to Cairo, Illinois, in the south, the Illinois River, and navigable portions of the Kaskaskia, Black, St. Croix, and Minnesota Rivers. In addition, this handbook describes the evolution of the General Wetland Vegetation Classification System, discusses the process of creating a vegetation data layer, and describes each of the 31 map classes in detail. The handbook also acts as a pictorial guide to each of the map classes as they may appear in the field, as well as on color-infrared imagery. This version is an update to the original handbook published in 2004.
\end{abstract}

\section{Introduction}

Vegetation mapping can be one of the most important tools used in vegetation science and landscape ecology (Zonneveld, 1988). It creates an inventory of existing vegetation types, along with information on their location and distribution at a particular moment in time. Changes in vegetation often occur more quickly and distinctly than changes in other ecological variables do, making vegetation a sensitive indicator of broader environmental changes (Zonneveld, 1988). Because vegetation is such an important indicator in the environment, scientists from many different disciplines are interested in vegetation data. Vegetation data layers within a geographic information system (GIS) can be used as a basis for analyzing the relations between vegetation types at a particular site or as a reference for observing and measuring change over time. This information can be extremely important for land-use planning.

This handbook describes a wetland vegetation classification system developed for large river floodplains in the Upper Midwest and explains how it can be used in the interpretation of aerial imagery to create vegetation data layers. The classification system consists of 31 map classes, and its primary use has been to interpret floodplain vegetation of the Upper Mississippi River System (UMRS) from color-infrared (CIR) aerial images. Descriptions are provided for each of the 31 map classes, illustrated with one or more representative images from the field. Also included are examples of each map class extracted from interpreted CIR aerial imagery and a description of the signature (the appearance of a particular map class on aerial imagery when viewed in stereo, including color and texture).

\section{Development of the Classification System}

Vegetation mapping is a critical component of the U.S. Army Corps of Engineers' Upper Mississippi River Restoration (UMRR) Program, which is a Federal and multistate partnership created under the Water Resources Development Act of 1986, and its Long Term Resource Monitoring (LTRM) element. The mission of the LTRM element is to provide decision makers with information to help facilitate maintenance of the ecosystem and navigation values of the UMRS. The long-term goals of the program are to understand the system, determine resource trends and impacts, develop management alternatives, and manage information. Vital to the LTRM element is the ability to accurately and efficiently map floodplain vegetation data layers. These data provide the framework for GIS analyses and for the ongoing evaluation of existing habitat conditions throughout the UMRS that guides the selection, design, and evaluation of Habitat Rehabilitation and Enhancement Projects (HREP). 
The classification of UMRS vegetation has evolved over time in response to partner-agency and data-interpreter feedback. The classification currently in use is a 2-tiered design that contains 151 genus-based classes, which collapse into the 31 general map classes that are the focus of this handbook. Known as the General Wetland Vegetation Classification System, this system was designed to be easily applied by interpreters and easily understood by resource managers. This classification has been in use since the 2000 UMRS mapping effort. The tiered classification approach allows for mapping at different scales and with different needs - a hydrology-based, genus-level classification for focused studies that collapses into broader categories for larger studies while maintaining the hydrologic distinctiveness of the detailed classes.

\section{Relation to Other Classification Systems}

Several vegetation classification systems have been widely used in describing vegetation patterns. These include the "Land Use and Land Cover Classification System for Use With Remote Sensor Data" as described by Anderson and others (1976), the "Classification of Wetlands and Deepwater Habitats of the United States" by Cowardin and others (1979), and the U.S. National Vegetation Classification (NVC) as established by the National Vegetation Classification Standard (NVCS; Federal Geographic Data Committee, 2008). The Anderson classification system was developed for use with remote sensing systems in the 1970s and is made up of a fourlevel hierarchy (Anderson and others, 1976). The Cowardin classification system places ecologically similar habitats into a more complex hierarchal system that includes several layers of detail for wetland classification (Cowardin and others, 1979). Lastly, the NVC was developed for use in conservation planning and biodiversity protection, as well as for the basic understanding of ecological patterns (Federal Geographic Data Committee, 2008). The NVC is also hierarchical and combines physiognomy and floristics. The General Wetland Vegetation Classification System incorporates the ability to crosswalk to the group level of the NVC in its attribute table. This allows resource managers, researchers, and analysts to view and analyze the data at the 31-class level or the NVC equivalent.

The General Wetland Vegetation Classification System described in this handbook originated in the mid-1970s as part of the Great River Environment Action Team study designed to look at the use of CIR aerial photography for a habitat analysis of the Upper Mississippi River floodplain (Hagen and others, 1977). It is most similar to the Cowardin classification system in that it relies heavily on hydrologic regime as the fundamental basis, and the regimes used to classify this system are derived from Cowardin and others (1979). Accordingly, each of the 31 map classes in the General Wetland Vegetation Classification System is associated with one of the 6 following hydrologic regimes:
- Permanently Flooded.-Water present all year round.

- Semipermanently Flooded.-Surface water present throughout the growing season, except in periods of extreme drought.

- Seasonally Flooded.-Surface water present for most of the growing season.

- Temporarily Flooded.-Surface water only present early in the growing season.

- Saturated Soil.- Substrate is saturated with water during the growing season.

- Infrequently Flooded.-Surface water rarely present.

\section{Discussion}

The UMRS has been classified and mapped three times as part of the LTRM element. These maps are referenced by the collection date of the imagery on which the map is based: the 1989 map, the 2000 map, and the 2010-2011 map. The 1989 map was based on 1:15,840-scale aerial photography that was interpreted by using a genus-level system. When the 1989 mapping began, resource managers wanted to know what genera, or mix of genera, were present, and also gain a sense of the associated hydrologic regimes. To accommodate these desires, mapping began with creating a vegetation classification system designed to combine genus and genus mixture information with the hydrologic regimes described by Cowardin in the "Classification of Wetlands and Deepwater Habitats of the United States." Although this hybrid classification provided much of the information that resource managers needed, the combination also made the classification cumbersome and difficult to consistently apply. The 1989 aerial photographs were interpreted with a revised classification that used simplified codes to describe genus-level information and added modifiers to denote approximate vegetation density and, for tree species, height. Cowardin's hydrologic regime descriptions were maintained but were referenced in a master lookup table that also provided additional descriptors for each vegetation class.

Often, a 0.4-hectare minimum mapping unit (MMU) is used when interpreting 1:15,840-scale aerial photographs or imagery; for the 1989 aerial photography, however, all distinctive features that could be identified and delineated were mapped. This process gave managers and analysts an unprecedented level of habitat information, but it also resulted in long interpretation times and complex map data layers. This effort was compounded by the time required for quality control and conversion to a digital format. The completed dataset presented a detailed snapshot of floodplain habitat, but it was an expensive process that took more than a decade to complete.

In 2000, the aerial photography of the UMRS was collected at a scale of 1:24,000. The General Wetland Vegetation Classification System was developed for use with this 
photography in order to map floodplain vegetation much more rapidly and efficiently. As the classification system was created and revised, the primary factors in determining the map classes became genus, genus-dominance for mixed classes, and hydrology. The 31 map classes of the General Wetland Vegetation Classification System are ecologically useful categories, based on hydrology that can be used in systemic studies where imagery is often taken at smaller scales, and a larger, 1.0-hectare MMU is used for interpretation. This process was used to interpret the 2000 aerial photography at about half the cost and in less than half the time required to interpret the 1989 aerial photography. If a more in-depth study is required, this classification breaks out into the finer detail of the 151-class tier, which would typically be used in a smaller study area with larger scale imagery to allow for a smaller MMU. The scalability of the classification system makes it a valuable tool for both broad and focused studies.

The next systemic mapping effort, which began in 2010, represented a major change in technologies. A digital mapping camera replaced the 22.86 - by 22.86 -centimeter film format camera, and imagery stored digitally on computers replaced the film prints and transparencies used in creating the 1989 and 2000 vegetation data layers. Another change was the decision to collect two different scales of imagery for different portions of the UMRS. Imagery was collected at $0.2 \mathrm{~meter} / \mathrm{pixel}$ above Lock \& Dam (L\&D) 13 and at 0.4 meter/pixel below L\&D 13 and along the Illinois River floodplain. There are two reasons for this distinction: (1) the floodplain above L\&D 13 is narrower and contains a greater diversity of wetland vegetation, making a higher level of detail desirable, and (2) below L\&D 13, the Upper Mississippi River is largely channelized, with less wetland vegetation, and the floodplain is wider, leveed, and dominated by agricultural use. This second condition holds true for much of the Illinois River as well, and the lower resolution imagery collected here allowed for more efficient acquisition, processing, and data automation. The same 31 map classes of the General Wetland Vegetation Classification System used in 2000 were used for this effort, with minimum mapping units of 0.4 hectare for the 0.2 meter/pixel imagery and 1.0 hectare for the 0.4 meter/pixel imagery.

There were sustained high-water conditions and extended flooding in 2010, which particularly affected the lower reaches of the Upper Mississippi River and the Illinois River. After imagery had been collected for portions of the UMRS, the decision was made to suspend imagery collection for the season and collect additional imagery in 2011 for the upper three pools of the Illinois River (because of cloud cover) and the portion of the Upper Mississippi River below L\&D 13 (because of flooding). Although 2011 was also a high-water year and flooded conditions were again present during collection, this imagery was interpreted, and the vegetation data layer is a combination of the 2010 (above L\&D 13 on the Upper Mississippi River and Alton-Marseilles Pools of the Illinois River) and 2011 (below L\&D 13 on the Mississippi River and Dresden, Brandon, and Lockport Pools of the Illinois River) imagery collection dates.
There is no perfect method for mapping vegetation. No matter how detailed or general a classification system is, delineating diverse habitats with limited-resolution satellite or aerial imagery will never be free of some subjectivity. A classification system that is flexible, easily updated, and applicable at various scales will have the greatest long-term utility. Experience also suggests three elements are critical when developing a classification system: (1) the management needs of decision makers (at what level of detail the vegetation must be described), (2) the funding available, and (3) the urgency with which the data are needed.

These factors will determine the scale of the imagery, the approach for classifying vegetation communities, and the funding and personnel needed to complete the mapping within a given timeframe. A carefully designed and implemented vegetation mapping program can be one of the most useful tools a resource manager has for making decisions. If possible, the classification system used should also be compatible with other vegetation classification systems to ensure that its scope is extended, as well as its longevity.

The appendixes of this handbook (appendixes 1-5) provide more detailed information about the classification and mapping of floodplain vegetation using the General Wetland Vegetation Classification System. Appendix 1 describes the process of creating a vegetation data layer. This process includes aerial-imagery acquisition, field reconnaissance, image processing, image interpretation, and accuracy assessment. Appendix 2 describes each of the 31 map classes as they appear in their environment, as they relate to a hydrologic regime, and as they appear to the interpreter on the aerial image. These descriptions are complemented with images of each class as it appears in the field, as well as examples extracted from interpreted aerial imagery as it appears onscreen. Appendix 3 provides a classification key used during field reconnaissance to classify the land features or vegetation types found at a field site into the General Wetland Vegetation Classification System. Appendix 4 provides a list of representative genera and species and the map classes with which they are commonly associated. Lastly, appendix 5 provides an example of a contingency table, also known as an error matrix, from a UMRS pool.

\section{References Cited}

Anderson, J.R., Hardy, E.E., Roach, J.T., and Witmer, R.E., 1976, Land use and land cover classification system for use with remote sensor data-A revision of the land use classification system as presented in U.S., Geological Circular 671: U.S. Geological Survey Professional Paper 964, 28 p.

Lea, Chris, 2010, Thematic accuracy assessment procedures - National Park Service Vegetation Inventory, Version 2.0: Fort Collins, Colo., National Park Service, Natural Resource Report NPS/NRPC/NRR-2010/204, 116 p. 
Cowardin, L.M.; Carter, Virginia; Golet, F.C.; and LaRoe, E.T., 1979, Classification of wetlands and deepwater habitats of the United States: Washington, D.C., U.S. Department of the Interior, Fish and Wildlife Service, $131 \mathrm{p}$.

Federal Geographic Data Committee (FGDC), 2008, National vegetation classification standard, Version 2: FGDC-STD005-2008 (Version 2), 119 p., accessed May 7, 2015, at http://www.fgdc.gov/standards/projects/FGDC-standardsprojects/vegetation/NVCS_V2_FINAL_2008-02.pdf.
Hagen, R.T., Werth, L.F., and Meyer, M.P., 1977, Upper Mississippi River habitat inventory: St. Paul, Minnesota, University of Minnesota, College of Forestry and the Agricultural Experiment Station, Institute of Agriculture, Forestry and Home Economics, Remote Sensing Laboratory, Research Report 77-5, 18 p.

Zonneveld, I.S., 1988, Introduction to the application of vegetation maps, in Kuchler, A.W., and Zonneveld, I.S., eds., Vegetation mapping: Norwell, Mass., Kluwer Academic Publishers, p. 487-490. 


\section{Appendixes}

1. Using the General Wetland Vegetation Classification System To Describe and Monitor Vegetation................................................................................................

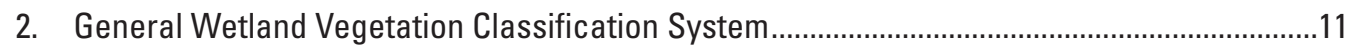

3. Classification Key for the General Wetland Vegetation

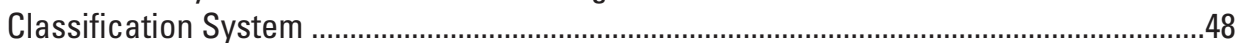

4. Representative Genera and Species and the Map Classes With Which They Are Commonly Associated.....................................................................................

5. Example Accuracy Assessment Contingency Table ................................................................51 


\section{Appendix 1. Using the General Wetland Vegetation Classification System To Describe and Monitor Vegetation}

Appendixes 1 and 2 describe the use of the General Wetland Vegetation Classification System. Appendix 1 provides a brief summary of the methods used to interpret aerial imagery and classify wetland vegetation. The steps in this process include acquiring aerial imagery, conducting field reconnaissance to verify vegetation signatures, image processing to prepare imagery for high resolution, three-dimensional (3D) viewing in a geographic information system (GIS) environment, image interpretation and the delineation of vegetation types as seen on the aerial imagery into a georeferenced data layer, and finally, assessing the accuracy of the vegetation data layer. Appendix 2 provides a detailed description of each of the 31 map classes used in the General Wetland Vegetation Classification System.

\section{Acquisition of Aerial Imagery}

Aerial imagery for vegetation interpretation is generally acquired in late summer (late July to early September), when aquatic and wetland vegetation is at peak biomass and when water levels are typically stable. The scale at which the imagery is acquired is dependent upon resolution needs and cost limitations. The General Wetland Vegetation Classification System is primarily used to interpret lower resolution imagery, whereas the more detailed 151-class tier is primarily used to interpret higher resolution imagery. A comparison of low- and high-resolution imagery is shown in figure 1-1.

For purposes of interpreting vegetation, color-infrared (CIR) aerial imagery is preferred over true-color aerial imagery because reflectance by vegetation is directly related to chlorophyll content - and the more vigorous the growth, the greater the reflectance. This helps the interpreter to better distinguish between plant and community types. However, CIR imagery does not work well for objects below a water surface, and submersed vegetation at low densities may be difficult to identify.

A flight plan (fig. 1-2) is prepared to cover a study area with images overlapping 60 percent along a flight line (end lap) and 30 percent between flight lines (side lap). The collection of images with 60-percent end lap allows for the same scene to be viewed from two slightly different perspectives, creating a stereoscopic coverage that will enable the interpreter to perceive depth on the overlapping portions of the images.

Figure 1-1. (upper right) Comparison of $(A)$, low-resolution color-infrared (CIR) imagery with $0.4 \mathrm{~meter} / \mathrm{pixel}$, and $(B)$, high-resolution CIR imagery with 0.2 meter/pixel.

Figure 1-2. (lower right) Example of a flight plan on the Illinois River, shown in Google Earth.
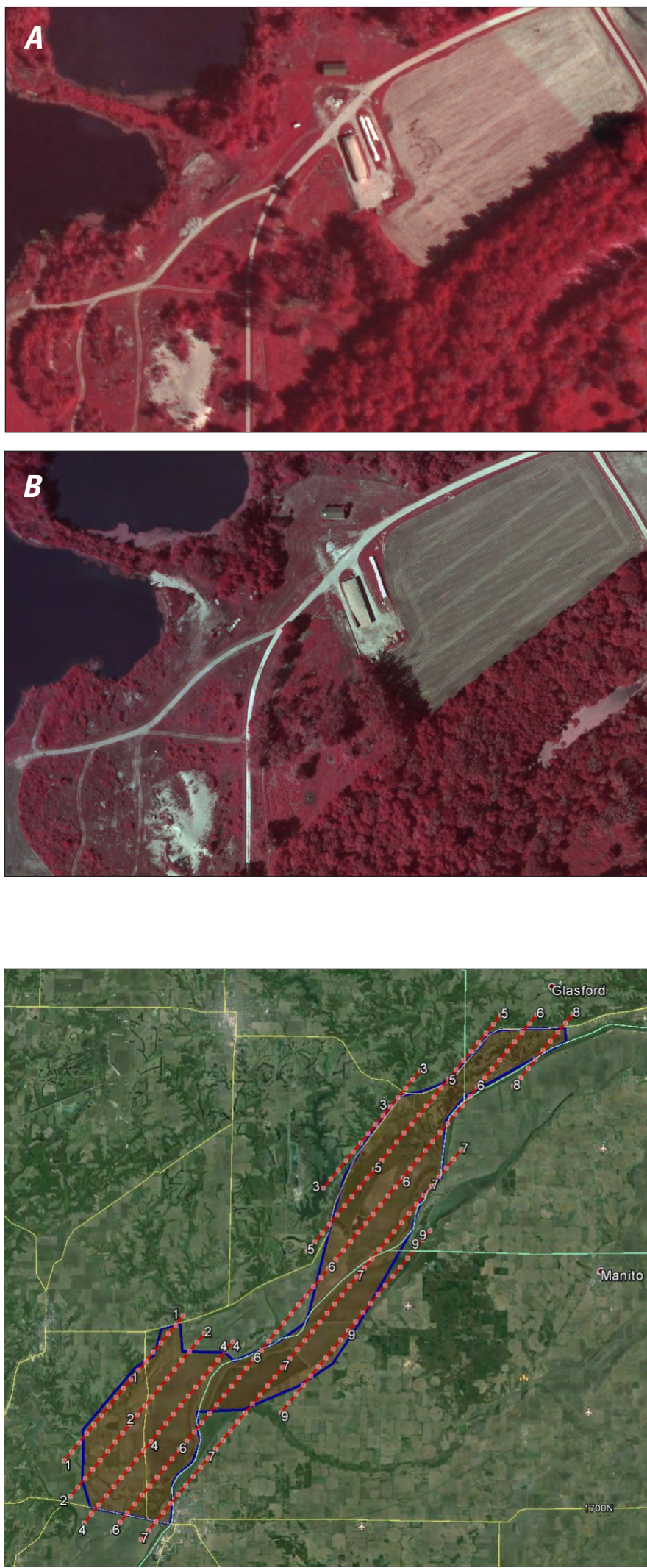


\section{Field Reconnaissance}

Before the CIR imagery is interpreted, field reconnaissance is performed (fig. 1-3). A georeferenced mosaic of the imagery is created, which can then be taken into the field on ruggedized tablet computers. Areas throughout the imagery that contain questionable vegetation communities and are accessible to a field visit are identified. In the field, notes are taken about the plant communities and land features observed in the area. These notes are recorded in a data layer that is referenced to the exact location of the observations by the integrated global positioning system (GPS) capability of the field computer. Through this procedure, the vegetation signatures on the image are verified with the vegetation found on the ground. A vegetation signature consists of several factors, such as color and tone, texture, pattern, shape, size, and location of the vegetation type. Once these representative areas have been investigated, the interpreter will be able to easily find and access the georeferenced field notes and utilize this information while interpreting across the rest of the study area.

During the field reconnaissance process, a classification key may be used to help classify a particular land feature, the vegetation type, or combination of vegetation types into the 31 map classes (appendix 3). The key gives examples of some, but not all, of the predominant vegetation types in the Upper Mississippi River System. The user of the key may need to extrapolate from the examples given and link certain species (for example, Polygonum spp.) to a similar hydrology. The user of the key will also look at the actual percent of the relative cover for each type of vegetation. This will determine which of the 31 map classes best describes the observed area. For example, the vegetation in an area may have a total cover of 90 percent, with a relative cover of 60 percent Sagittaria spp. and 40 percent Schoenoplectus spp. The dominant vegetation will determine which of the 31 map classes would best describe the area. In this example, the Deep Marsh Perennial map class would best describe the area observed because Sagittaria spp. is the dominant vegetation. A list of representative genera and species, and the map classes with which they are commonly associated, is found in appendix 4 .

\section{Image Processing}

While the digital imagery is being collected, the camera's GPS and Inertial Measurement Unit (IMU) are recording precise information regarding the sensor's location and position in space at the point of each image exposure. Camera calibration files and correction images are used to process the raw image files and generate full-resolution images in Tagged Image File Format (TIFF). Other operations such as lens falloff correction and histogram optimization are performed to enhance image quality. Individual images are georeferenced by using the GPS and IMU records generated by the camera, along with digital elevation data, to produce orthorectified images that are color balanced and stitched together to create a mosaic covering the entire study area.

Specialized GIS software imports the GPS and IMU data and uses it along with an elevation layer to generate stereo models. The stereo model uses unrectified imagery in order to preserve the image displacement required for $3 \mathrm{D}$ viewing, along with a block file containing the georeferencing data necessary to align the images with each other. The stereo model allows for the viewing of each image pair in 3D by using the appropriate computer hardware and software environment. The $3 \mathrm{D}$ perspective allows the interpreter to see subtle changes in height and texture that are key to identifying different vegetation communities, whereas the georeferencing information allows for the images to be displayed in their correct geospatial position along with other data layers.

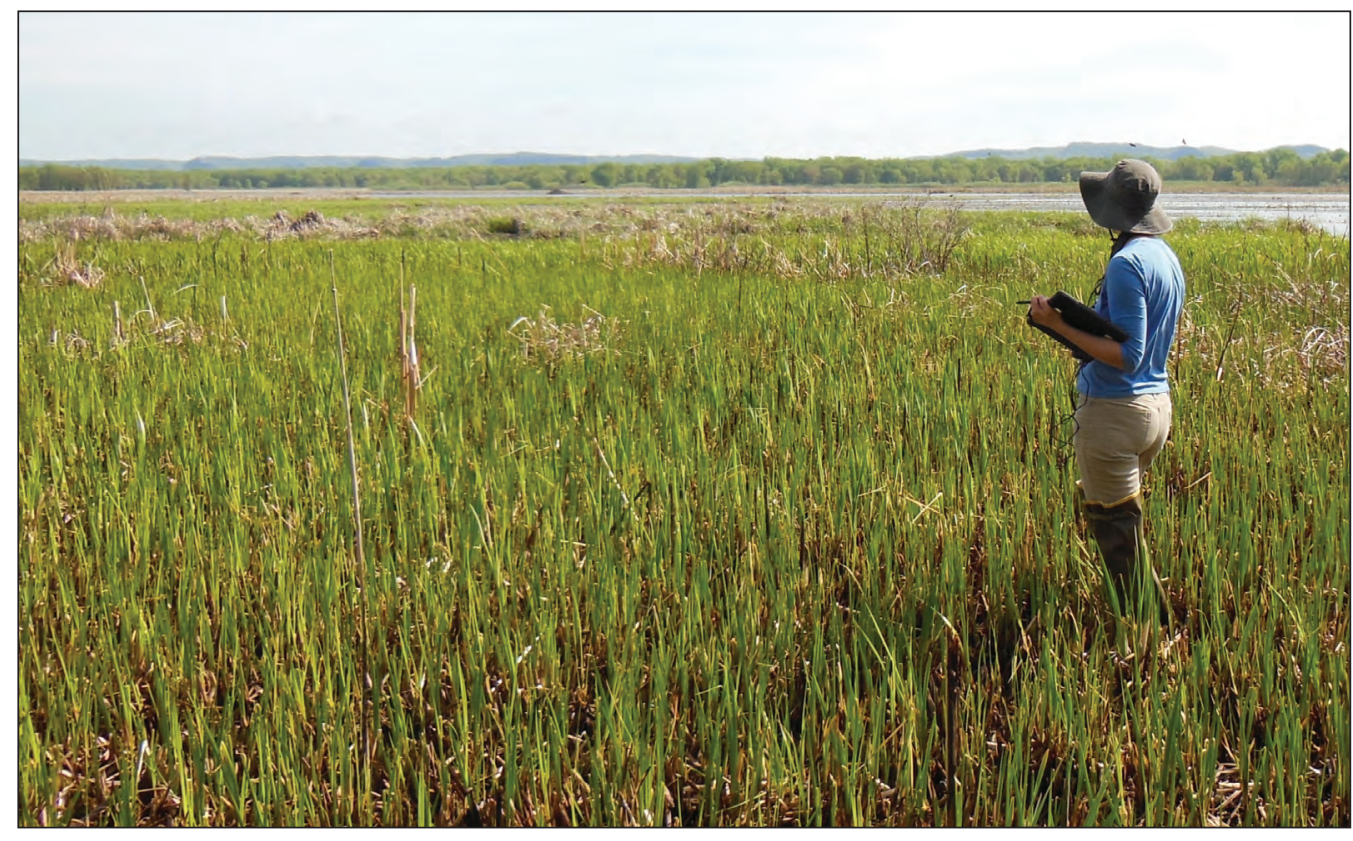

Figure 1-3. Field reconnaissance being performed by use of a ruggedized tablet computer. 


\section{Image Interpretation}

Before interpretation begins, a minimum mapping unit (MMU; smallest unit mapped) is determined (fig. 1-4). The MMU is dependent upon the resource manager's needs, the resolution of the imagery, and the cost of the project. For example, CIR aerial imagery taken at a lower resolution of 0.4 meter/pixel generally allows for a MMU of 1.0 hectare. CIR aerial imagery taken at a higher resolution of 0.2 meter/pixel generally allows for a MMU of 0.4 hectare because of the increased detail. However, mapping efforts using higher resolution imagery will require more images to cover the same study area and more time for the greater detail of the interpretation.

During the interpretation process, delineations made on screen by using a mouse and mapping software are instantly georeferenced and can be overlaid with other useful map layers, such as the field reconnaissance notes (fig. 1-5). Vegetation polygons are delineated to the 31-map-class level, and each polygon is given an attribute. The attribute consists of the map code, which is an abbreviation of the map class, followed by modifiers when applicable. The modifiers, which typically represent density and height, were developed with respect to what the interpreter can reliably identify and what may be ecologically meaningful to the user. The 31 map classes and their map codes, along with their respective modifiers, are listed in table $1-1$.

Vegetation density is determined in each polygon according to the relative cover of that polygon and by life form, with the taller life form taking precedence when more than one vegetative layer exists. For example, if delineating a polygon that contains both rooted-floating vegetation and submersed vegetation, the density would only apply to the rooted-floating vegetation because it is the taller life form. Another example would be with the shrub and tree classes. These classes generally have a grassy understory. However, shrubs and trees are generally taller than grasses, so the density modifier would only apply to the percent canopy cover of the shrubs or trees in that polygon. Modifiers for density are as follows:

- $\mathrm{A}=10-33$ percent

- $\mathrm{B}=34-66$ percent

- $\mathrm{C}=67-90$ percent

- $\mathrm{D}=91-100$ percent

An example of an attribute in a polygon that delineates an area of Shallow Marsh Perennial (SMP) with a density of approximately 75 percent would be SMPC.

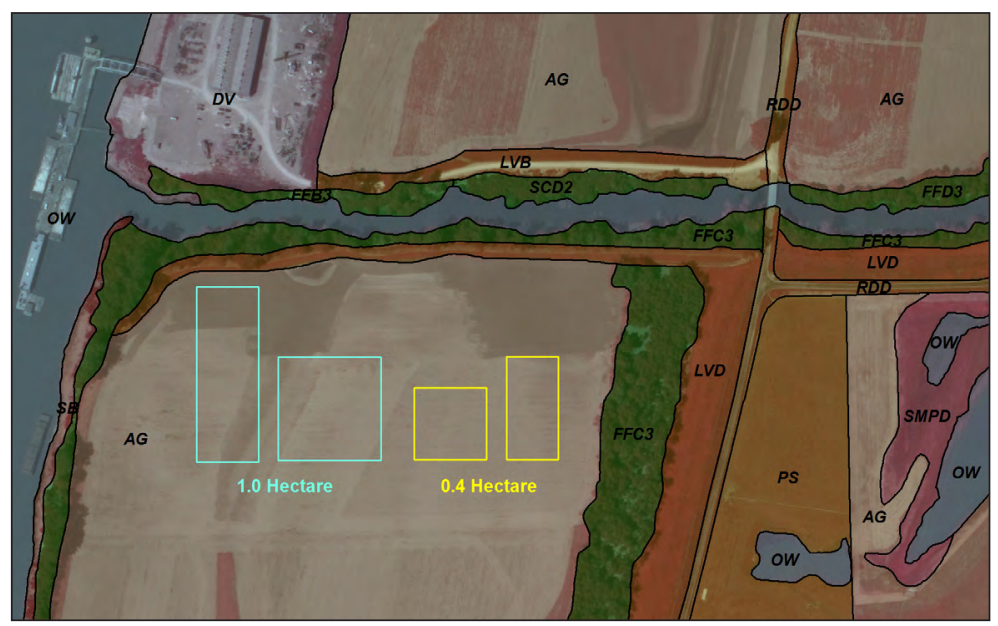

Figure 1-4. A depiction of two different minimum mapping unit sizes ( 1 hectare and 0.4 hectare).

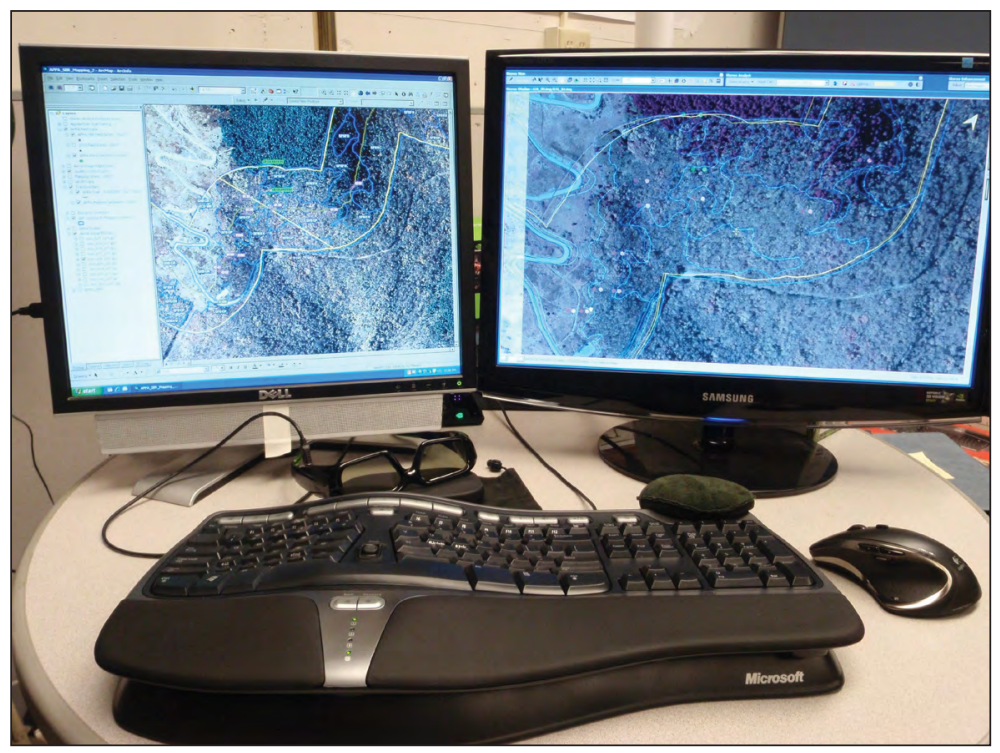

Figure 1-5. A three-dimensional (3D) workstation used for image interpretation.

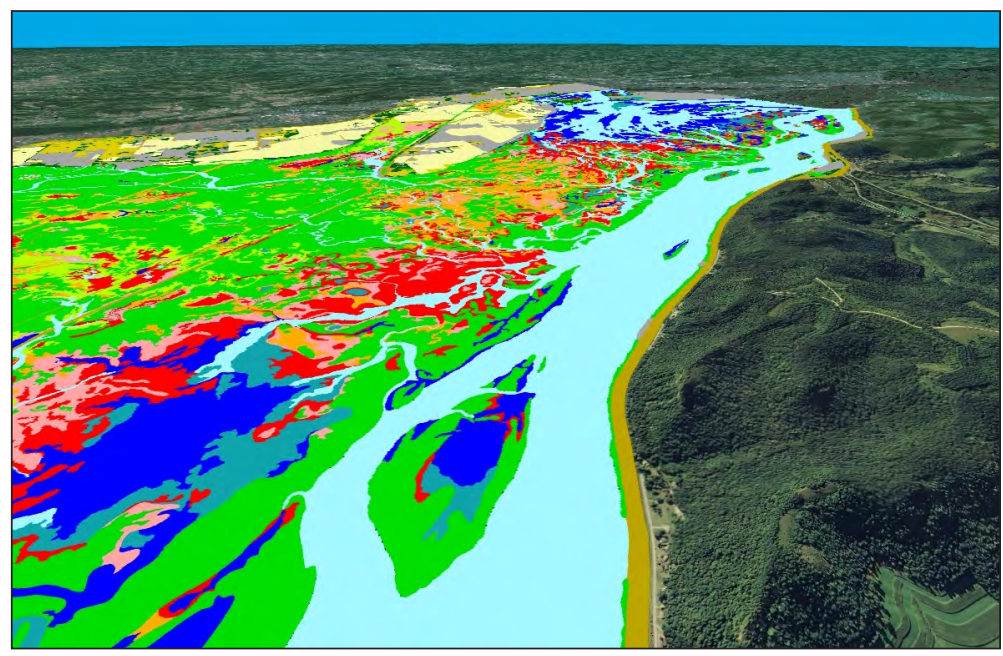

Figure 1-6. Depiction of the interpreted vegetation data layer, shown in Google Earth. 
Table 1-1. The 31 map classes, together with their respective codes, hydrologic regimes, and modifiers.

[Density and height modifiers designated by an X indicate that they apply to that map class]

\begin{tabular}{|c|c|c|c|c|}
\hline Map class & Map code & Hydrologic regime & Density & Height \\
\hline Open Water & OW & Permanently Flooded & & \\
\hline Submersed Vegetation & SV & Permanently Flooded & $\mathrm{X}$ & \\
\hline Rooted Floating Aquatics & RFA & Permanently Flooded & $\mathrm{X}$ & \\
\hline Deep Marsh Annual & DMA & Semipermanently Flooded & $\mathrm{X}$ & \\
\hline Deep Marsh Perennial & DMP & Semipermanently Flooded & $\mathrm{X}$ & \\
\hline Shallow Marsh Annual & SMA & Seasonally Flooded & $\mathrm{X}$ & \\
\hline Shallow Marsh Perennial & SMP & Seasonally Flooded & $\mathrm{X}$ & \\
\hline Sedge Meadow & SM & Temporarily Flooded & $\mathrm{X}$ & \\
\hline Wet Meadow & WM & Saturated Soil & $\mathrm{X}$ & \\
\hline Deep Marsh Shrub & DMS & Semipermanently Flooded & $\mathrm{X}$ & \\
\hline Shallow Marsh Shrub & SMS & Seasonally Flooded & $\mathrm{X}$ & \\
\hline Wet Meadow Shrub & WMS & Saturated Soil & $\mathrm{X}$ & \\
\hline Scrub-Shrub & SS & Infrequently Flooded & $X$ & \\
\hline Wooded Swamp & WS & Semipermanently Flooded & $\mathrm{X}$ & $\mathrm{X}$ \\
\hline Floodplain Forest & $\mathrm{FF}$ & Seasonally Flooded & $\mathrm{X}$ & $\mathrm{X}$ \\
\hline Populus Community & $\mathrm{PC}$ & Seasonally Flooded & $\mathrm{X}$ & $\mathrm{X}$ \\
\hline Salix Community & $\mathrm{SC}$ & Seasonally Flooded & $\mathrm{X}$ & $\mathrm{X}$ \\
\hline Lowland Forest & $\mathrm{LF}$ & Temporarily Flooded & $\mathrm{X}$ & $\mathrm{X}$ \\
\hline Agriculture & AG & Infrequently Flooded & & \\
\hline Conifers & $\mathrm{CN}$ & Infrequently Flooded & $\mathrm{X}$ & $\mathrm{X}$ \\
\hline Plantation & $\mathrm{PN}$ & Infrequently Flooded & $\mathrm{X}$ & $\mathrm{X}$ \\
\hline Upland Forest & UF & Infrequently Flooded & $\mathrm{X}$ & $\mathrm{X}$ \\
\hline Developed & DV & Infrequently Flooded & & \\
\hline Grassland & GR & Infrequently Flooded & $\mathrm{X}$ & \\
\hline Levee & LV & Infrequently Flooded & $\mathrm{X}$ & \\
\hline Pasture & PS & Infrequently Flooded & & \\
\hline Roadside & $\mathrm{RD}$ & Infrequently Flooded & $\mathrm{X}$ & \\
\hline Mudflat & MUD & Seasonally Flooded & & \\
\hline Sand Bar & SB & Temporarily Flooded & & \\
\hline Sand & SD & Infrequently Flooded & & \\
\hline No Coverage & $\mathrm{NC}$ & No Coverage & & \\
\hline
\end{tabular}

Height modifiers are only applicable to the tree classes. Shrub classes do not receive a height modifier because it is assumed that shrubs would have a height $<6$ meters. Tree height is expressed as an estimate of the average height of a stand. Modifiers for height are as follows:

- $\quad 1=0-6$ meters(young, regenerating stands)

- $2=>6-15$ meters (maturing stands)

- $3=>15$ meters (mature stands)

If height is used as a modifier, it will always follow the density modifier. An example of an attribute in a polygon that delineates Populus Community (PC) with a canopy cover of approximately 40 percent and an average height of approximately 20 meters would be PCB3.

The interpreted vegetation data goes through a qualitycontrol process and is merged together to create a single seamless layer (fig. 1-6). This vegetation data layer can then be distributed through the Upper Midwest Environmental Sciences Center's Web site to resource managers, researchers, and analysts to be used in the study and management of natural resources. 


\section{Accuracy Assessment}

The accuracy of a vegetation data layer can be assessed by selecting stratified random sites on the data layer and then going into the field to determine whether those particular locations have been properly classified. This process provides a quantitative measure of the overall accuracy of the data layer, as well as an indication of how well individual map classes have been interpreted. An accuracy assessment (AA) provides an estimate of thematic errors in the data, which gives users information they need to determine how suitable the data might be for a particular application. There are two ways an AA can be viewed: as "producers' accuracy," which is the probability that an AA site has been mapped correctly (also referred to as "error of omission"), and as "users' accuracy," which is the probability that the map represents what was found in the field at the AA site (also referred to as "error of commission"). Producers' and users' accuracies are obtained from the same set of data by using different analyses.

A stratified random sampling design described in version 2.0 of "Thematic Accuracy Assessment Procedures" (Lea, 2010) is used to assess map classes that represent natural and seminatural vegetation communities. After sampling sites have been selected, field crews navigate to the precise location by using GPS and evaluate the target assessment area (the approximate size of the MMU), recording their notes. The classification key is used to determine which map class best fits the site.
The map class determined in the field is then compared to the designation in the vegetation data layer for each site. If the data layer and field determinations are conflicting, an attempt is made to reconcile the difference. A disagreement between the map class determined for a site in the field and the map class assigned during image interpretation may occur when a site falls in a transition zone between vegetation communities or in an area that is too small to delineate (termed an inclusion). Vegetation-community changes that occur over time are another source of disagreements between field assessments and image interpretation. An example of a driver of this type of vegetation-community change would be water levels that have fluctuated significantly between the time the imagery was collected and when the AA site was assessed in the field. GPS errors or a questionable field call due to poor vantage points or an unreachable site also may account for some discrepancies. These kinds of errors, termed false errors, are corrected if possible, reconciling the vegetation data layer with the field determinations.

After false errors have been identified and reconciled, an error matrix is generated. This matrix, also called a contingency table, reports the frequency of agreement between the map codes assigned in the data layer and the AA field assessment of the same site. Percentage values of users' and producers' accuracies are calculated for each map class, as well as the overall accuracy. An example of an accuracy assessment matrix is included as appendix 5 . 


\section{Appendix 2. General Wetland Vegetation Classification System}

Appendix 2 provides a detailed description of each of the 31 map classes in the General Wetland Vegetation Classification System. Provided for each map class is at least one example of how that class may appear in the field, as well as examples extracted from interpreted aerial imagery as it appears onscreen. For each of the interpreted imagery examples, a description is provided of the map class signature (the appearance on imagery when viewed in stereo). The attributes are shown on these images as assigned by the interpreter. An attribute is made up of the map code, followed by the density modifier (A, B, C, or D) and height modifier (1, 2, or 3), when applicable (table 2-1). For example, a mapped polygon in the data layer identified as Submersed Vegetation (SV) occurring at a density of 10-33 percent would be designated by the attribute SVA.

Table 2-1. The 31 map classes, together with their respective codes, and possible density and height modifiers.

[Density and height modifiers designated by an X indicate that they apply to that map class]

\begin{tabular}{|c|c|c|c|}
\hline Map class & Map code & Density & Height \\
\hline Open Water & OW & & \\
\hline Submersed Vegetation & SV & $X$ & \\
\hline Rooted Floating Aquatics & RFA & $\mathrm{X}$ & \\
\hline Deep Marsh Annual & DMA & $X$ & \\
\hline Deep Marsh Perennial & DMP & $\mathrm{X}$ & \\
\hline Shallow Marsh Annual & SMA & $\mathrm{X}$ & \\
\hline Shallow Marsh Perennial & SMP & $\mathrm{X}$ & \\
\hline Sedge Meadow & $\mathrm{SM}$ & $\mathrm{X}$ & \\
\hline Wet Meadow & WM & $\mathrm{X}$ & \\
\hline Deep Marsh Shrub & DMS & $\mathrm{X}$ & \\
\hline Shallow Marsh Shrub & SMS & $\mathrm{X}$ & \\
\hline Wet Meadow Shrub & WMS & $\mathrm{X}$ & \\
\hline Scrub-Shrub & SS & $\mathrm{X}$ & \\
\hline Wooded Swamp & WS & $\mathrm{X}$ & $\mathrm{X}$ \\
\hline Floodplain Forest & $\mathrm{FF}$ & $\mathrm{X}$ & $\mathrm{X}$ \\
\hline Populus Community & $\mathrm{PC}$ & $\mathrm{X}$ & $\mathrm{X}$ \\
\hline Salix Community & $\mathrm{SC}$ & $\mathrm{X}$ & $\mathrm{X}$ \\
\hline Lowland Forest & LF & $\mathrm{X}$ & $\mathrm{X}$ \\
\hline Agriculture & AG & & \\
\hline Conifers & $\mathrm{CN}$ & $\mathrm{X}$ & $\mathrm{X}$ \\
\hline Plantation & $\mathrm{PN}$ & $\mathrm{X}$ & $\mathrm{X}$ \\
\hline Upland Forest & UF & $\mathrm{X}$ & $\mathrm{X}$ \\
\hline Developed & DV & & \\
\hline Grassland & GR & $X$ & \\
\hline Levee & LV & $\mathrm{X}$ & \\
\hline Pasture & PS & & \\
\hline Roadside & $\mathrm{RD}$ & $\mathrm{X}$ & \\
\hline Mudflat & MUD & & \\
\hline Sand Bar & $\mathrm{SB}$ & & \\
\hline Sand & SD & & \\
\hline No Coverage & $\mathrm{NC}$ & & \\
\hline
\end{tabular}




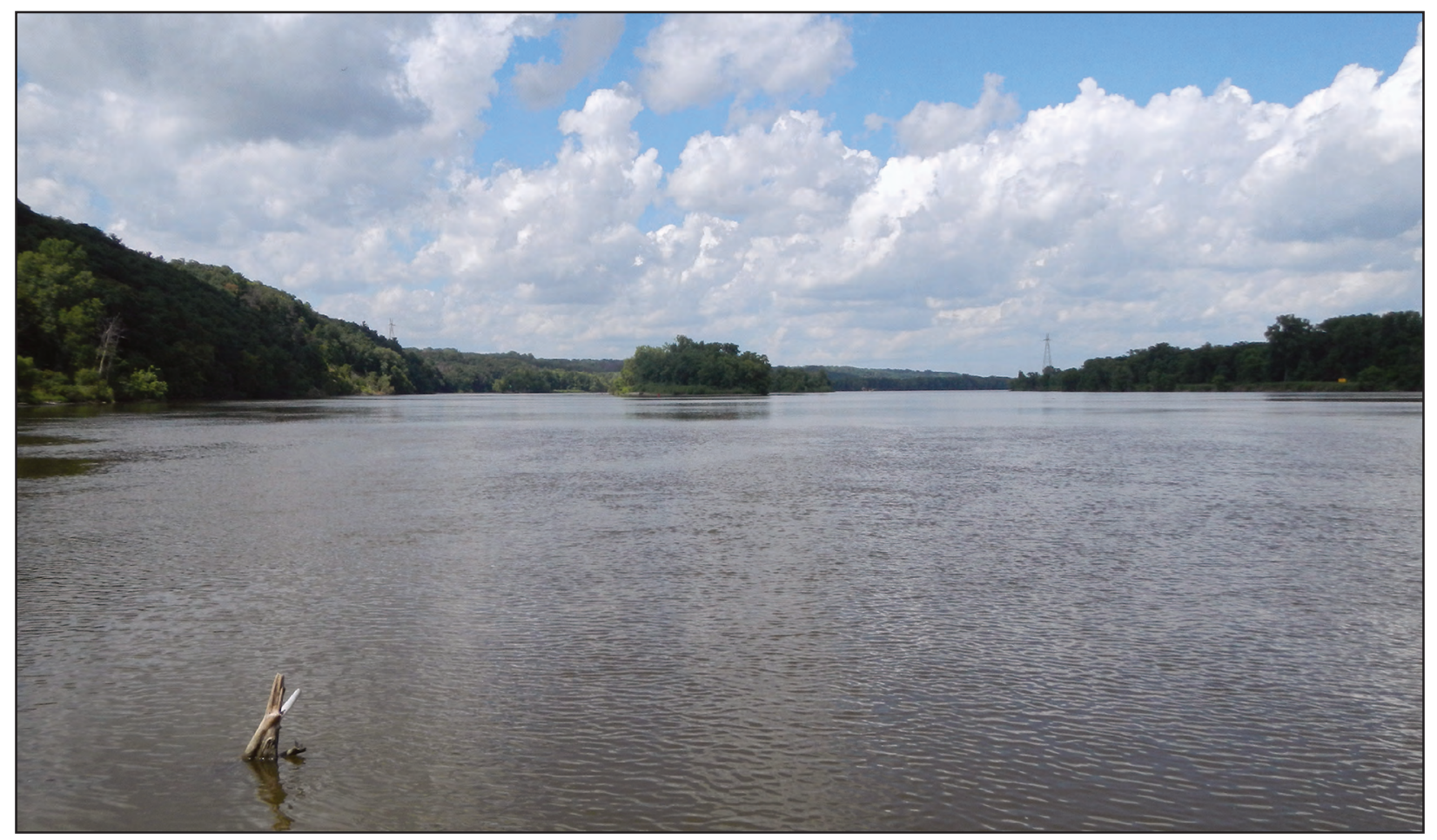

\section{Open Water (OW)}

The Open Water (OW) map class represents the main channel and portions of lakes, ponds, and backwaters that remain permanently flooded all year and appear $<10$ percent vegetated. Areas that have $>10$ percent vegetation are classified into a map class that best represents the vegetation present, except in the instance of duckweed (Lemnaceae) and other nonrootedfloating aquatics. Because duckweed is free floating, it can relocate day to day depending on current and wind direction. Therefore, any area of water containing dense duckweed will be classified as Open Water.

In image $A$, the signature for water appears smooth and blue, but it may range from light blue to black. Variation in color is typically due to differences in water depth, turbidity, and sediment type. Generally, the clearer the water, the darker it appears. In an instance where duckweed covers the water, the signature appears white, as seen in image $B$. It is unknown to the interpreter what lies beneath the duckweed, so it is attributed as Open Water.

Images $A$ and $B$ were taken in August 2010.
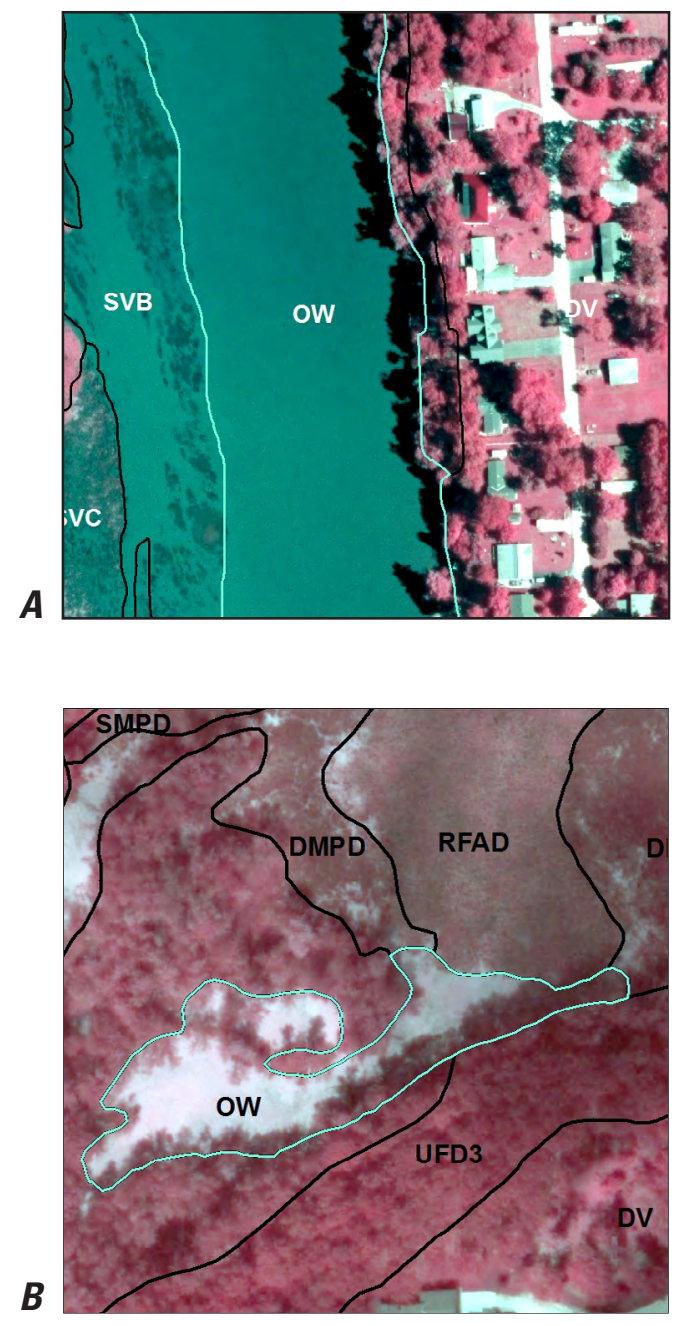


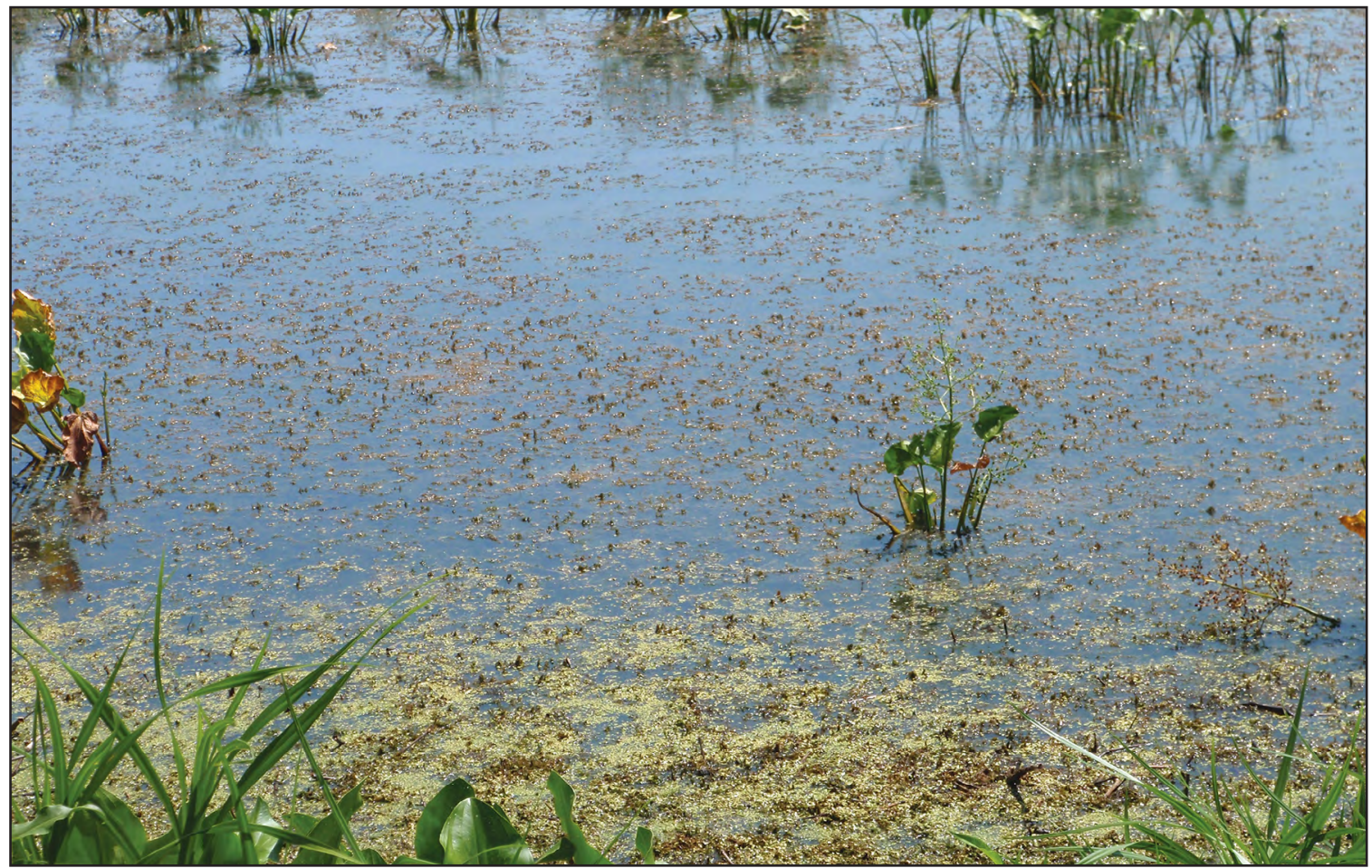

\section{Submersed Vegetation (SV)}

The Submersed Vegetation (SV) map class represents portions of lakes, ponds, channel borders, or backwaters that appear $>10$ percent vegetated with vegetation growing and remaining underwater. This map class is dominated by submersed vegetation but may have inclusions of nonrootedfloating aquatics, rooted-floating aquatics, or emergent vegetation. Vegetation in this class generally grows between water depths of 0.5 and 2.0 meters (m). This map class remains permanently flooded all year. Submersed vegetation that does not reach the water's surface may not be visible on the aerial imagery and would be classified as Open Water (OW).

The signature for submersed vegetation is generally dark grayish blue to black and appears discontinuous and clumped or gradational in the water. This can be seen in images $A$ and $B$. Image $B$ also has small white patches of duckweed, but the duckweed is sparse and positioned erratically enough to determine that submersed vegetation is present. The submersed vegetation signature in image $B$ also contains small pink patches of rooted-floating leaved aquatics, which are too small to be mapped on their own.

Images $A$ and $B$ were taken in August 2010.
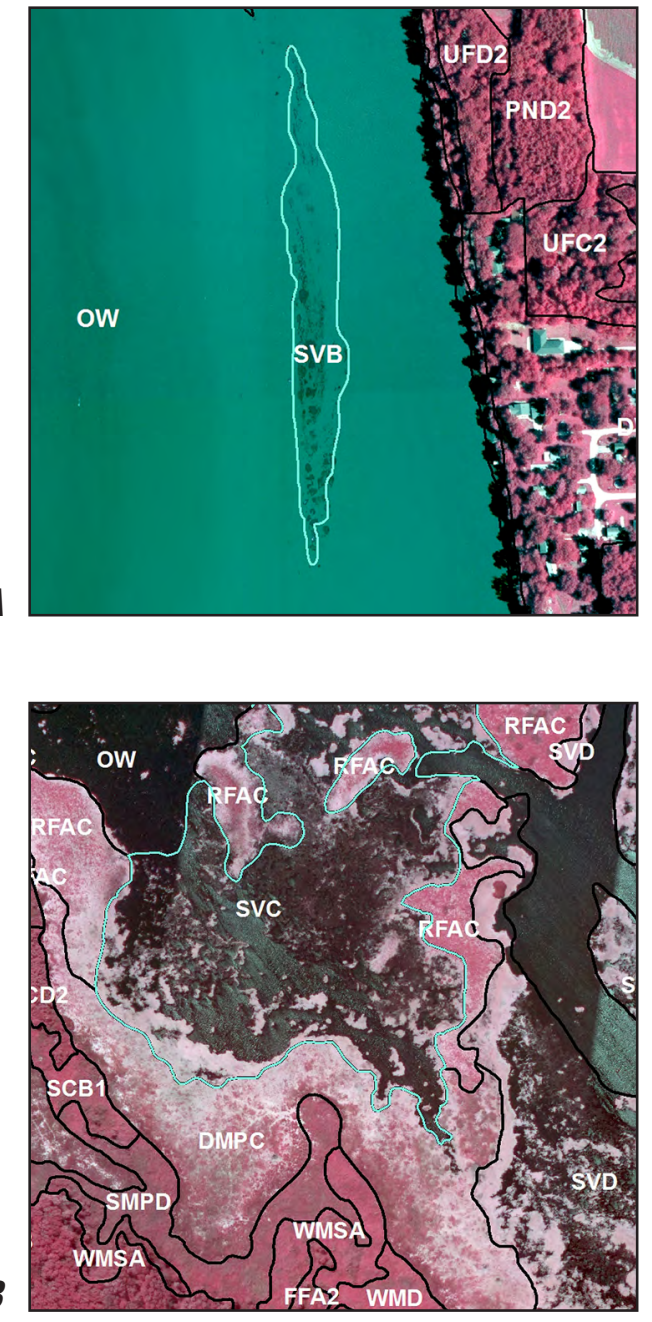


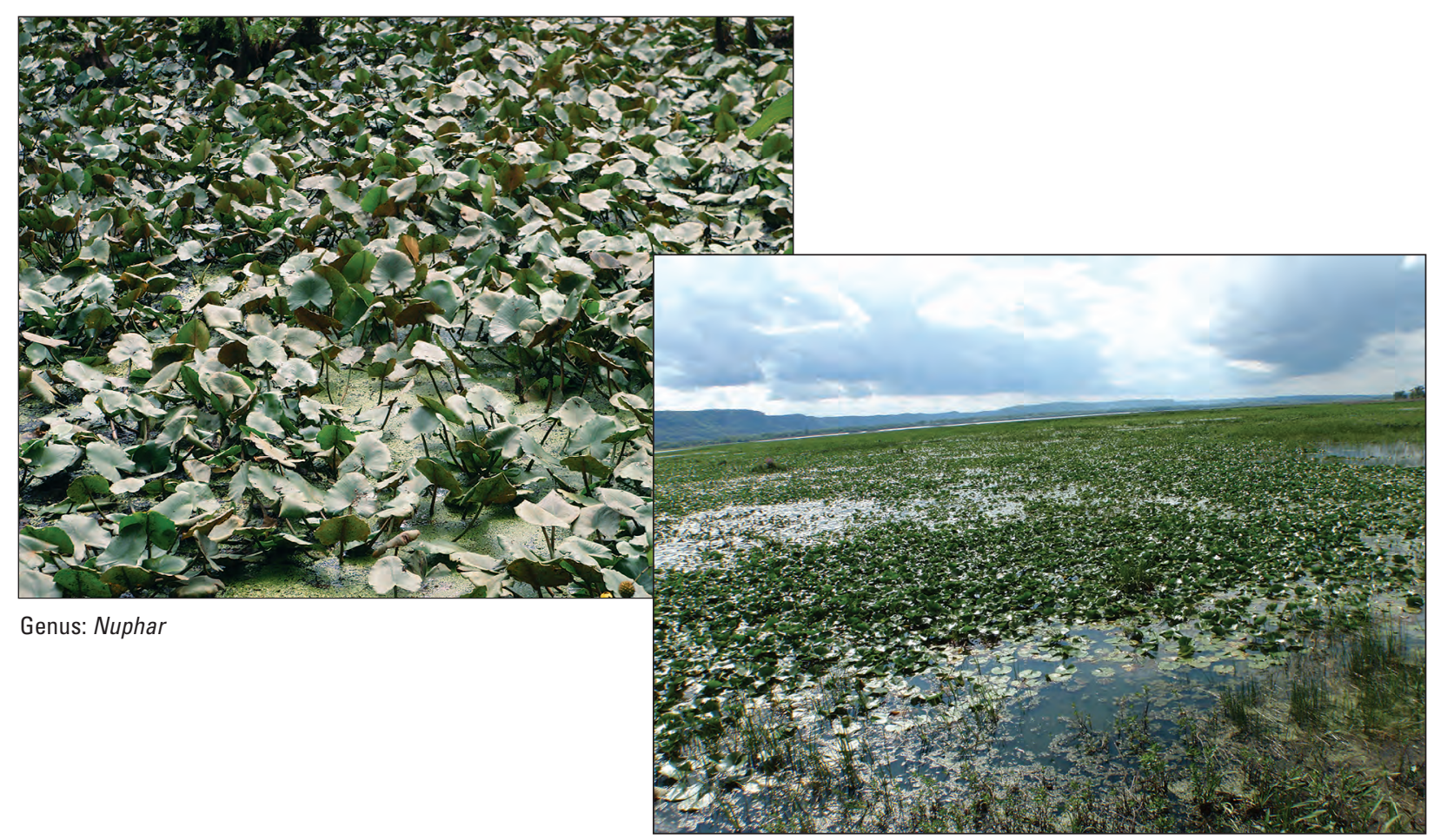

Genus: Nymphaea

\section{Rooted Floating Aquatics (RFA)}

The Rooted Floating Aquatics (RFA) map class represents portions of lakes, ponds, marshes, backwaters, or channel borders that are $>10$ percent vegetated with water lilies (Nymphaea spp. and Nuphar spp.) or American lotus (Nelumbo lutea). This map class is dominated by rootedfloating aquatic plants but may have inclusions of submersed, nonrooted-floating aquatics or emergent vegetation. Vegetation in this class is typically found growing between water depths of 0.25 and $2.0 \mathrm{~m}$. This map class remains permanently flooded all year.

Images $A$ and $B$ show examples of the water lily signature. It lies on the water and appears flat, opaque, and pale pink. The signature in image $A$ appears a fairly solid pink with few areas of open water present. In image $B$, the water lily is most concentrated in the center of the polygon, whereas duckweed, which appears white, is present around the edges.

Images $A$ and $B$ were taken in August 2010.
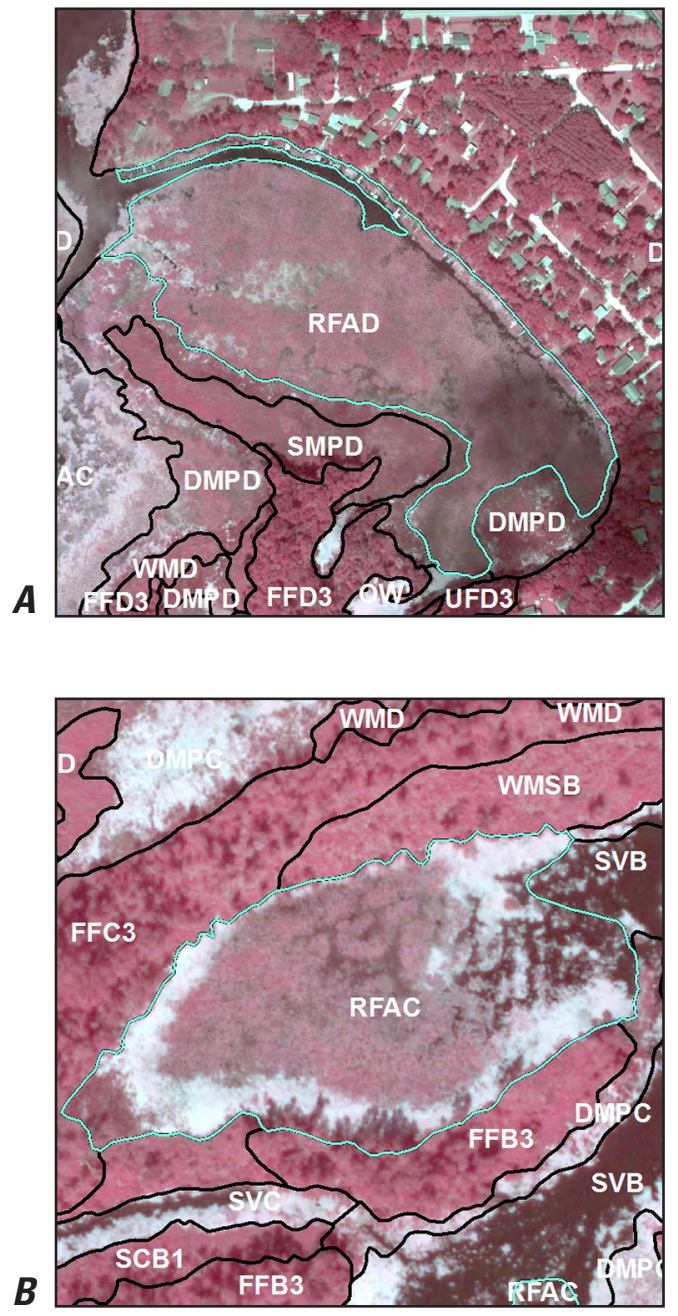


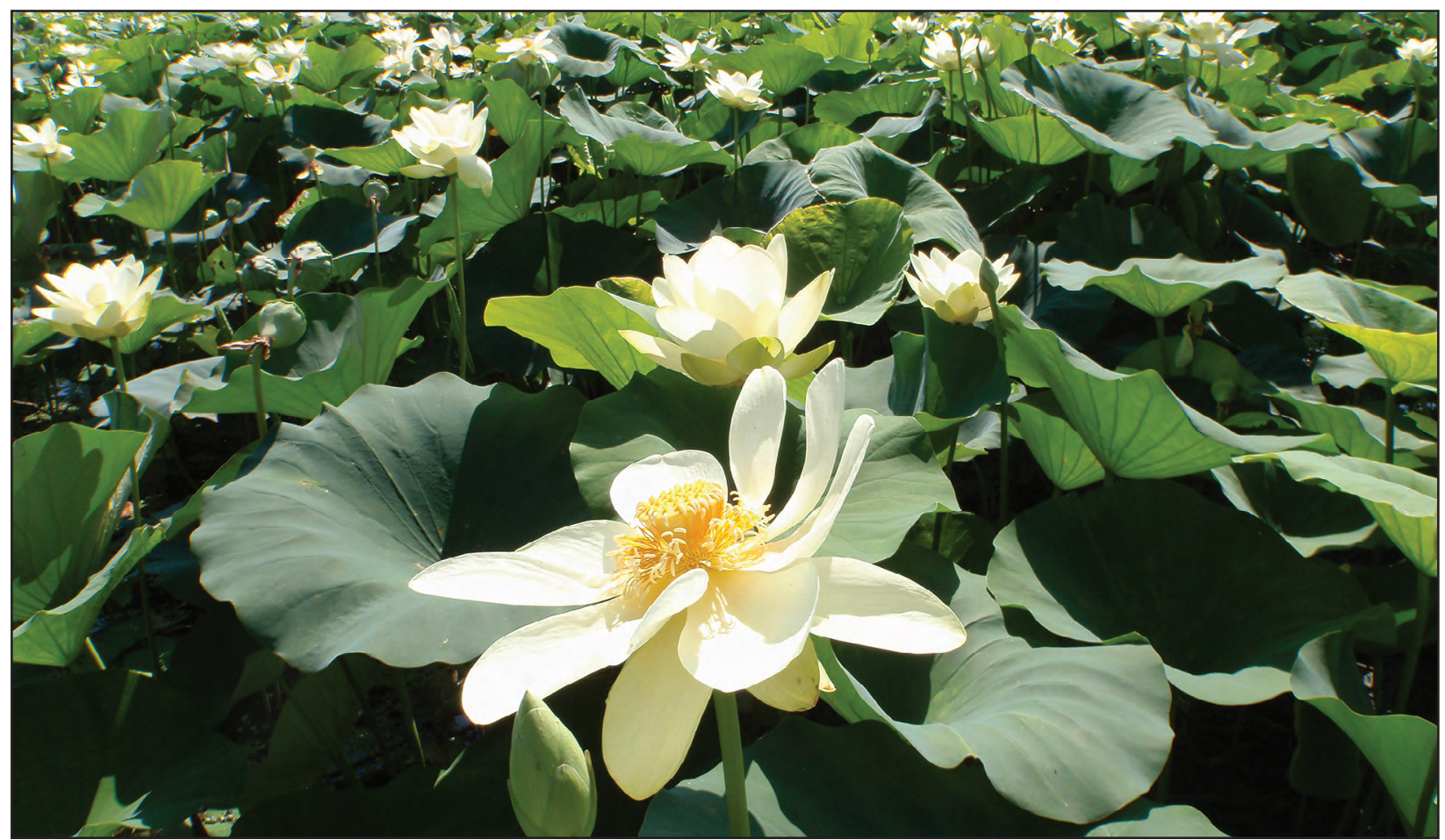

Genus: Nelumbo

\section{Rooted Floating Aquatics (RFA) — Continued}

Images $C$ and $D$ show examples of the American lotus signature. It appears bright pink, rough, and elevated above the surface of the water. The signature in image $C$ contains small patches of white duckweed within the polygon. The signature in image $D$ appears bright pink and shows the characteristic "textured" look of the American lotus signature.

Images $C$ and $D$ were taken in August 2010.
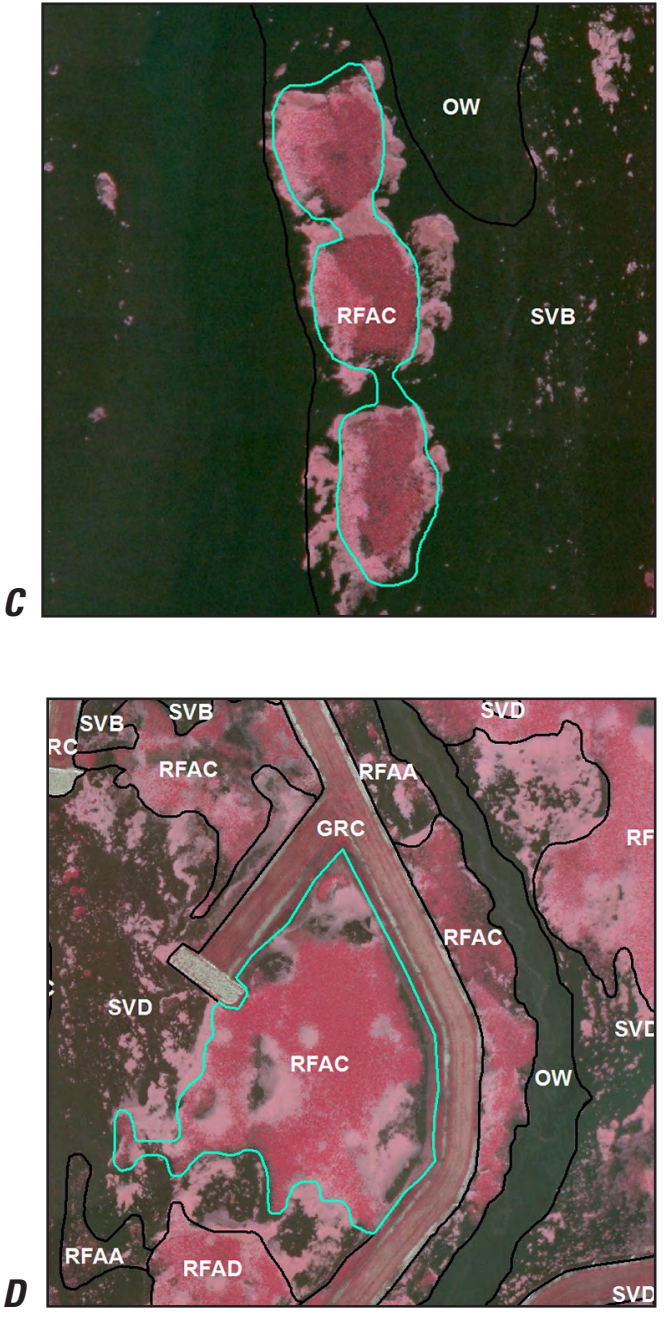


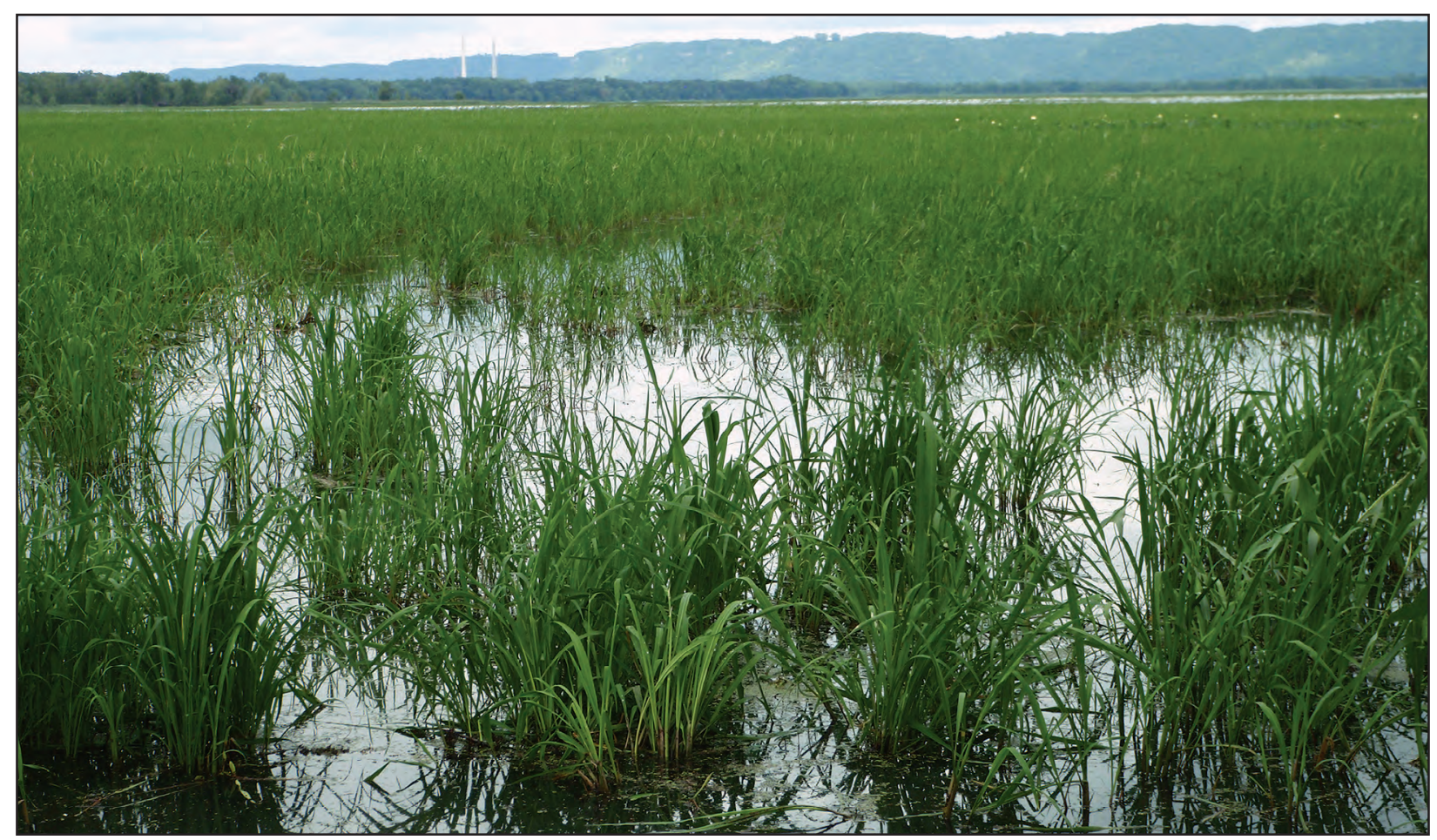

Genus: Zizania

\section{Deep Marsh Annual (DMA)}

The Deep Marsh Annual (DMA) map class represents portions of lakes, ponds, marshes, or backwaters that are $>10$ percent vegetated with wild rice (Zizania aquatica). This map class is dominated by wild rice but may have inclusions of submersed, nonrooted-floating aquatics, rooted-floating aquatics, or emergent vegetation. Vegetation in this class is typically found growing between water depths of 0.25 and $2.0 \mathrm{~m}$ with a silt or mucky substrate. This map class is semipermanently flooded throughout the year.

Images $A$ and $B$ show examples of the wild rice signature. It is generally pink to grayish pink and appears tall and fluffy. The darker blue areas visible within the wild rice signature are water. In image $B$, there are darker pink areas where other emergent vegetation is mixed in with the wild rice.

Images $A$ and $B$ were taken in August 2010.
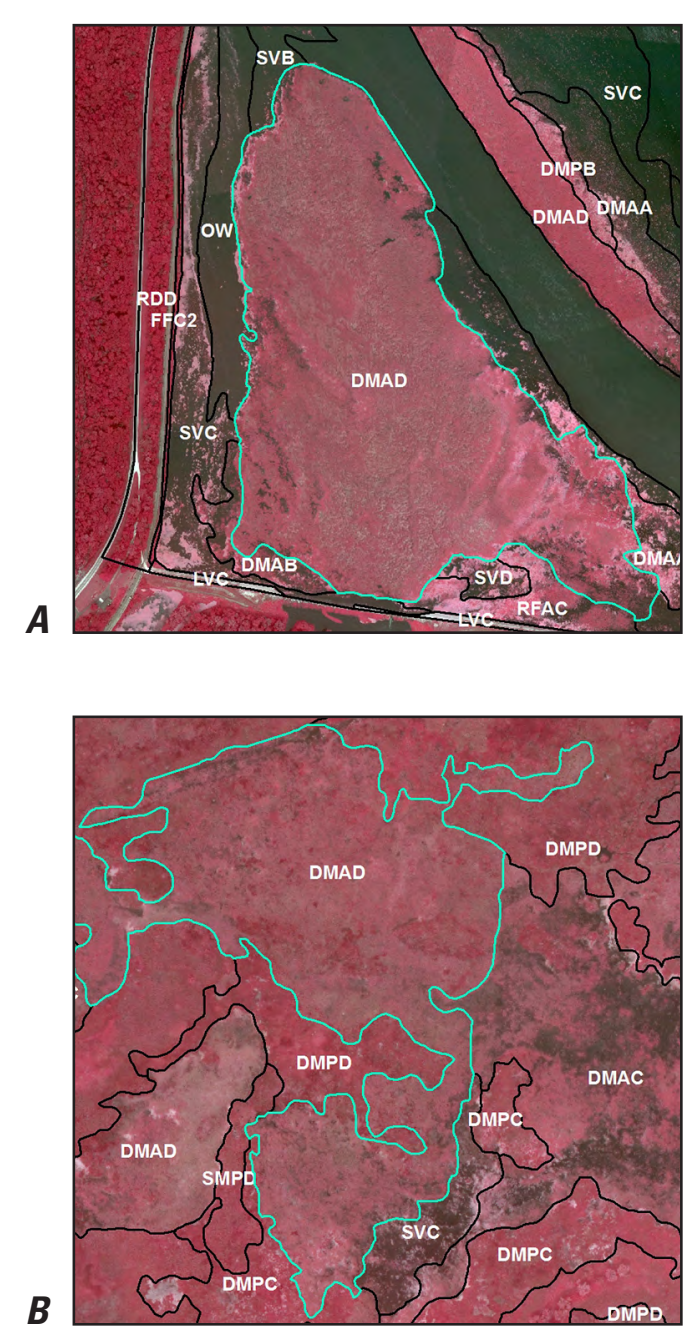


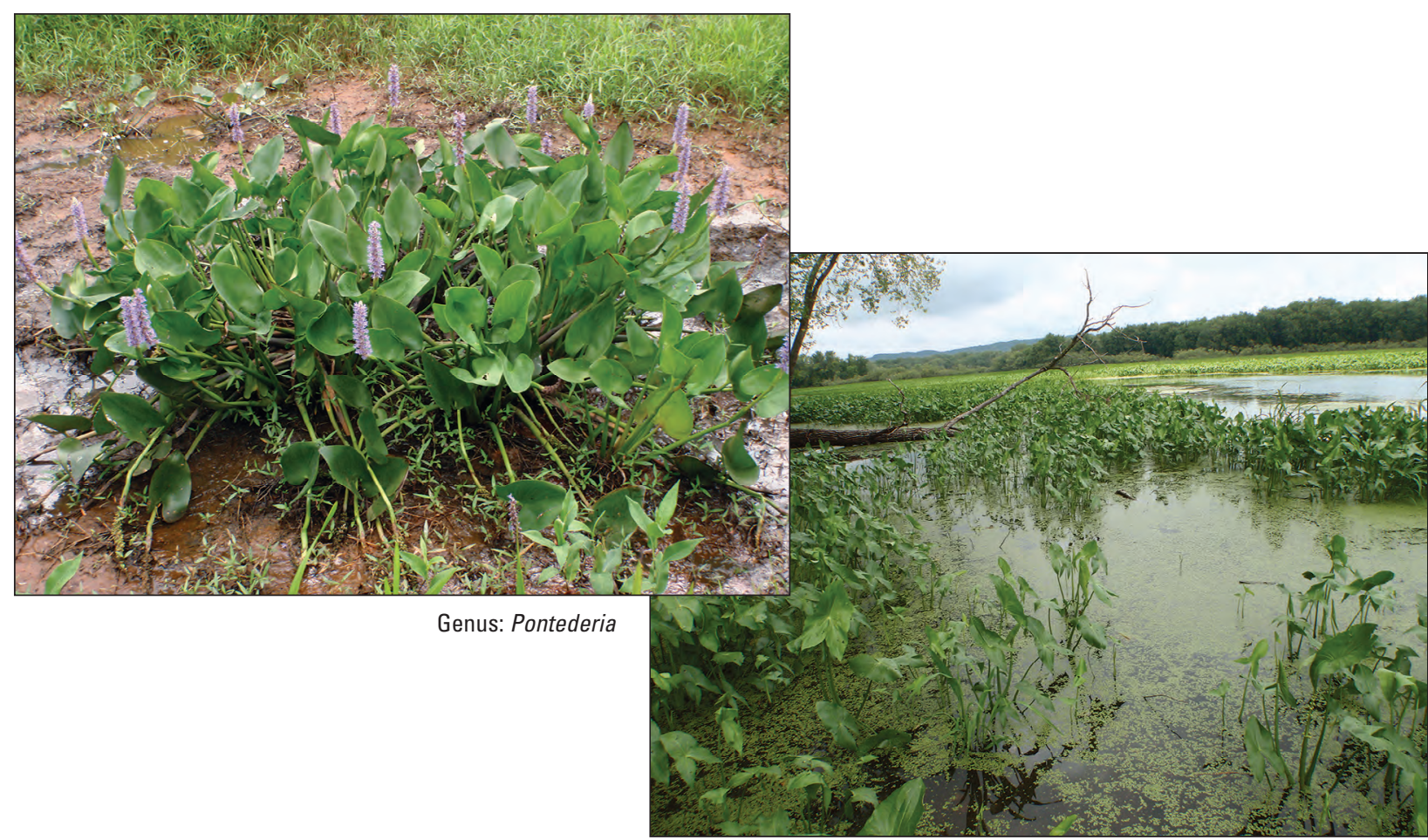

Genus: Sagittaria

\section{Deep Marsh Perennial (DMP)}

The Deep Marsh Perennial (DMP) map class represents portions of lakes, ponds, marshes, or backwaters that are semipermanently flooded and $>10$ percent vegetated with persistent emergent vegetation dominated by pickerelweed (Pontederia cordata), arrowhead (Sagittaria spp.), cattail (Typha spp.), bur-reed (Sparganium eurycarpum), flowering rush (Butomus umbellatus), or a combination of these.

(Flowering rush is a nonnative invasive species that is now prevalent in at least one pool of the Upper Mississippi River System [UMRS]). This map class may have inclusions of submersed, nonrooted-floating aquatics, rooted-floating aquatics, or other emergent vegetation and is typically found in water up to $1.0 \mathrm{~m}$ deep.

Images $A$ and $B$ show examples of the arrowhead signature. Arrowhead generally grows at the water's edge or in shallow water and appears as pink to red velvety clumps. Pickerelweed is similar in signature to that of arrowhead but generally appears deeper red and is usually present in much smaller patches than arrowhead. The arrowhead signature in image $A$ is pink and velvety. In image $B$, the arrowhead is in the deeper water and is mixed with some deeper red bur-reed and cattail growing along the shoreline. Image $B$ also contains some white duckweed on the water's surface.

Images $A$ and $B$ were taken in August 2010.
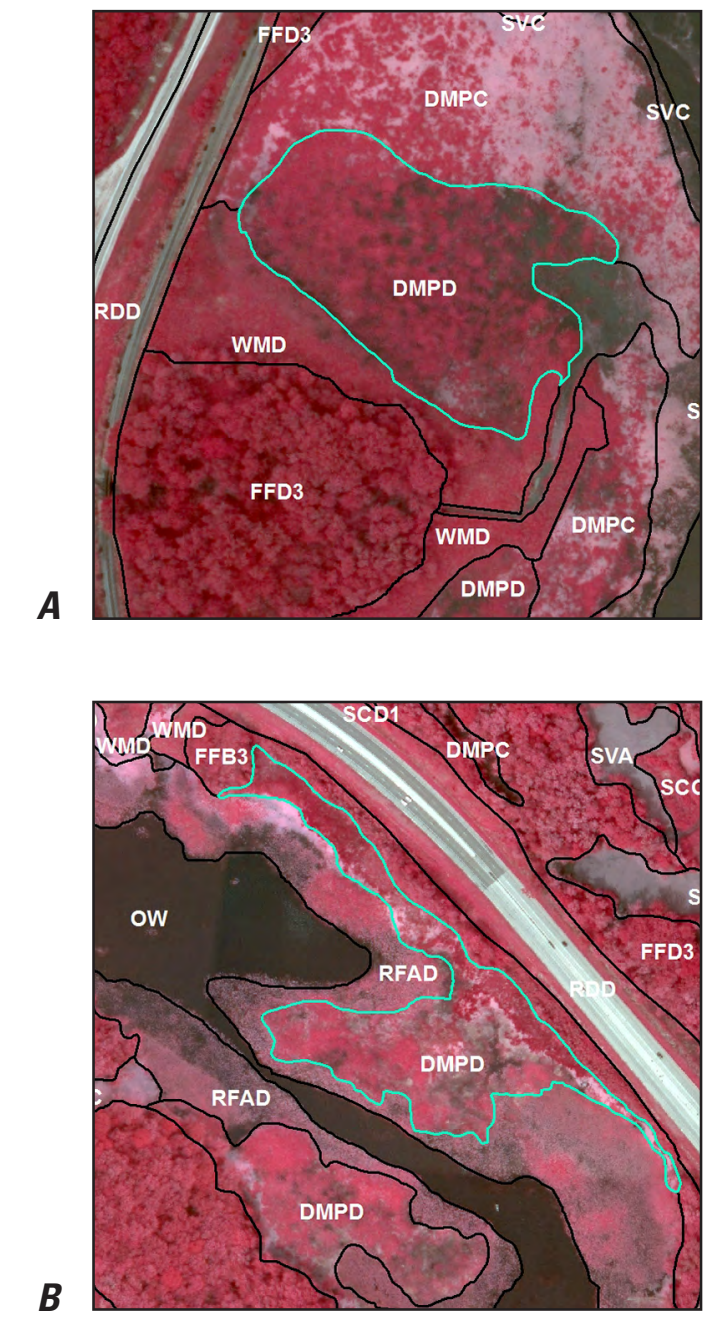

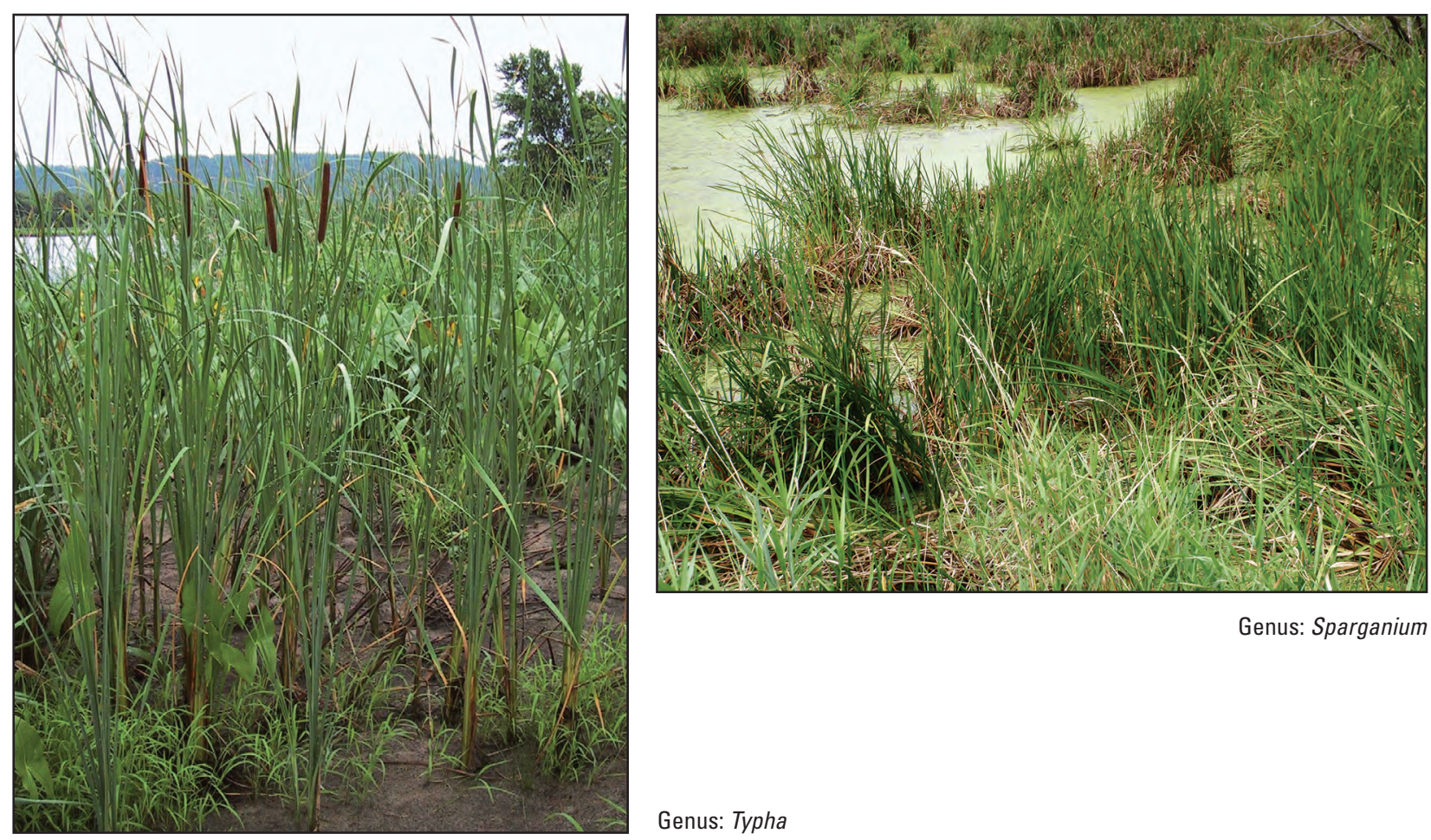

Genus: Sparganium

Genus: Typha

\section{Deep Marsh Perennial (DMP)_Continued}

Images $C$ and $D$ show examples of the cattail and bur-reed signatures. The cattail and bur-reed signatures may be similar, appearing textured and deep red to brown, although cattail can have a very variable signature ranging in color from pink to gray to deep red to brown depending on hydrology, nutrients, and other factors. The most prominent distinguishing characteristic of the two signatures is that cattail often grows clonally, whereas bur-reed grows irregularly and often near the water's edge. Image $C$ is dominated by cattail and image $D$ by bur-reed. Field reconnaissance is often needed to accurately differentiate between the two signatures.

Images $C$ and $D$ were taken in August 2010 .
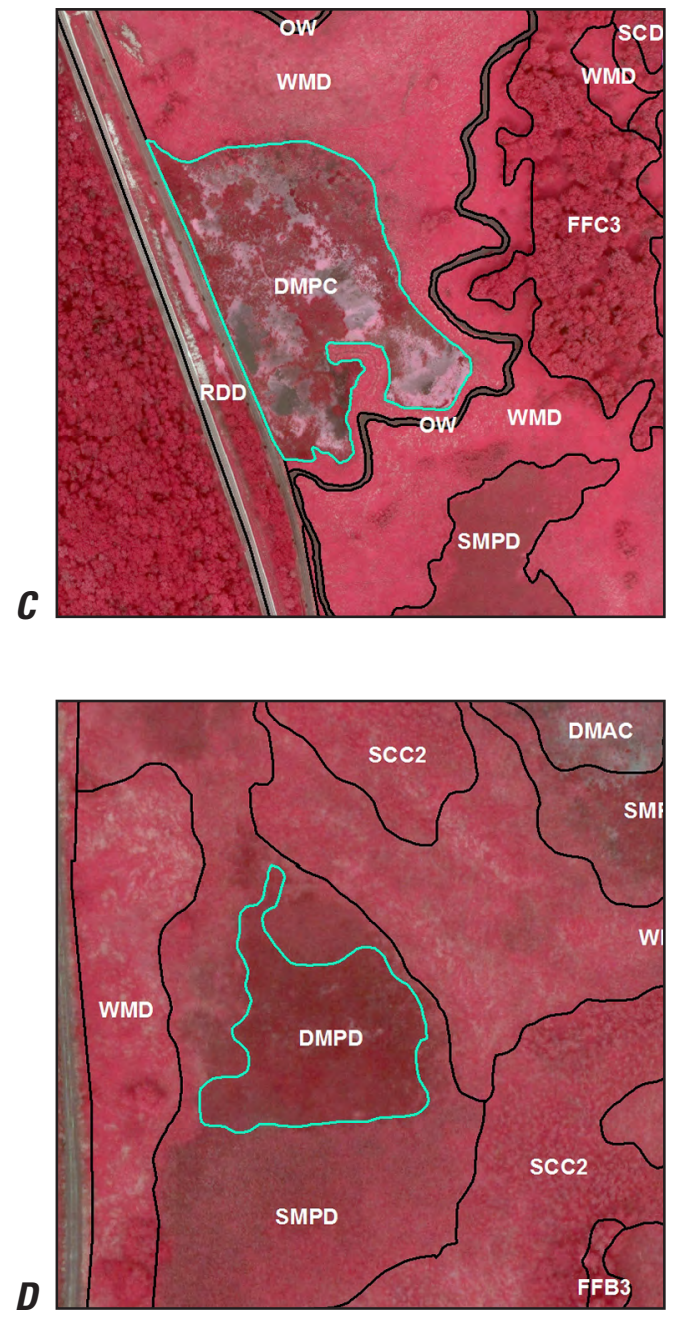


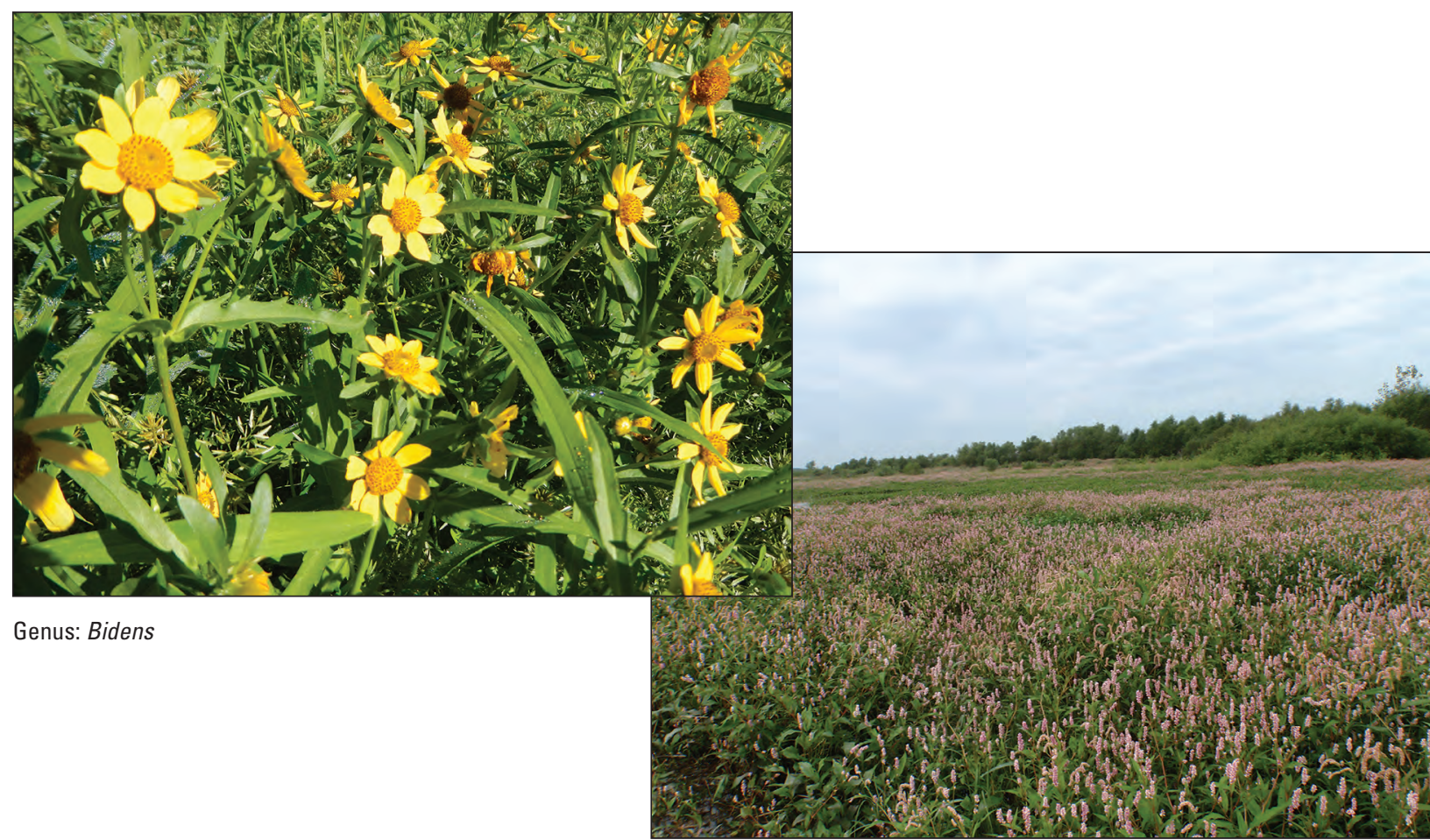

Genus: Polygonum

\section{Shallow Marsh Annual (SMA)}

The Shallow Marsh Annual (SMA) map class represents portions of lakes, ponds, backwaters, mudflats, or shorelines that are seasonally flooded and $>10$ percent vegetated with annual (nonpersistent) emergent vegetation. Common species include barnyard grass (Echinochloa spp.), pinkweed (Polygonum pensylvanicum), spike-rush (Eleocharis spp.), flatsedges (Cyperus spp.), cocklebur (Xanthium strumarium), pigweed (Amaranthus spp.), and beggarticks (Bidens spp.). This map class may have inclusions of submersed, nonrooted-floating aquatics or persistent emergent vegetation. Vegetation in this class is typically found growing on soils that are saturated or inundated by water up to $0.2 \mathrm{~m}$ deep.

Images $A$ and $B$ show examples of the Shallow Marsh Annual signature. With the exception of barnyard grass, which can appear red, the signature most often appears short, fluffy, and pale to bright pink. Image $A$ is an area that is more disturbed and may be used agriculturally in drier years. Image $B$ is a more natural area that is probably dominated by annuals in most years.

Images $A$ and $B$ were taken in August 2011.
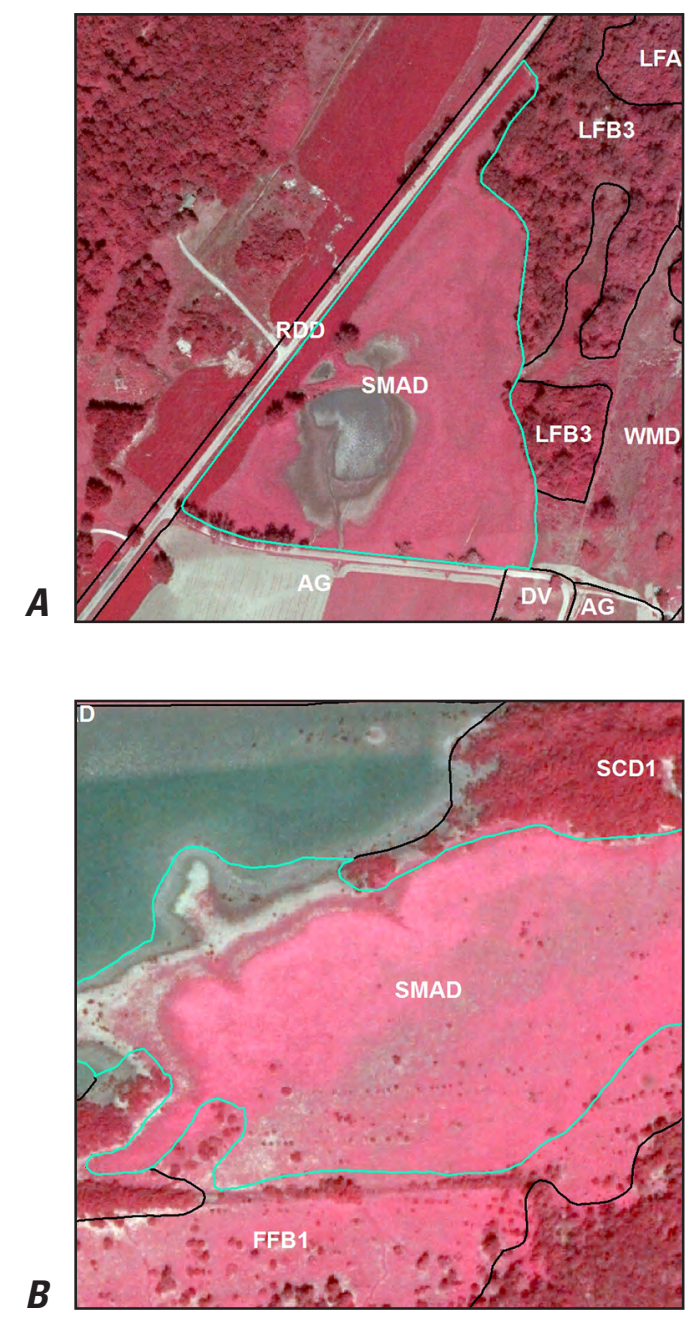

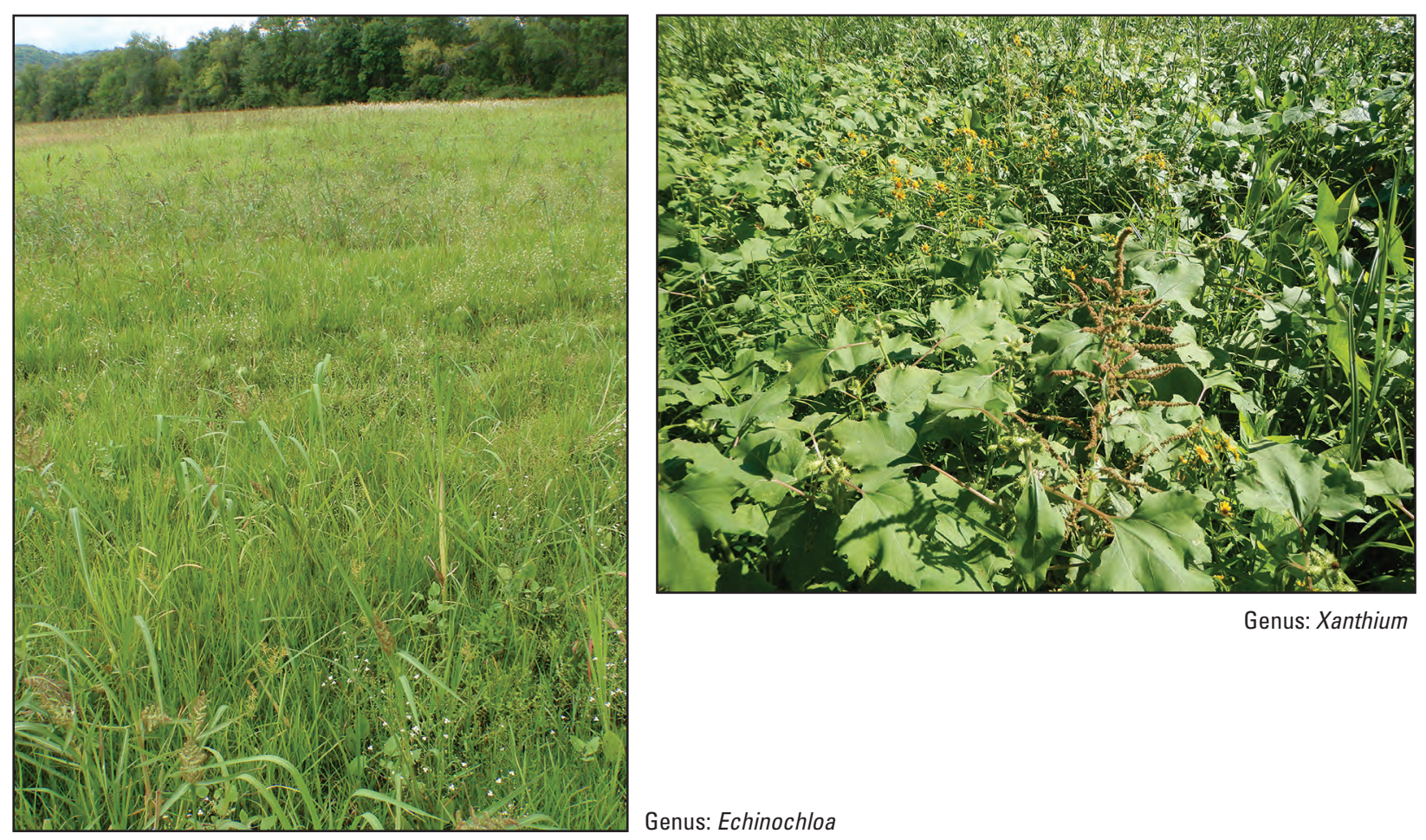

Genus: Xanthium

\section{Shallow Marsh Annual (SMA)_Continued}

Genus: Echinochloa

Image $C$ shows the barnyard grass signature. It is generally found growing near the water's edge or along muddy areas recently emerged from flooding. It appears tall and brownish pink to bright red. The barnyard grass signature in image $C$ is mostly around the wetter central pond areas. This polygon also contains the signature of other light-pink shallow marsh annuals. Because barnyard grass is a shallow marsh annual, both signatures become part of the same polygon.

Image $C$ was taken in August 2011

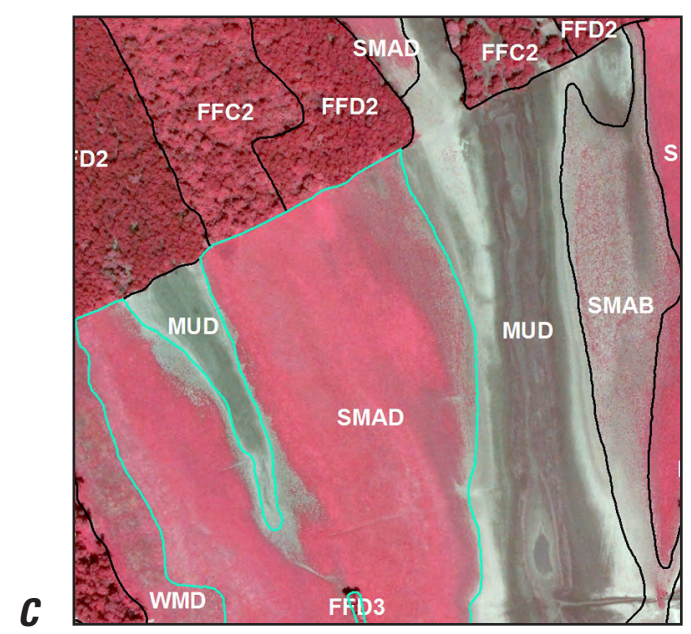




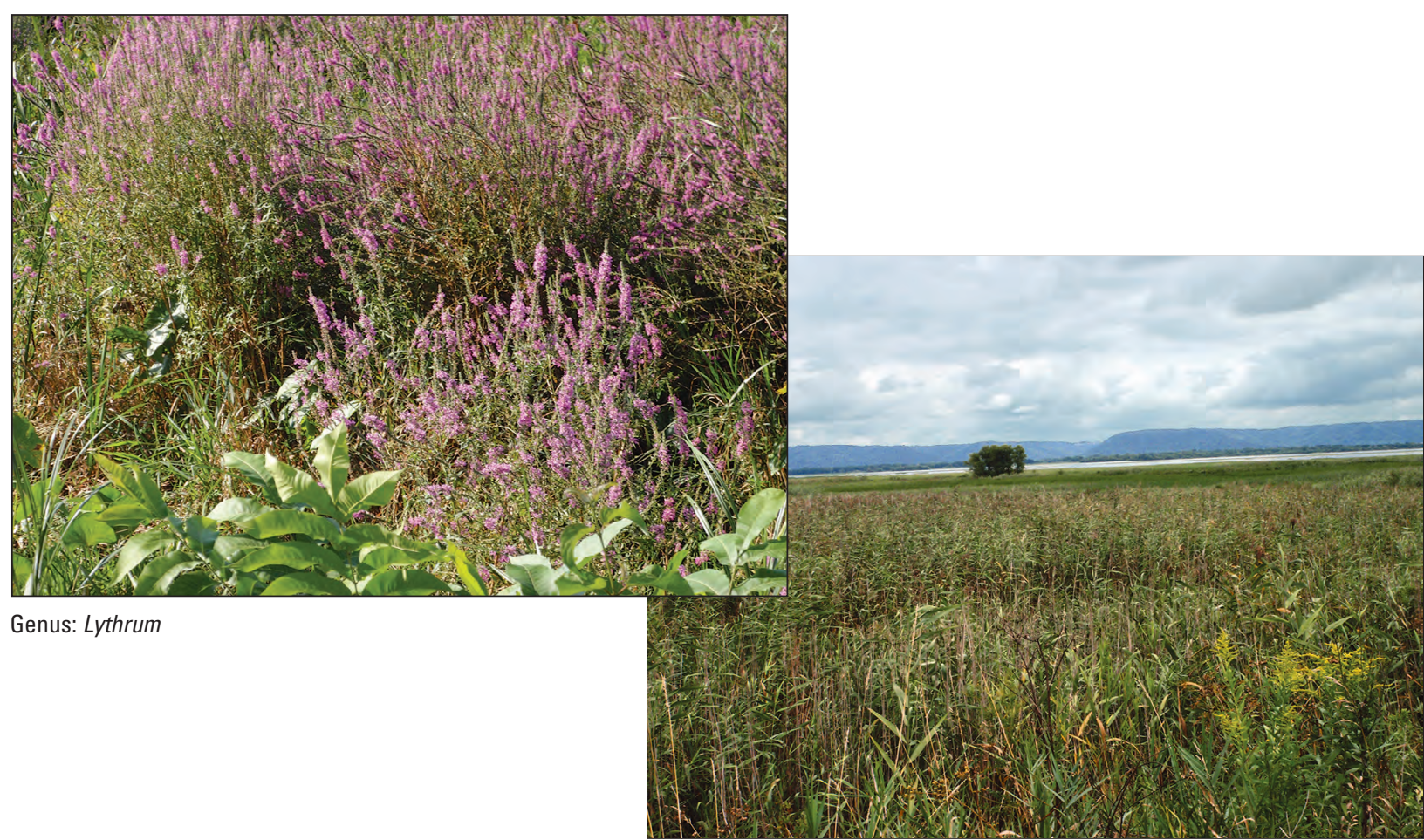

Genus: Phragmites

\section{Shallow Marsh Perennial (SMP)}

The Shallow Marsh Perennial (SMP) map class represents portions of lakes, ponds, backwaters, or shorelines that are seasonally flooded and $>10$ percent vegetated with persistent emergent vegetation. The Shallow Marsh Perennial map class will often denote the transition zone between the Deep Marsh Perennial (DMP) map class and the Wet Meadow (WM) map class. Common vegetation includes bulrush (Schoenoplectus spp.), purple loosestrife (Lythrum salicaria), giant reed (Phragmites spp.), and perennial smartweeds (Polygonum spp.). This map class may have inclusions of submersed, nonrooted floating aquatics or other emergent vegetation. It is typically found growing on soils that are saturated or inundated by water up to $0.2 \mathrm{~m}$ deep.

Images $A-D$ show examples of the Shallow Marsh Perennial signature. As seen in these images, a great deal of variation occurs within the SMP signature depending upon the dominant species. It may range from grayish green to orange or red and generally appears thick and textured.

In image $A$, the signature is thick and appears hummocky or shrubby and can range from orange to pink. This signature represents purple loosestrife. Purple loosestrife generally appears orange but can also range into grayish pink or white depending on environmental factors.

In image $B$, the signature appears deep maroon red to dark brown, but the vegetation does not appear to be growing in deep water. This is cattail growing as a Shallow Marsh Perennial. (Cattail can also be considered Deep Marsh Perennial when found growing in wetter conditions.) Cattail generally grows clonally and often completely dominates an area.
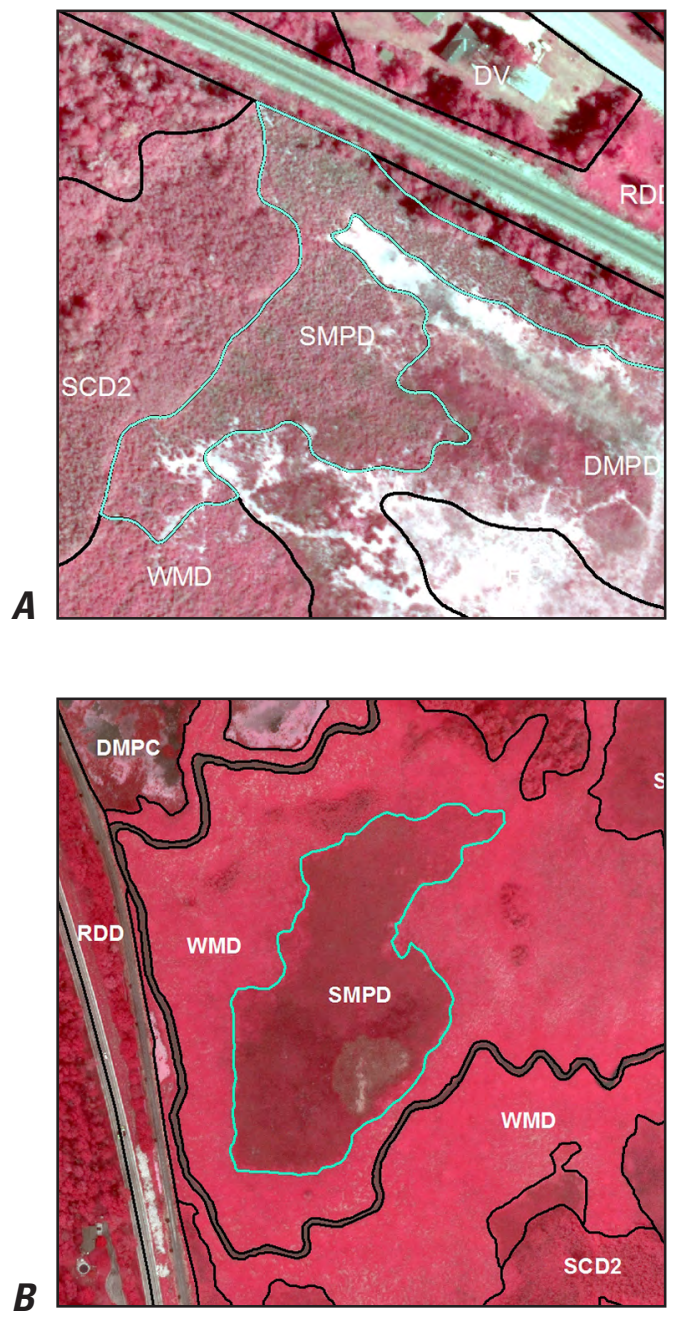


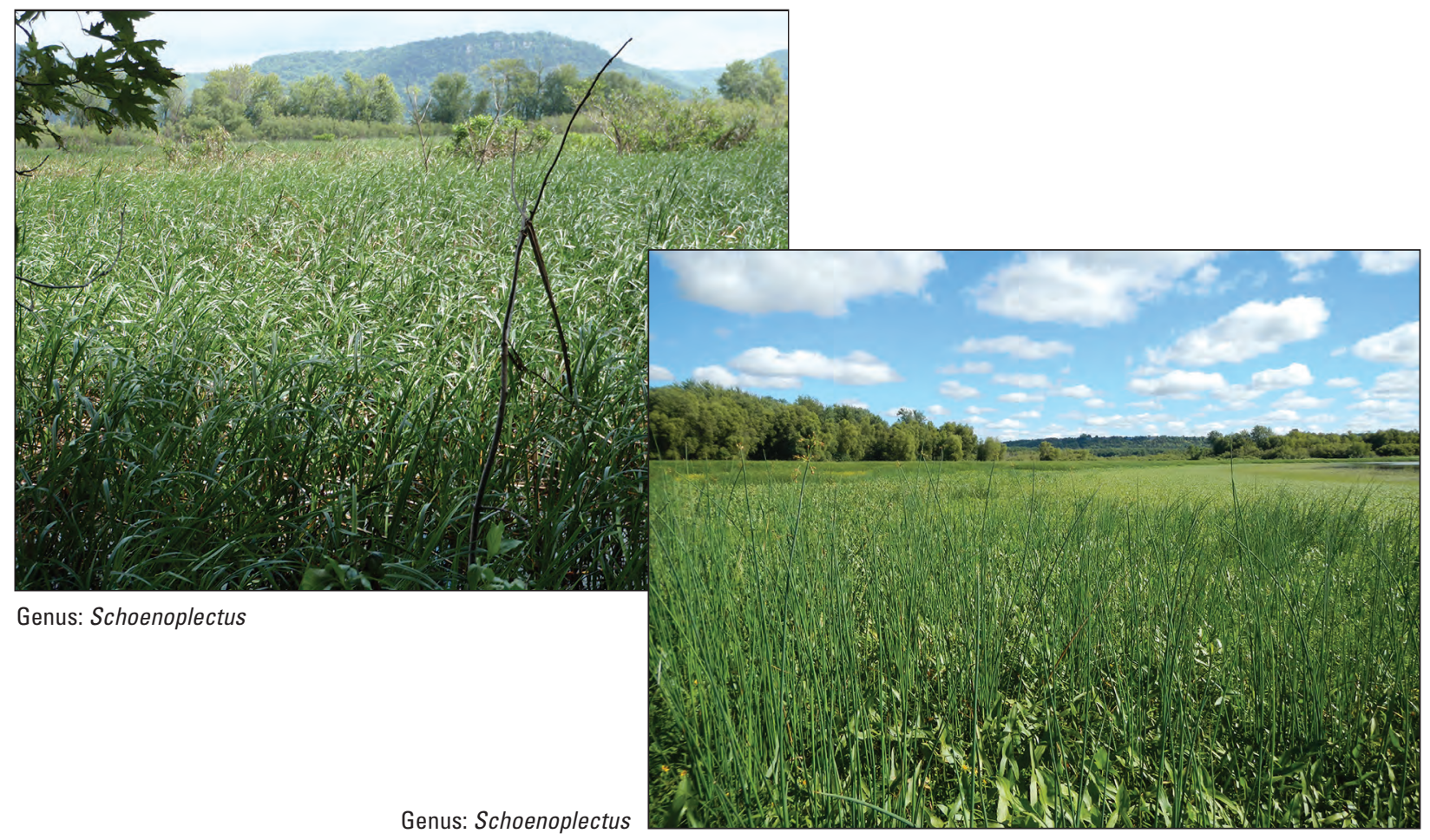

\section{Shallow Marsh Perennial (SMP)—Continued}

In images $C$ and $D$, the signature again appears thick and reddish brown or pinkish brown. These areas are overlain with patches of taller, gray emergent vegetation. These signatures represent bulrush and giant reed. Bulrush can range from grayish green to red, whereas giant reed generally appears gray or white and taller than other emergents.

Images $A-D$ were taken in August 2010.

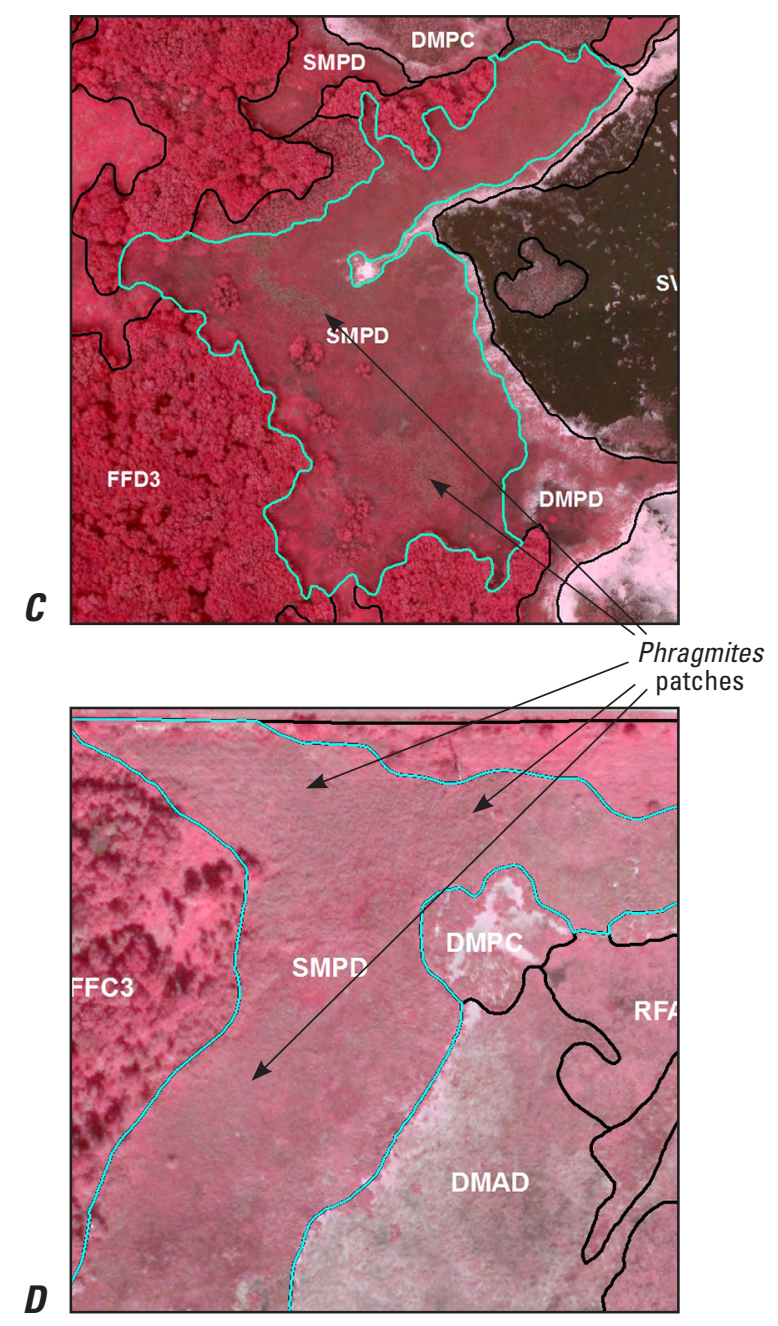




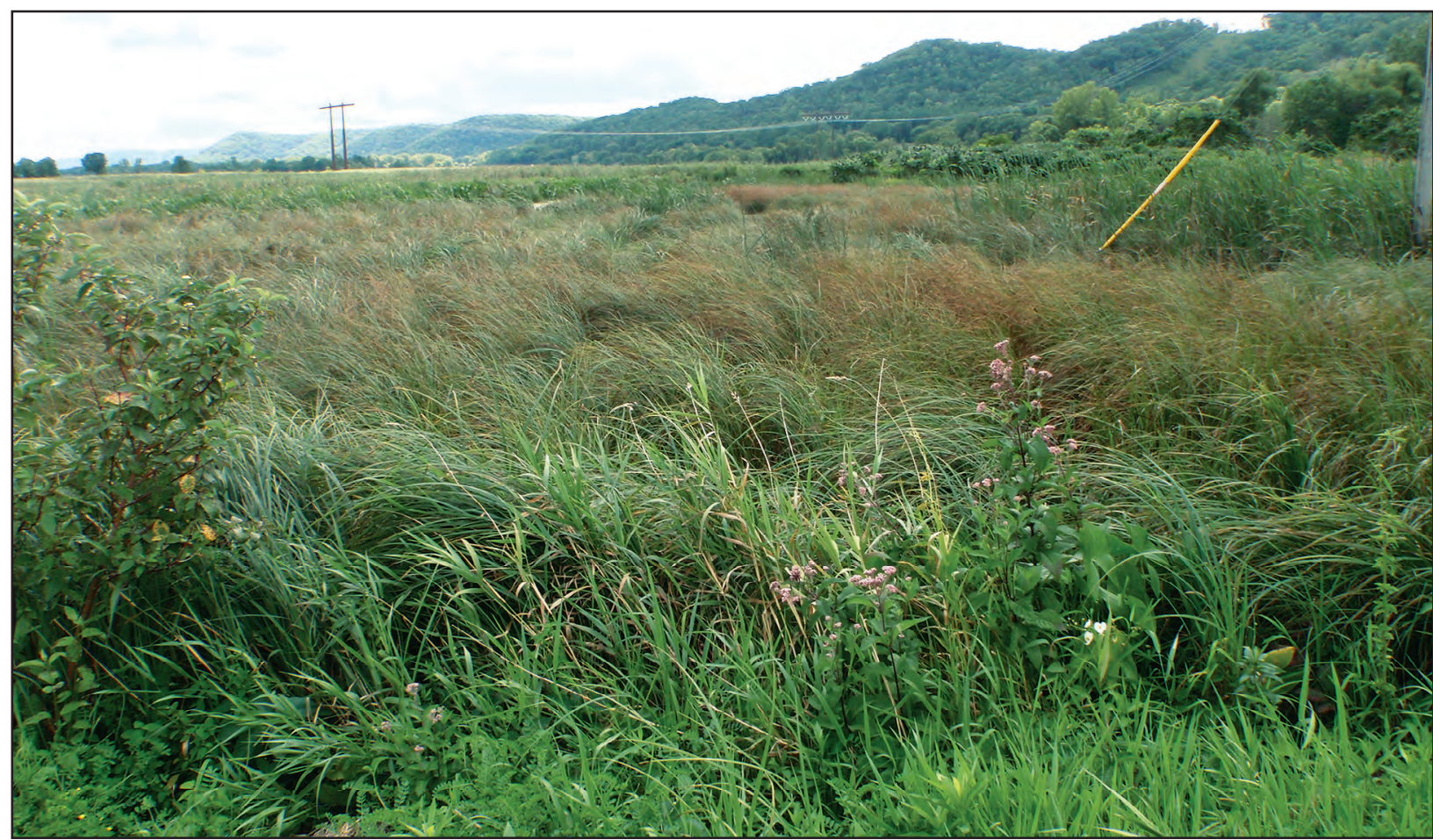

Genus: Carex

\section{Sedge Meadow (SM)}

The Sedge Meadow (SM) map class represents areas around lakes, ponds, and backwaters and along shorelines that are temporarily flooded and $>10$ percent vegetated with sedge meadow species. Sedge Meadow is dominated by sedge (Carex spp.) at a relative density of $>50$ percent. This map class may have inclusions of moist soil grasses and forbs or persistent emergent vegetation. Vegetation in this class is typically found growing on saturated soils composed of peat or muck but will often grade into shallow marshes or wet meadows. This class tends to be fairly rare and limited in area in the UMRS.

Image $A$ shows an example of the Sedge Meadow signature. It generally appears pinkish brown and textured. The signature for Sedge Meadow tends to be similar to that of the Wet Meadow (WM) map class but appears more textured and wetter than the WM polygon directly adjacent to it.

This map class is distinguishable from Wet Meadow only on larger scale imagery where its distinctive hummocky texture is visible.

Image $A$ was taken in August 2010.

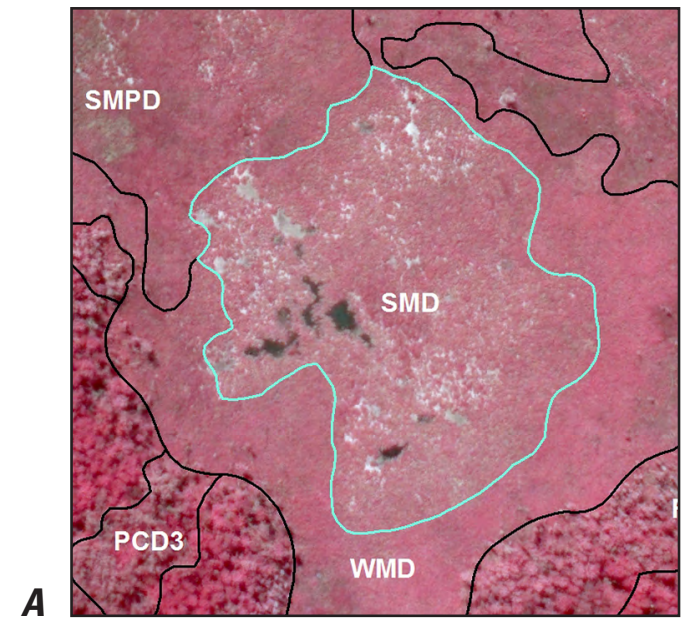




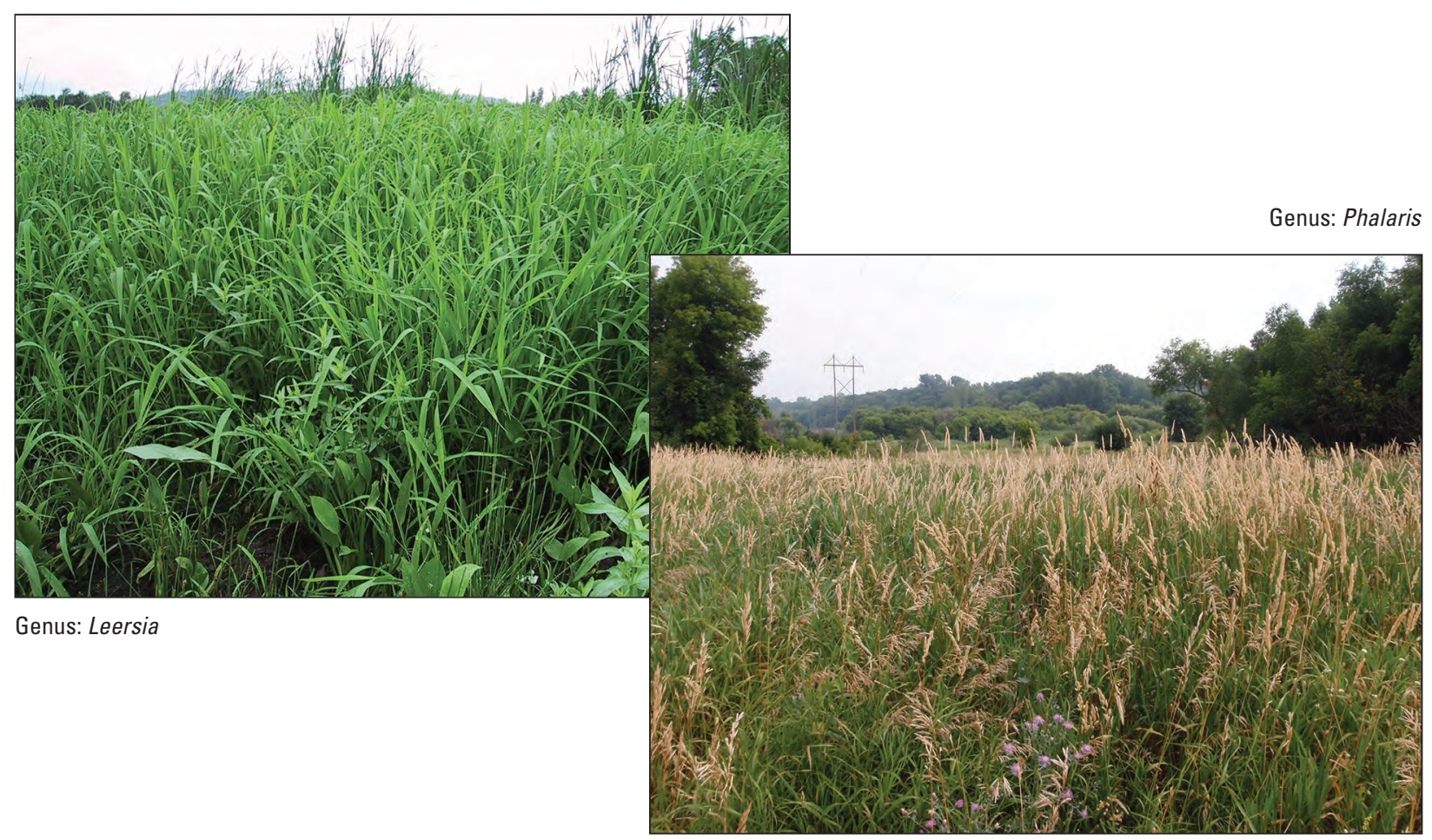

\section{Wet Meadow (WM)}

The Wet Meadow (WM) map class represents lowland areas that are $>10$ percent vegetated with perennial grasses and forbs. Common vegetation includes reed canary grass (Phalaris arundinacea), rice cutgrass (Leersia oryzoides), and various moist-soil forbs. This map class may have small inclusions of woody vegetation, sedges, or emergent vegetation such as smartweed or purple loosestrife. Vegetation in this class is typically found growing on saturated soils, and the map class is often considered the transition zone between aquatic communities and uplands.

The signature for Wet Meadow can vary depending on the dominant species or mixture of species. Image $A$ shows a monotypic stand of rice cutgrass. This signature is bright pink and smooth, and the environment often appears very wet. Image $B$ shows a monotypic stand of reed canary grass. It appears medium pink with white speckles. Both images depict the transition zone between emergent vegetation and drier wooded areas.

Images $A$ and $B$ were taken in August 2010.
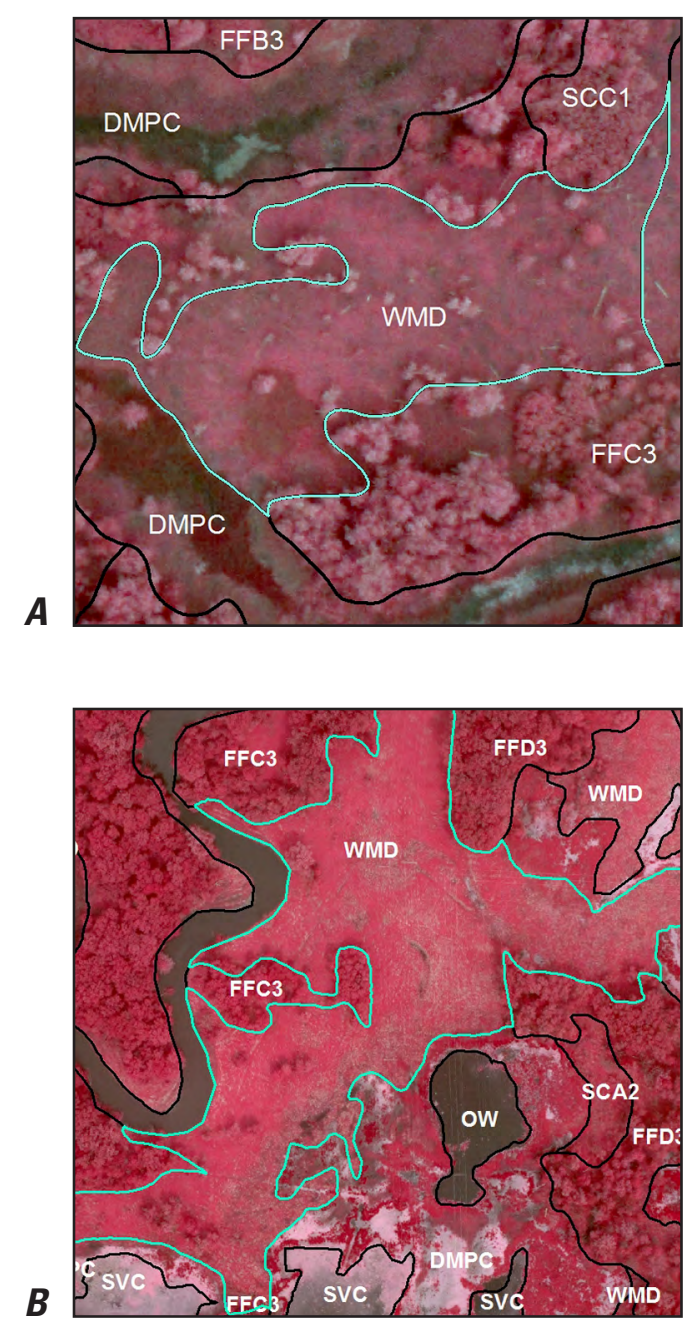

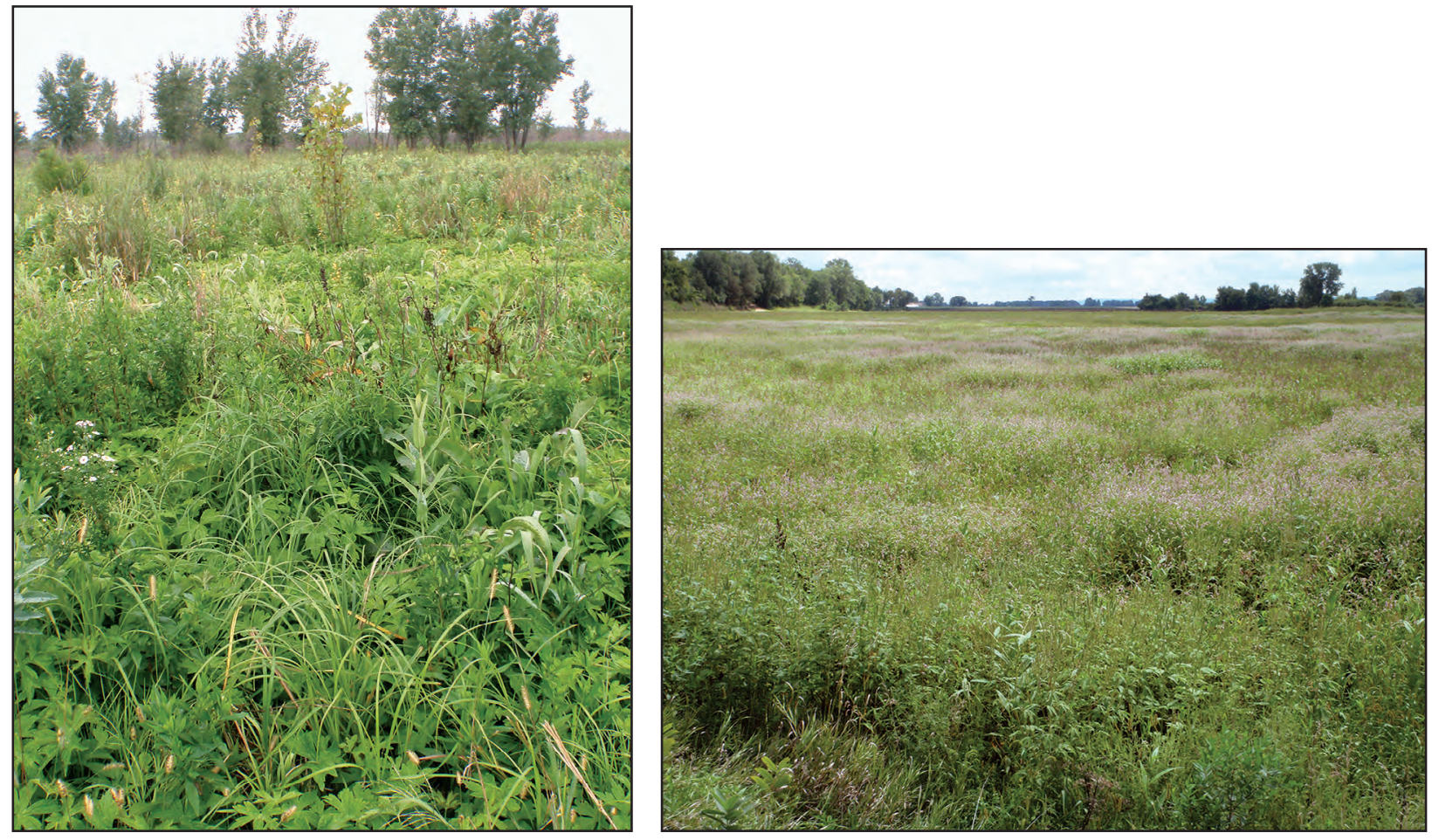

\section{Wet Meadow (WM)—Continued}

Stands that are not monotypic can appear in a variety of colors, including gray, brown, pink and red. The range in color is generally a result of the type of vegetation present, as well as how saturated the soil may be. Image $C$ shows an example of a signature comprising a mix of wet grasses and forbs. Notice the rectangular area with substantially more color and texture variation; this area was likely originally part of the nearby agricultural or hayed area and still has enough weedy forbs to produce a more varied look. The signature appears rough, with several shades ranging from pinks to brown. This area of Wet Meadow is near an area that is hayed or planted as agricultural crops in drier years.

Image $C$ was taken in August 2010.

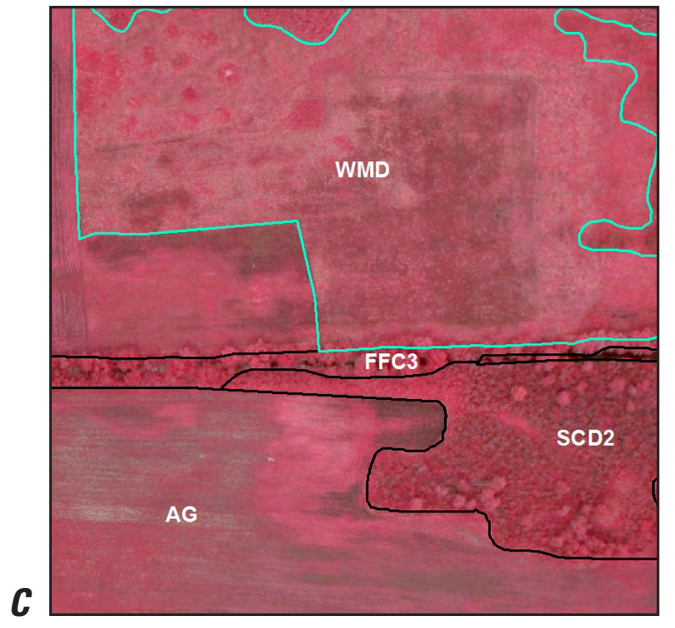




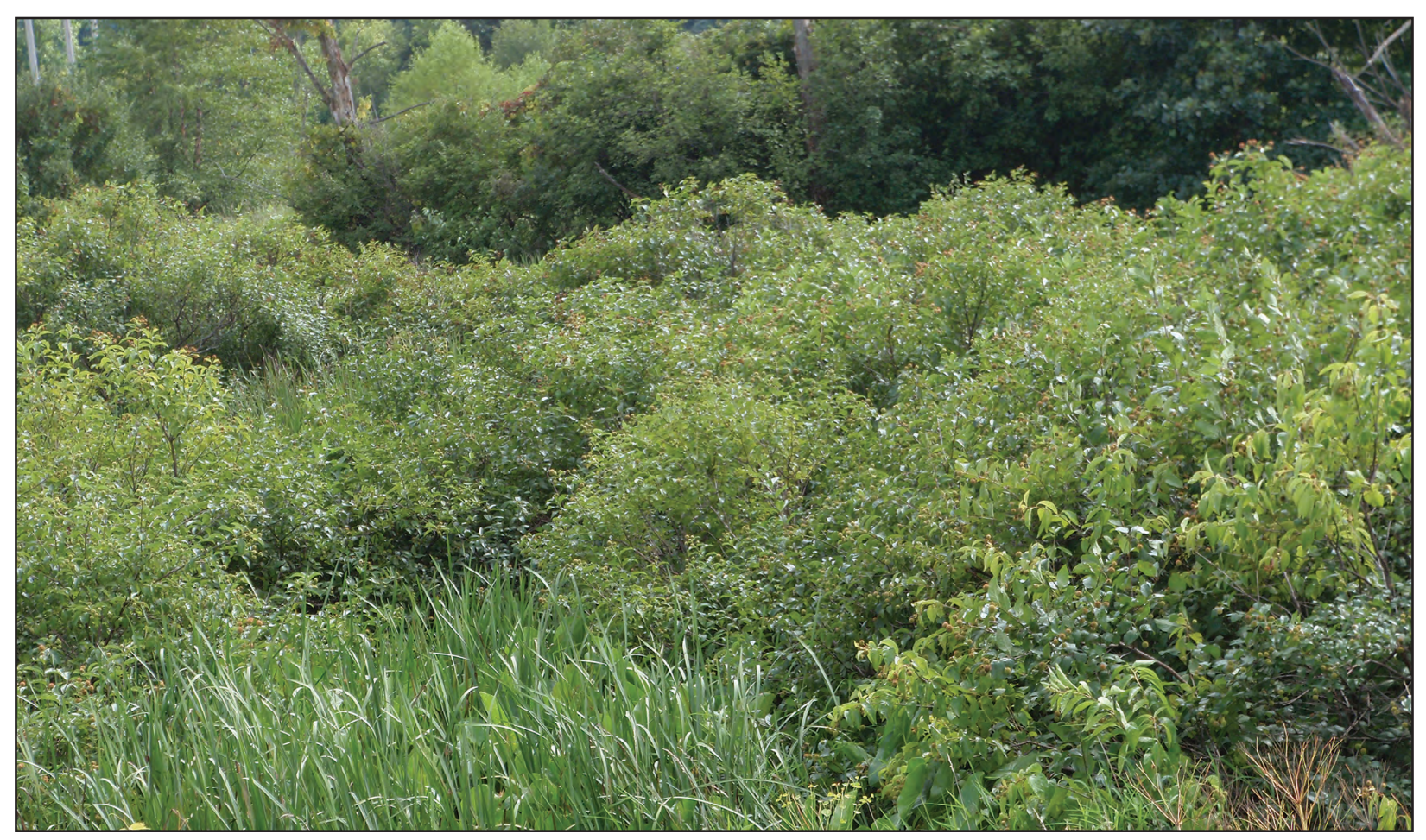

\section{Deep Marsh Shrub (DMS)}

The Deep Marsh Shrub (DMS) map class represents areas in or around lakes, ponds, backwaters, or shorelines that are $>25$ percent vegetated with semipermanently flooded shrubby vegetation. Common species include buttonbush (Cephalanthus occidentalis) and swamp loosestrife (Decodon verticillatus). This map class may have inclusions of submersed, nonrooted-floating aquatic, rooted-floating aquatic, or emergent vegetation. Vegetation in this class is typically found growing in shallow water. Deep Marsh Shrub tends to be more common and cover larger areas in the lower UMRS.

Images $A$ and $B$ show examples of the Deep Marsh Shrub signature. They generally appear deep pink to red and speckled or beady. The signature in image $A$ is lighter than in image $B$. This is primarily because the shrubs in image $A$ are mostly swamp loosestrife, which tends to be a smaller and sparser shrub than the buttonbush shown in image $B$, which tends to form mounds. Also, the Deep Marsh Shrub in image $A$ is sparser and is surrounded by emergent vegetation. In both images, some amount of water is visible between the shrubs.

Images $A$ and $B$ were taken in August 2011.
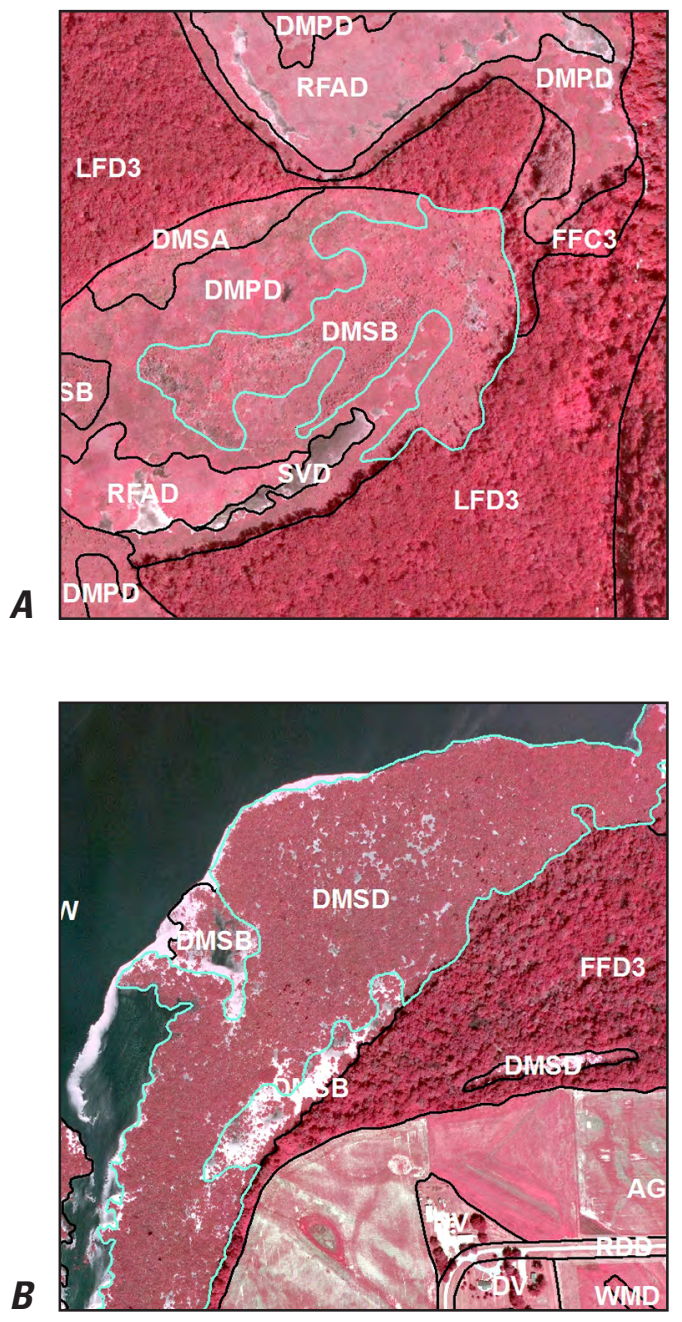


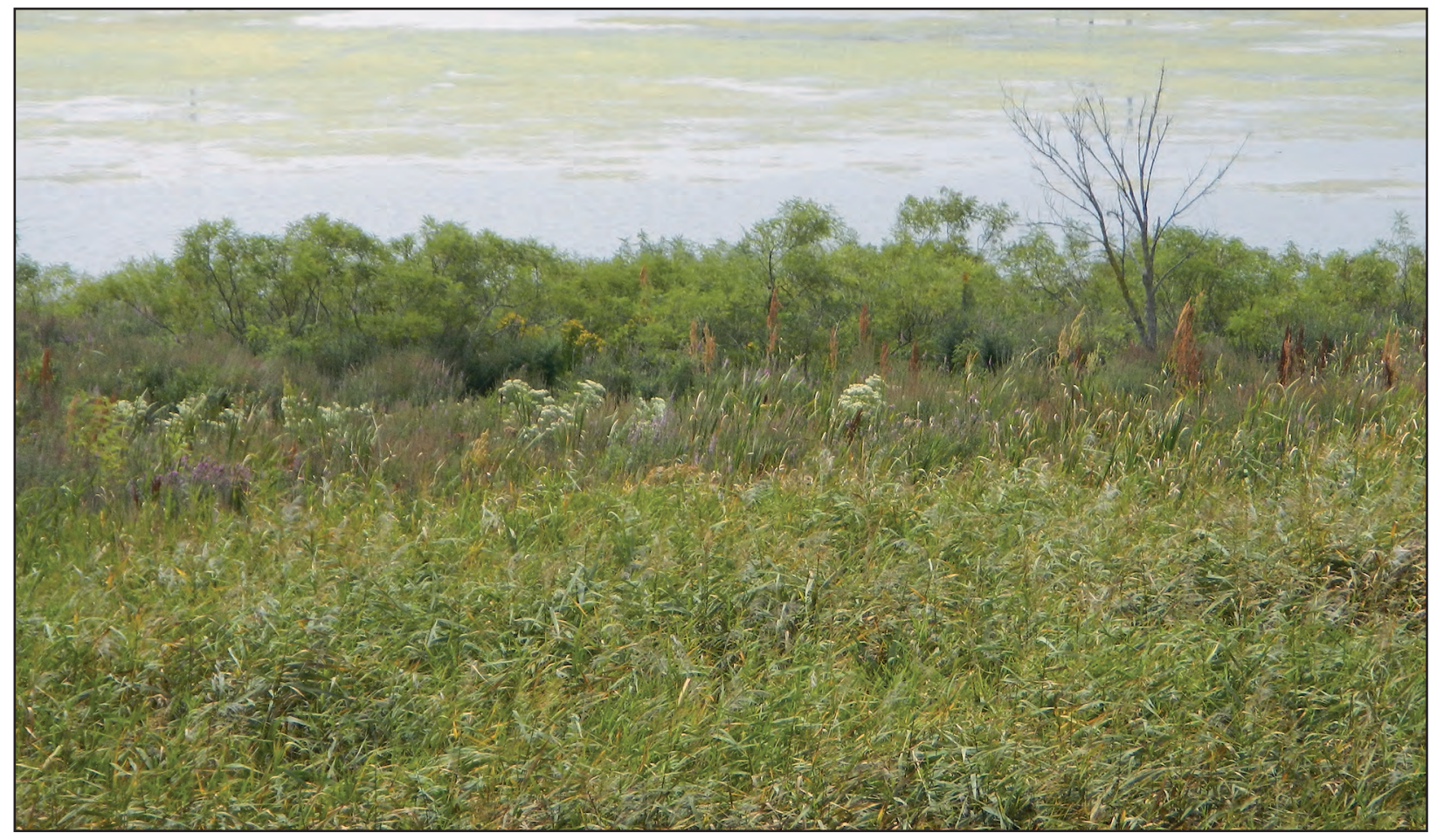

\section{Shallow Marsh Shrub (SMS)}

The Shallow Marsh Shrub (SMS) map class represents areas near the shoreline or in shallow water around lakes, ponds, and backwaters that are $>25$ percent vegetated with seasonally flooded shrubby vegetation. These shrubs typically grow with mixed emergents, grasses, and forbs. This map class tends to be drier than Deep Marsh Shrub (DMS) but wetter than Wet Meadow Shrub (WMS). Sandbar willow (Salix interior) may be growing in this mix of shrubby vegetation. Shallow Marsh Shrub can encompass a wide range of species including dogwood (Cornus spp.), false indigo (Amorpha fruticosa), and swamp privet (Forestiera acuminata), as well as shrubs like buttonbush (Cephalanthus occidentalis) and swamp loosestrife (Decodon verticillatus), which can be found in more deep marsh environments as well. Shallow Marsh Shrub is typically found growing on soils that are saturated or inundated with little water.

Images $A$ and $B$ show examples of the Shallow Marsh Shrub signature. The shrubs are sporadic and appear pink to red and speckled or beady. In image $A$, the shrubs are diverse and are mixed with a few trees. In image $B$, the shrubs look to be all of one type. Throughout both polygons, the ground layer consists of a mix of emergent vegetation with little to no grasses and forbs.

Images $A$ and $B$ were taken in August 2010.
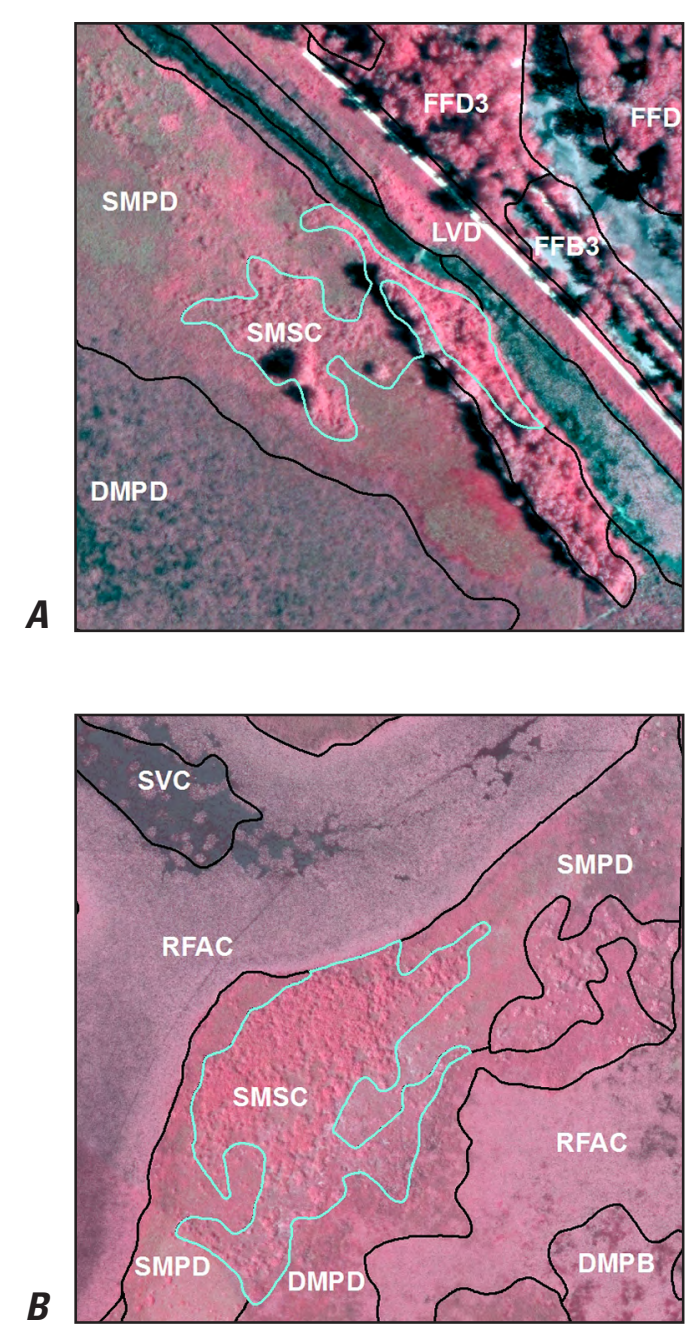


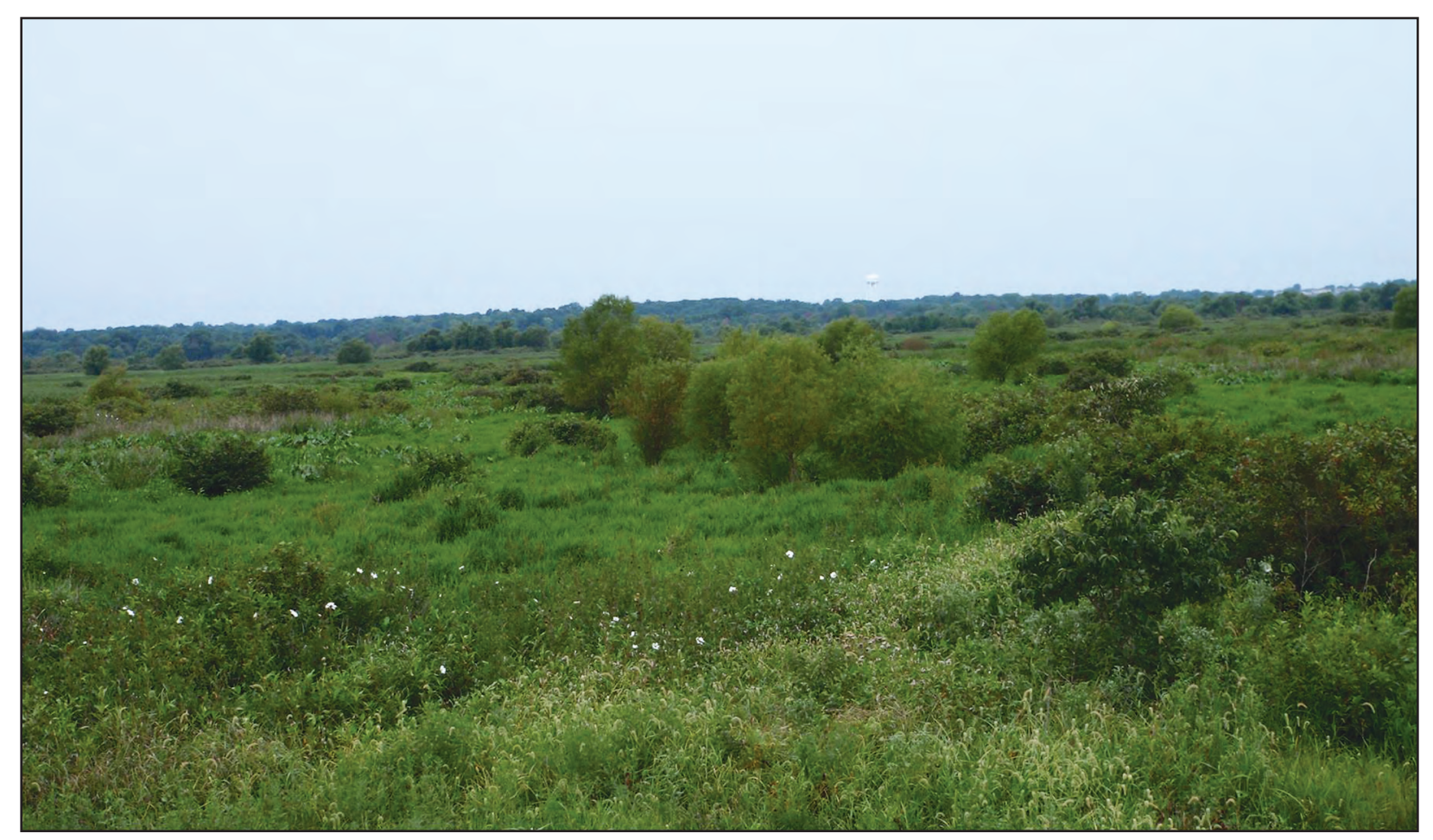

\section{Wet Meadow Shrub (WMS)}

The Wet Meadow Shrub (WMS) map class represents lowland areas that are $>25$ percent vegetated with temporarily flooded shrubby vegetation. This map class tends to be drier than Shallow Marsh Shrub (SMS) but wetter than Scrub-Shrub (SS), and it typically has a mix of sedges, grasses, and forbs. Common vegetation includes alder (Alnus spp.), elder (Sambucus spp.), false indigo (Amorpha fruticosa), dogwood (Cornus spp.), and willow (Salix spp.). Wet Meadow Shrub is typically found growing on saturated soils.

Images $A$ and $B$ show examples of the Wet Meadow Shrub signature. The shrubs are generally sporadic and appear pink to red and speckled or beady. In images $A$ and $B$, the darker pink areas are the shrubs, and the lighter pink areas are the ground layer consisting of a mix of grasses and forbs.

Image $A$ was taken in August 2010, and image $B$ was taken in August 2011.
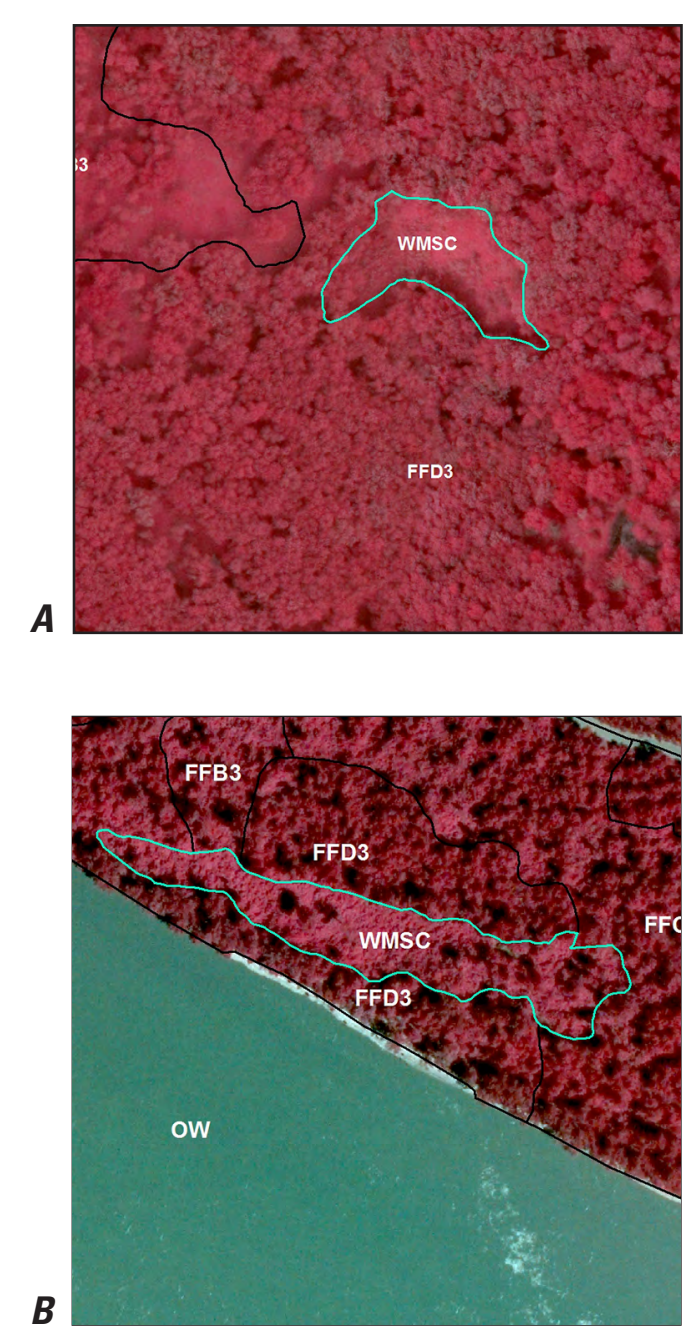


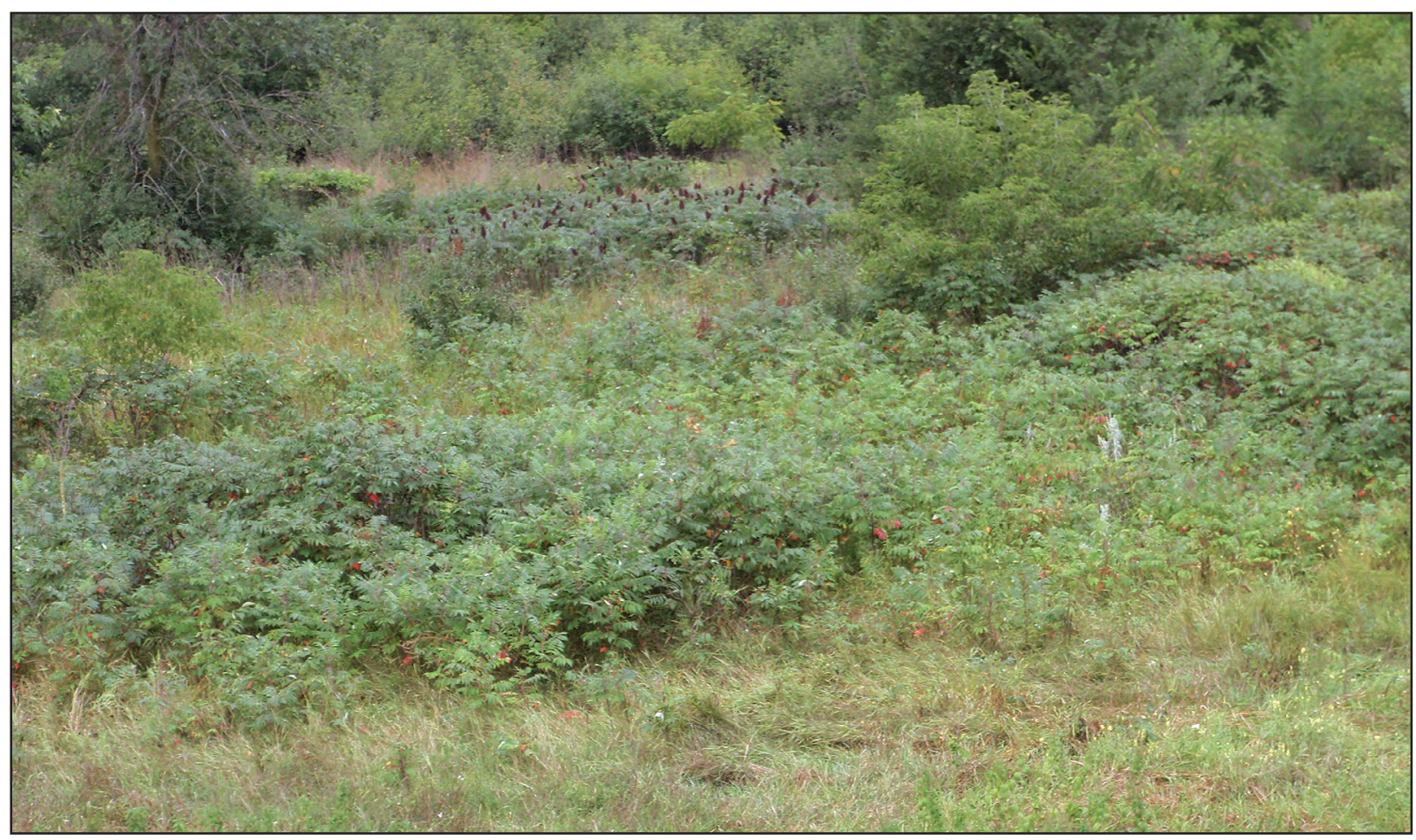

\section{Scrub-Shrub (SS)}

The Scrub-Shrub (SS) map class represents upland areas that are $>25$ percent vegetated with infrequently flooded shrubby vegetation. This map class is the driest of the shrub classes and typically consists of a mix of grasses and forbs on drier soils. Common species found in Scrub-Shrub are sumac (Rhus spp.), Russian olive (Elaeagnus angustifolia) and autumn olive (Elaeagnus umbellata), and buckthorn (Rhamnus spp.). Scrub-Shrub may contain scattered trees at $<10$ percent cover.

Images $A$ and $B$ show examples of the Scrub-Shrub signature. Shrubs are generally sporadic and appear pink to red and speckled or beady. In image $A$, the shrubs are growing on a hill where soils are dry. The shrubs appear pink, with a grassy ground layer that is pinkish gray. In image $B$, the shrubs are on a sand island in the river, the shrubs appearing pink and mostly surrounded by upland grasses and forbs represented by grayish-pink areas. Although this island is raised, parts of it may flood periodically during very high water events. Because of its sandy soil composition, this area can support upland species.

Images $A$ and $B$ were taken in August 2010.
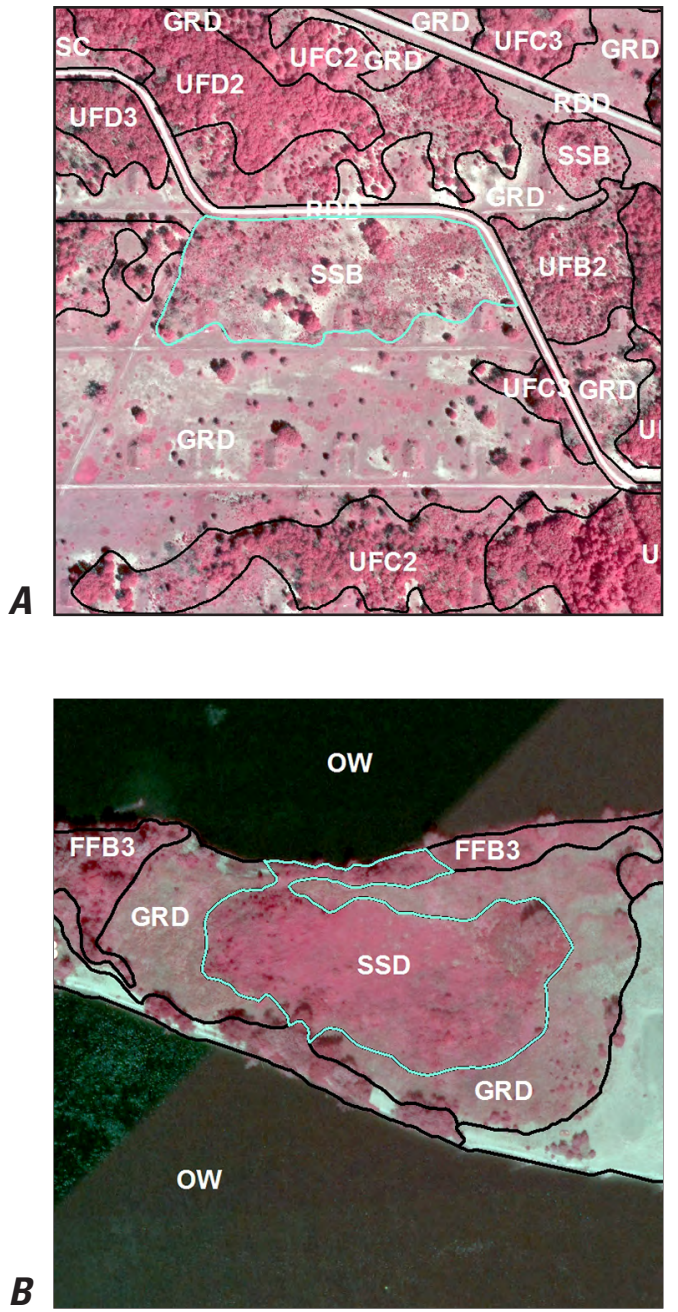


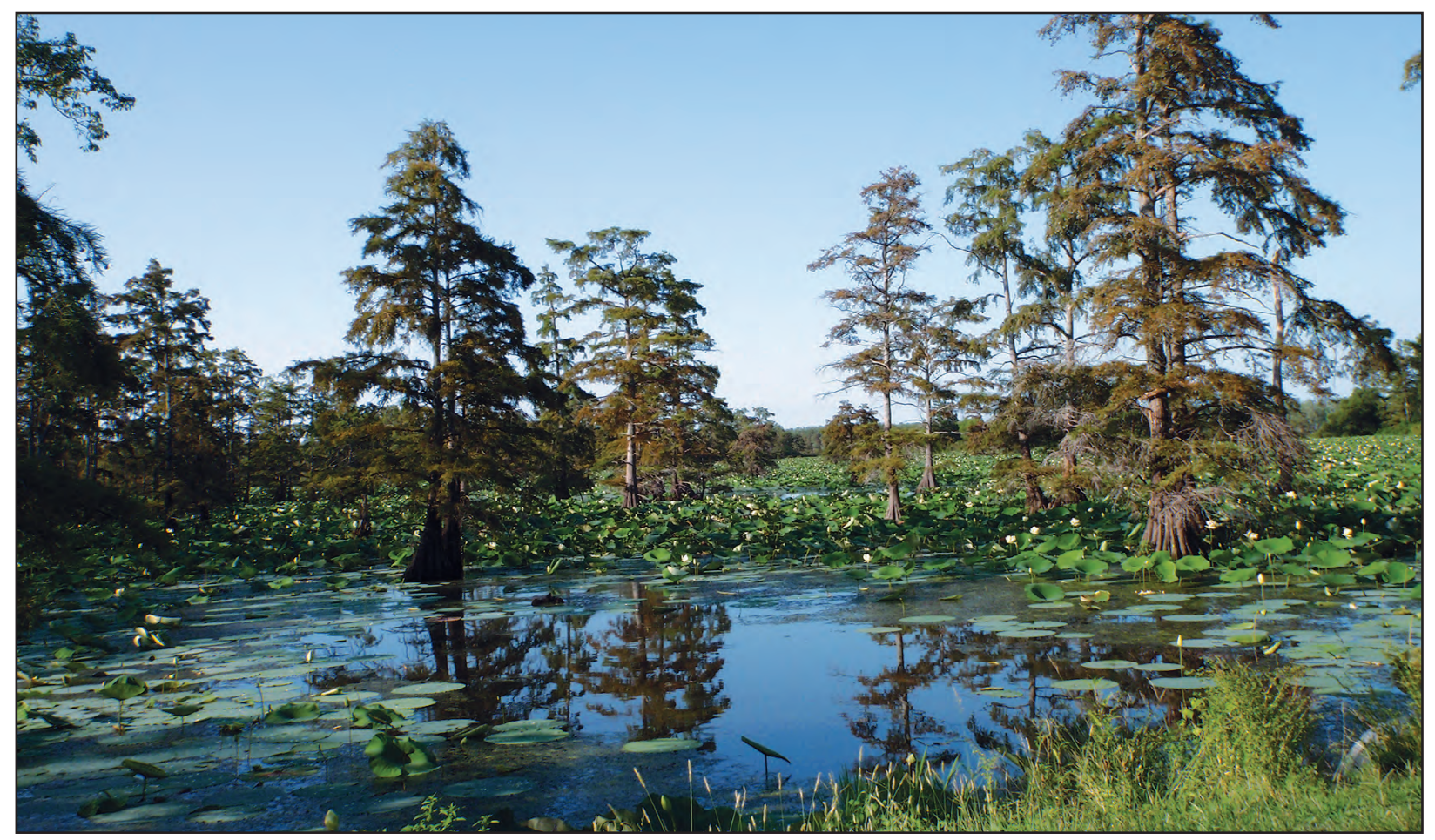

\section{Wooded Swamp (WS)}

The Wooded Swamp (WS) map class represents areas in or around shallow lakes, ponds, oxbows, or backwaters that are $>10$ percent vegetated with semipermanently flooded forests. Common species include bald cypress (Taxodium distichum), water tupelo (Nyssa aquatica), and black ash (Fraxinus nigra). This map class is most common in southern reaches of the UMRS. It may have inclusions of submersed, nonrooted-floating aquatic, rooted-floating aquatic, or emergent vegetation. Vegetation in this class is typically found growing in shallow water.

Image $A$ shows an example of a Wooded Swamp signature. It generally ranges from red or pink to brown and purple. The signature in image $A$ shows purple-brown trees with dark blue patches of water interspersed between them. (Note in some of the nonhighlighted wooded swamp polygons in image $A$ that the water is covered with a layer of duckweed, which makes it appear white.) Image $B$ shows these trees growing over rooted-floating aquatics that display as a bright pink layer on the water. All of the trees in the water in these images are bald cypress and have the dark purple-brown signature of conifers. Deciduous trees like black ash or water tupelo would have a brighter pink or red signature.

Images $A$ and $B$ were taken in August 2011.
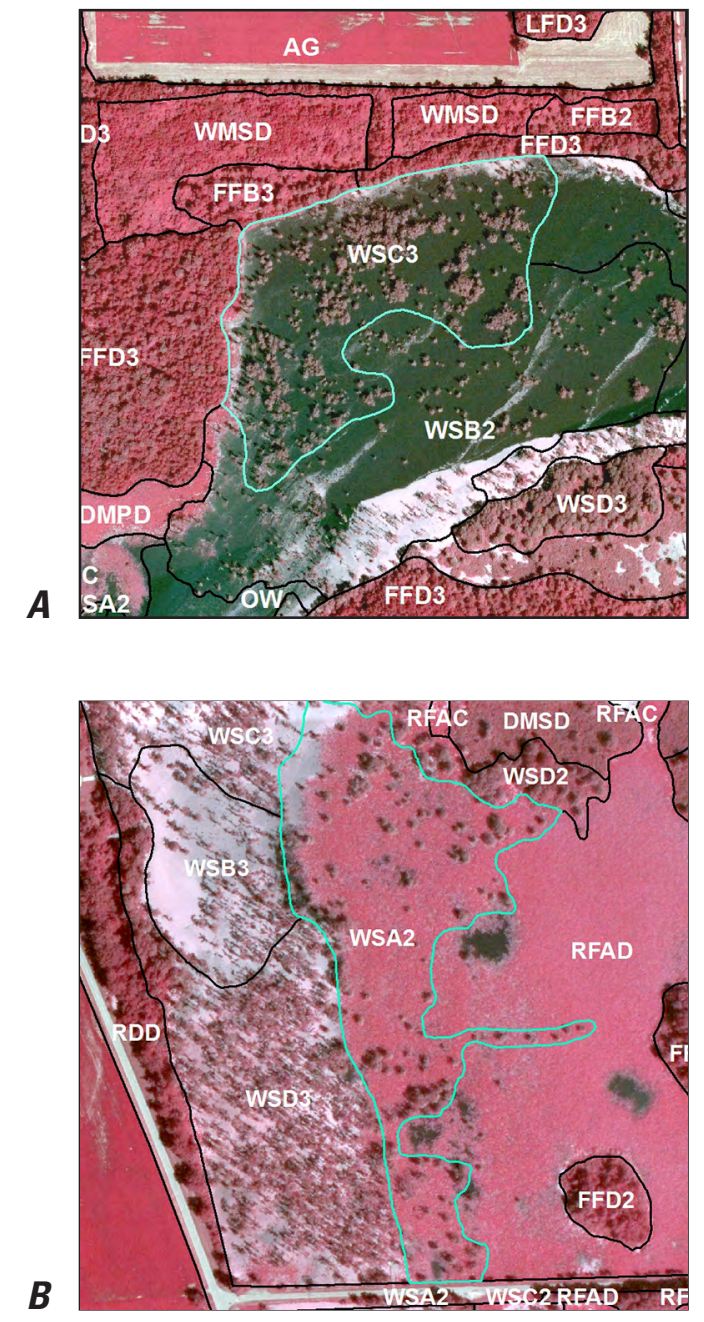


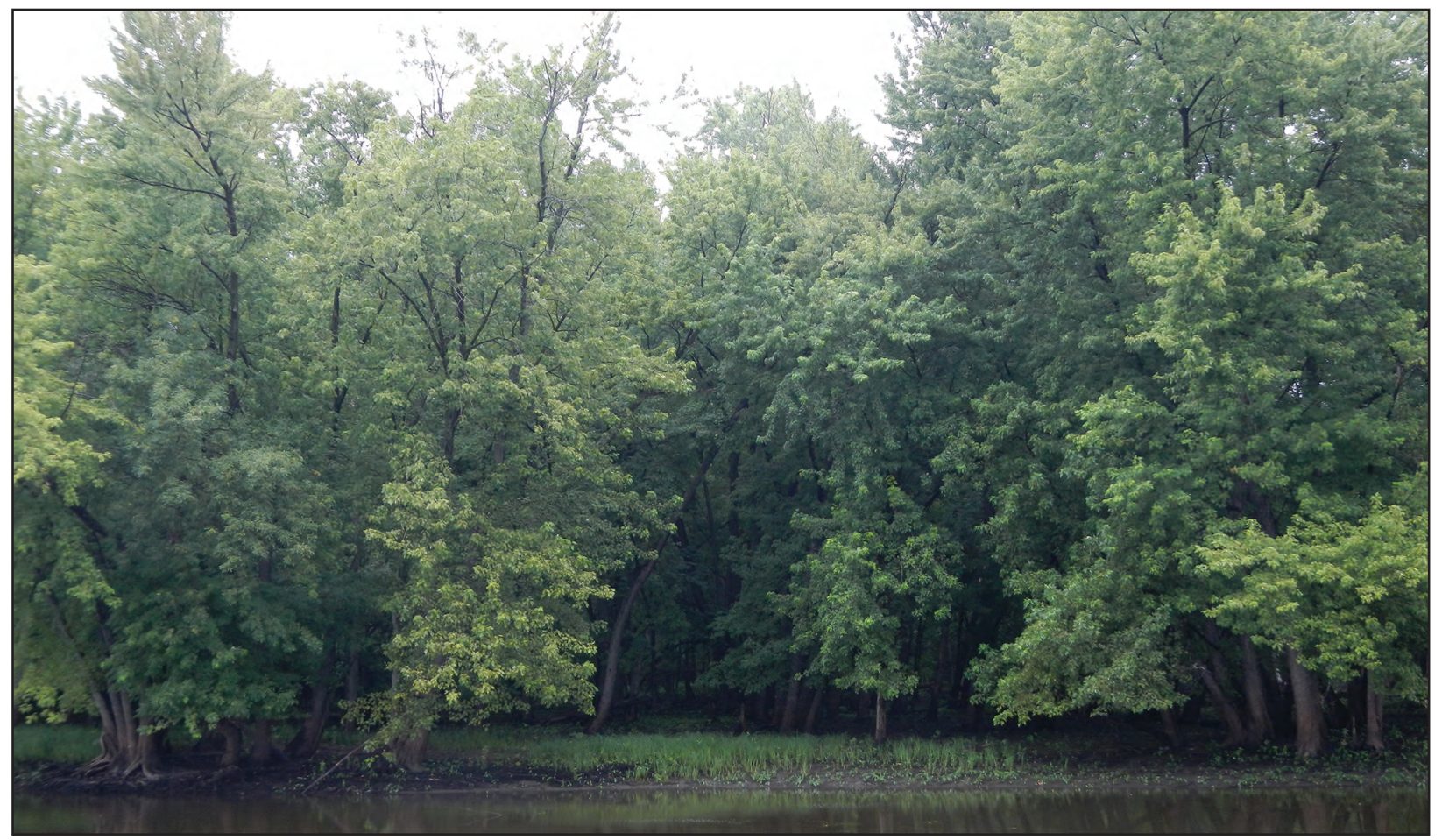

\section{Floodplain Forest (FF)}

The Floodplain Forest (FF) map class represents areas on islands, near the shoreline, or around lakes, ponds, and backwaters that are $>10$ percent vegetated with seasonally flooded forests. These forests may also be fairly far removed from the river on very flat flood-prone topography. These forests are predominantly silver maple (Acer saccharinum), but they also include cottonwood (Populus deltoides), black willow (Salix nigra), ash (Fraxinus spp.), elm (Ulmus spp.), and river birch (Betula nigra). Vegetation in this map class is typically found growing at or near the water table where it becomes inundated from spring flooding and high-water events.

Images $A$ and $B$ show examples of the Floodplain Forest signature. Image $A$ is an island in the main channel; the trees, which are primarily silver maple, appear red with the dark blue water all around. In image $B$, the trees also appear red; however, they are not as uniform. This is primarily because the trees in image $B$ are more diverse and have a slightly drier hydrology than the trees in image $A$. The Floodplain Forest in image $B$ is adjacent to a small stream but is also still part of the larger Mississippi River floodplain.

Image $A$ was taken in August 2010, and image $B$ was taken in August 2011.
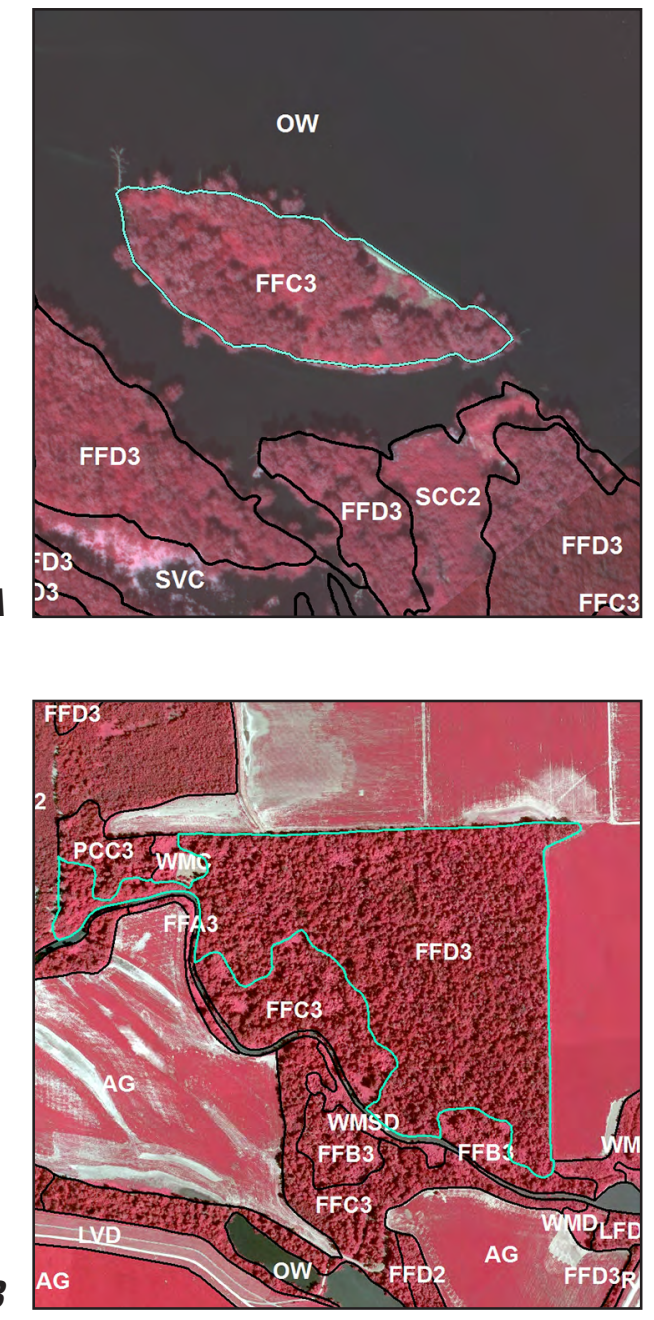


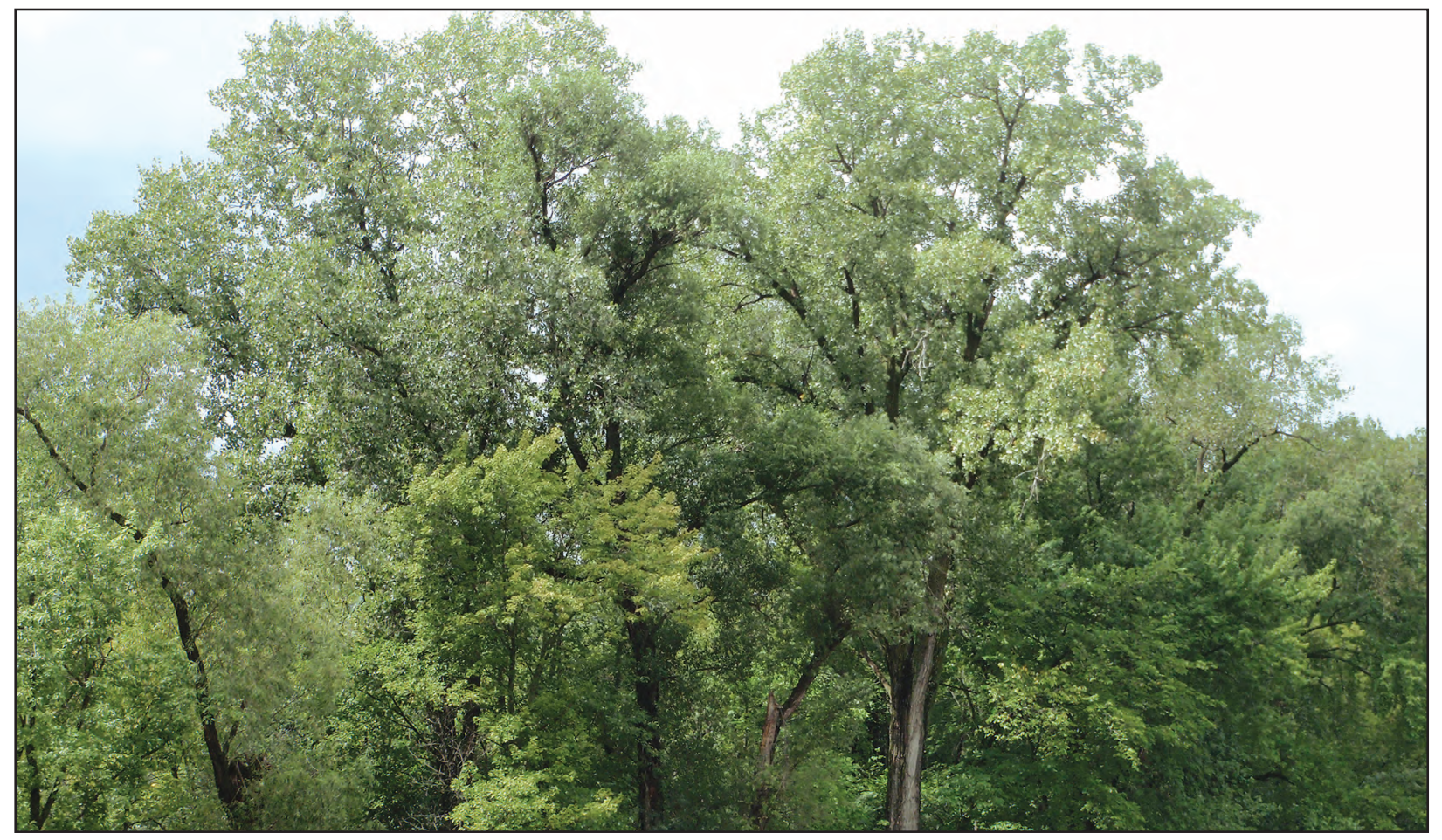

\section{Populus Community (PC)}

The Populus Community (PC) map class represents lowland areas that are $>10$ percent vegetated with seasonally flooded cottonwood trees. These forests are $>50$ percent cottonwood (Populus deltoides) by relative density and may include other floodplain and lowland forest types at $<50$ percent relative density. This map class is typically a pioneering species of disturbed areas and is generally found growing on moist soils. Trees in the Populus Community can grow very tall and often grow monotypically, as well as adjacent to or along with floodplain forest or lowland forest types.

Images $A$ and $B$ show examples of the Populus Community signature. The signature generally ranges from light brown to purple to white. Compared to other trees, cottonwood trees generally have a looser, more branched crown, which has a distinctive appearance when viewed in stereo. In both images $A$ and $B$, the stands are fairly monotypic and are adjacent to other forest types. In image $A$, the cottonwood trees are purplish brown and look large and branchy. In image $B$, the cottonwood trees are light brown and smaller. These trees are densely packed and not fully mature, so they do not show the large branchy structure typical of mature cottonwood.

Image $A$ was taken in August 2010, and image $B$ was taken in August 2011.
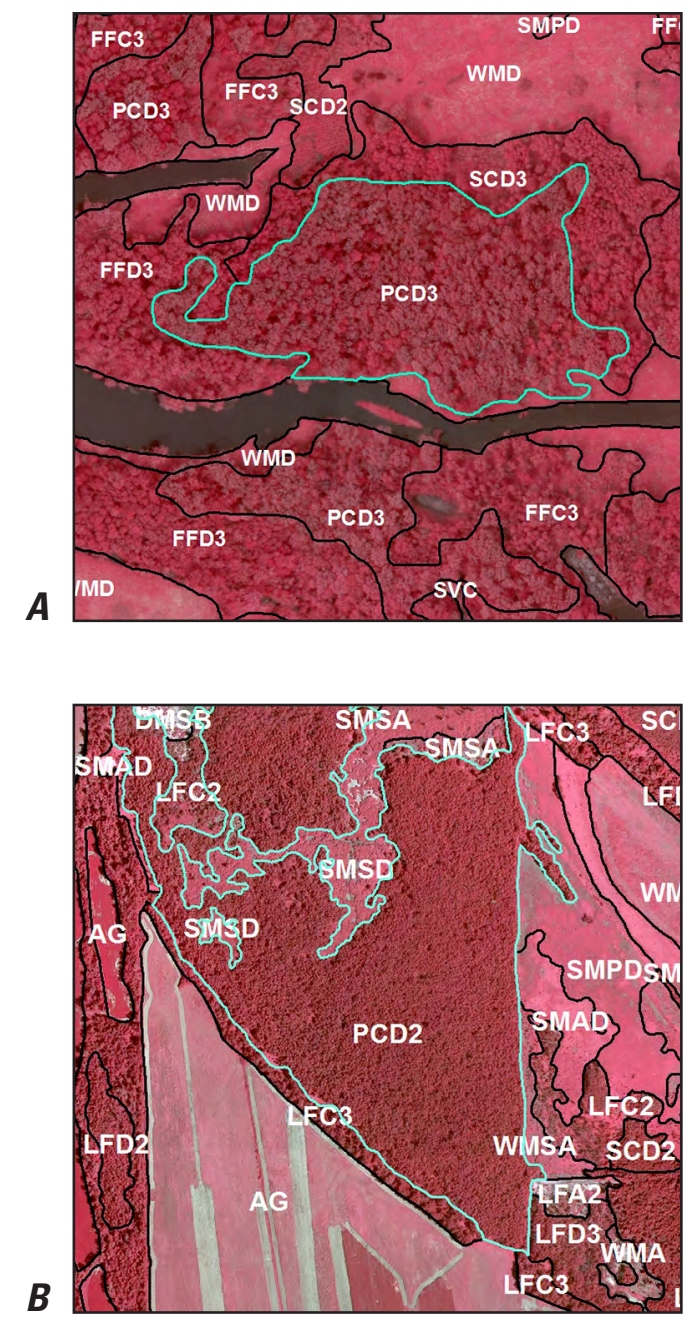


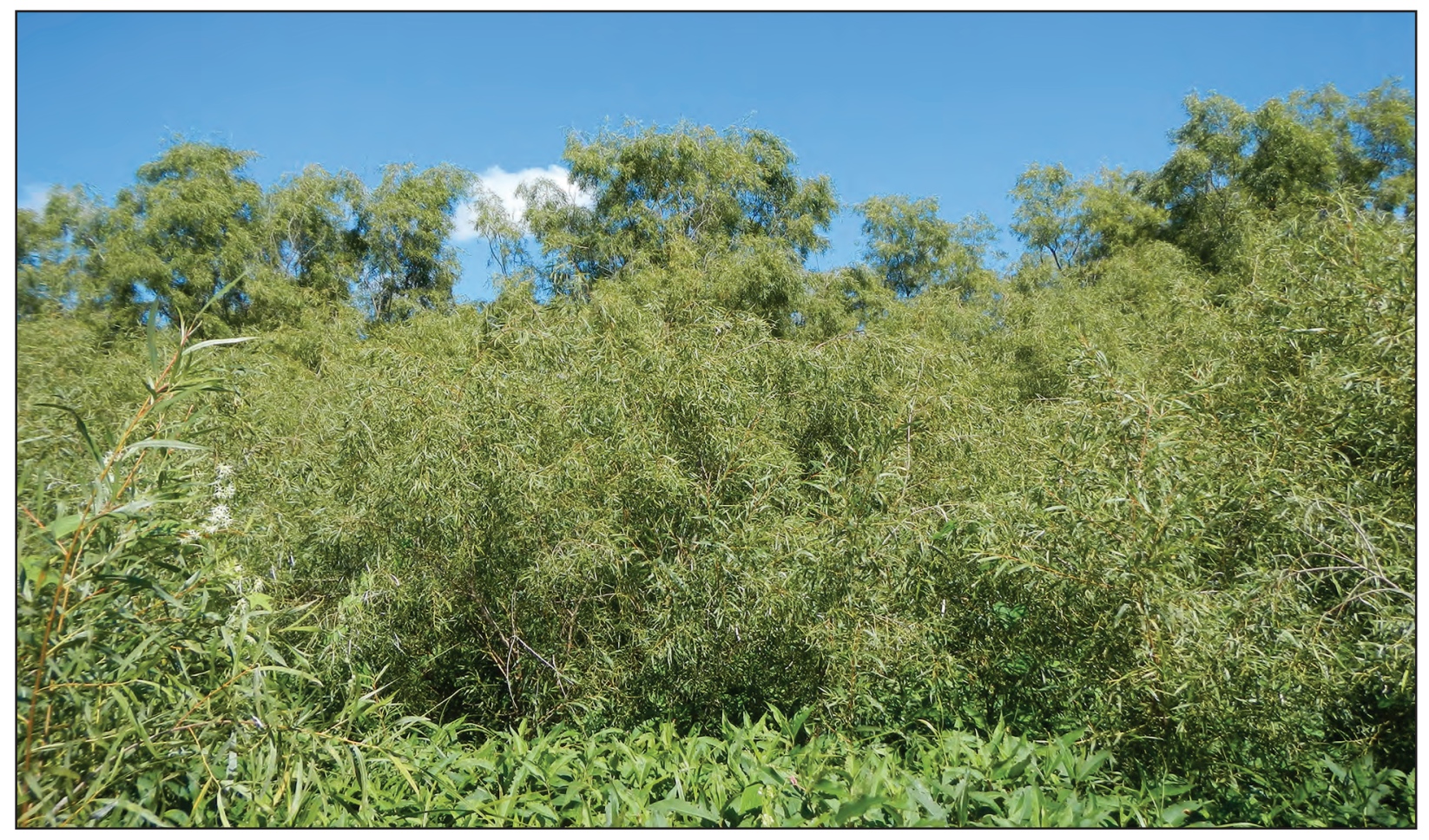

\section{Salix Community (SC)}

The Salix Community (SC) map class represents areas near the shoreline or around lakes, ponds, and backwaters that are $>10$ percent vegetated with seasonally flooded willow trees or shrubs. These forests or shrub communities are $>50$ percent willow (Salix spp.) and may include other floodplain forest types. This map class typically grows with an emergent, grass, and (or) forb understory on moist and saturated soils.

Images $A$ and $B$ show examples of the Salix Community signature, which is often dense, textured, and light to medium pink. In image $A$, the willow shrubs are medium pink, and the highlighted polygon shows tall black willow (Salix nigra) trees, which have a distinctive balled top. (Shrub-height willows can be sandbar willow (Salix interior) or black willow, whereas tree height willows are almost exclusively black willow). In image $B$, the willow shrubs are dense and medium pinkish brown. In image $A$, the willows are adjacent to Floodplain Forest (FF) and Wet Meadow (WM). In image $B$ sandbar willows are growing on a sandy island just off the main channel.

Image $A$ was taken in August 2010, and image $B$ was taken in August 2011.
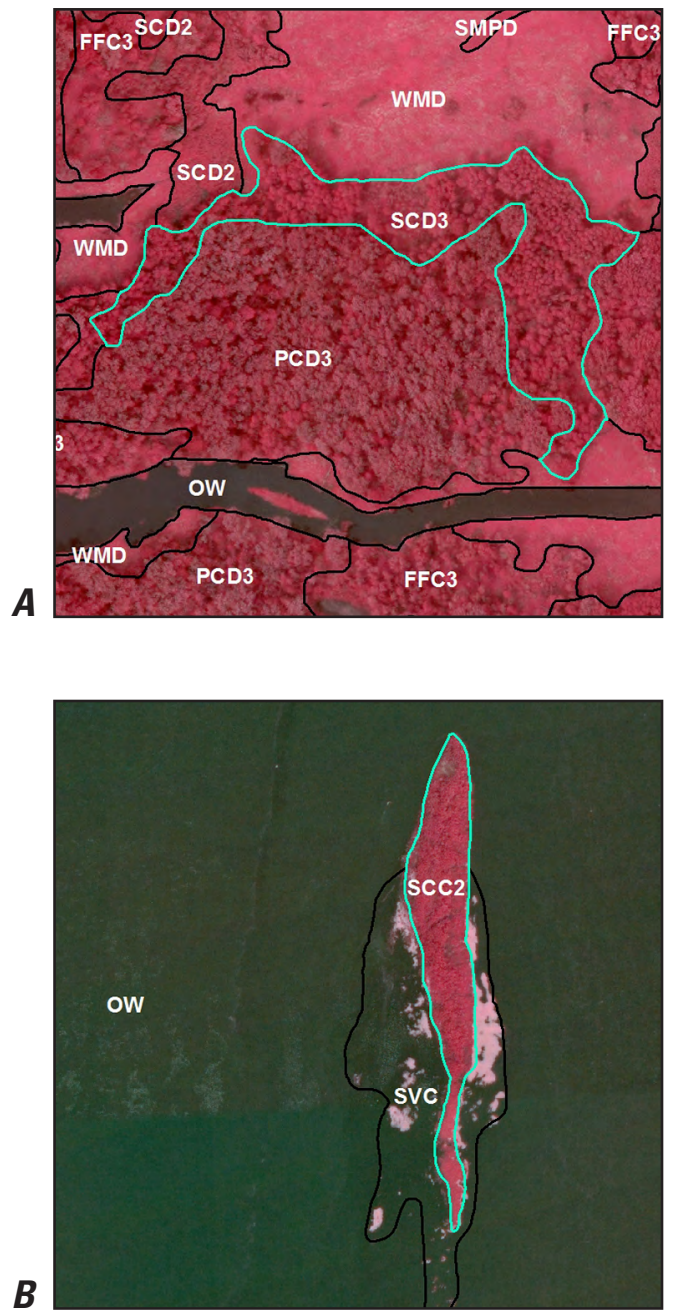


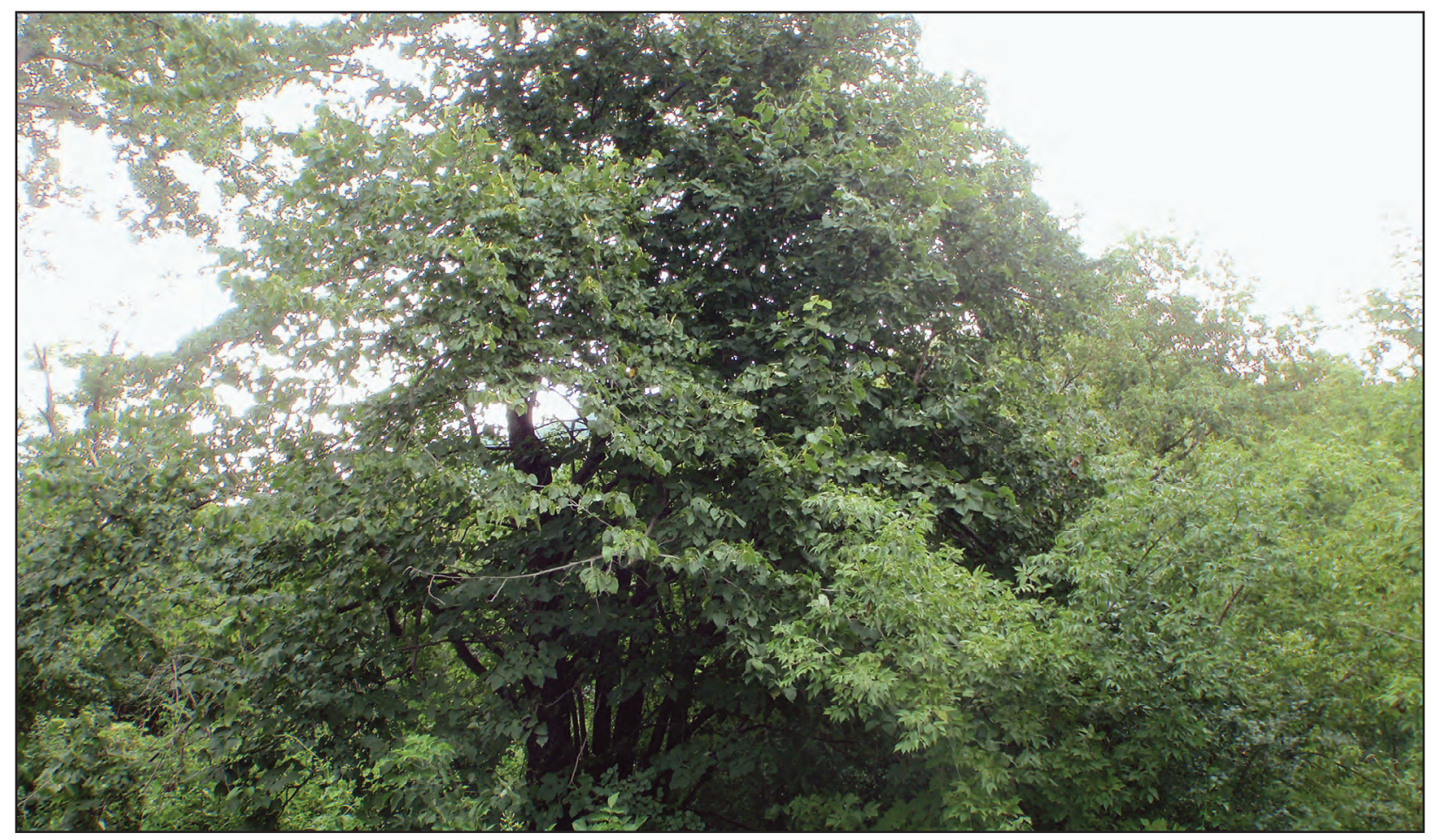

\section{Lowland Forest (LF)}

The Lowland Forest (LF) map class represents areas along riverbanks and within the floodplain that are drier than floodplain forest sites and are $>10$ percent vegetated with temporarily flooded forests. In the lower UMRS, oak flatwoods forests (low-relief oak forests on poorly drained soils that often experience spring and fall flooding) make up sizeable tracts of the Lowland Forest category. Lowland Forest is also common along smaller streams and rivers that have higher embankments where flooding occurs less often or for shorter periods than in Floodplain Forest (FF). Common species include oaks (Quercus spp.), pecan (Carya illinoinensis), hickory (Carya spp.), river birch (Betula nigra), sycamore (Platanus occidentalis), basswood (Tilia americana), boxelder (Acer negundo), and hackberry (Celtis occidentalis). Lowland Forest is typically found growing on moist soils.

Images $A$ and $B$ show examples of the Lowland Forest signature. In both images, the Lowland Forest appears red to dark red, indicating some oak species. The Lowland Forest in image $A$ is an oak flatwoods forest. It is within the greater floodplain, but the flooding experienced in this area is more likely to be driven by pooled water from poorly draining soils than by sustained overland flooding. The Lowland Forest in image $B$ is a more mixed forest located on a high stream embankment. Both stands of Lowland Forest are within the floodplain and are surrounded by agriculture.

Images $A$ and $B$ were taken in August 2011.
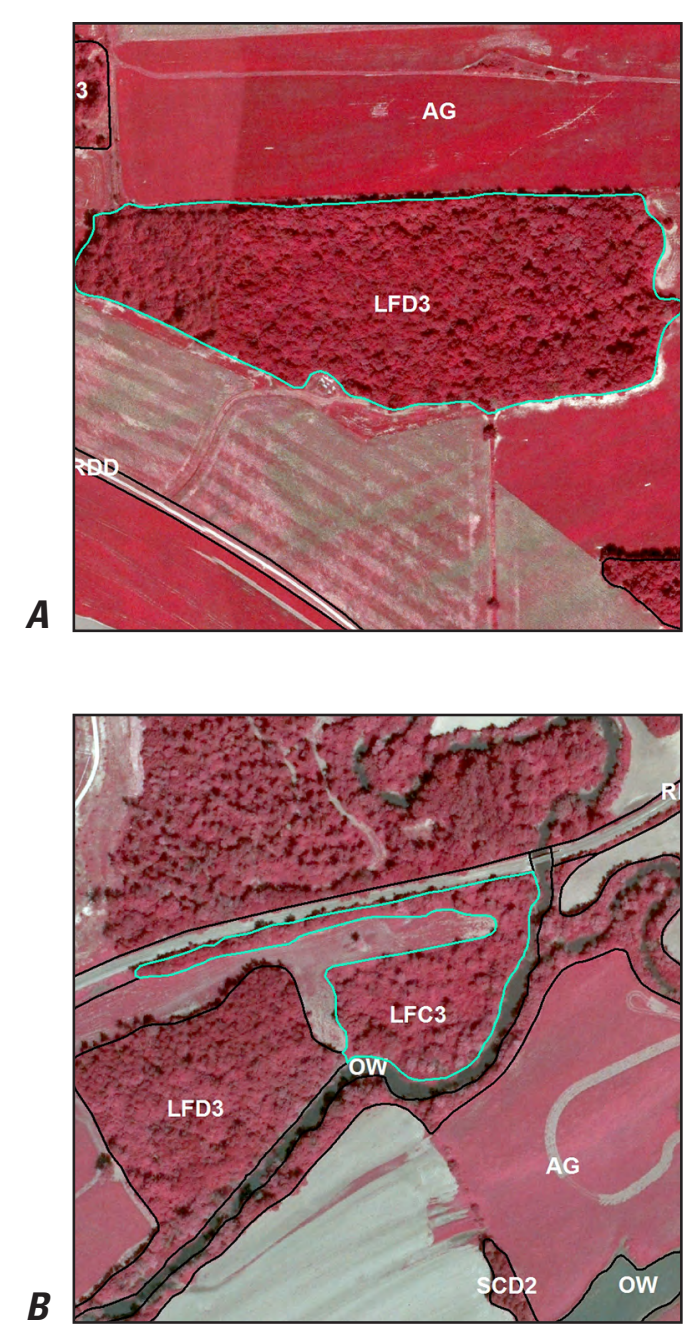


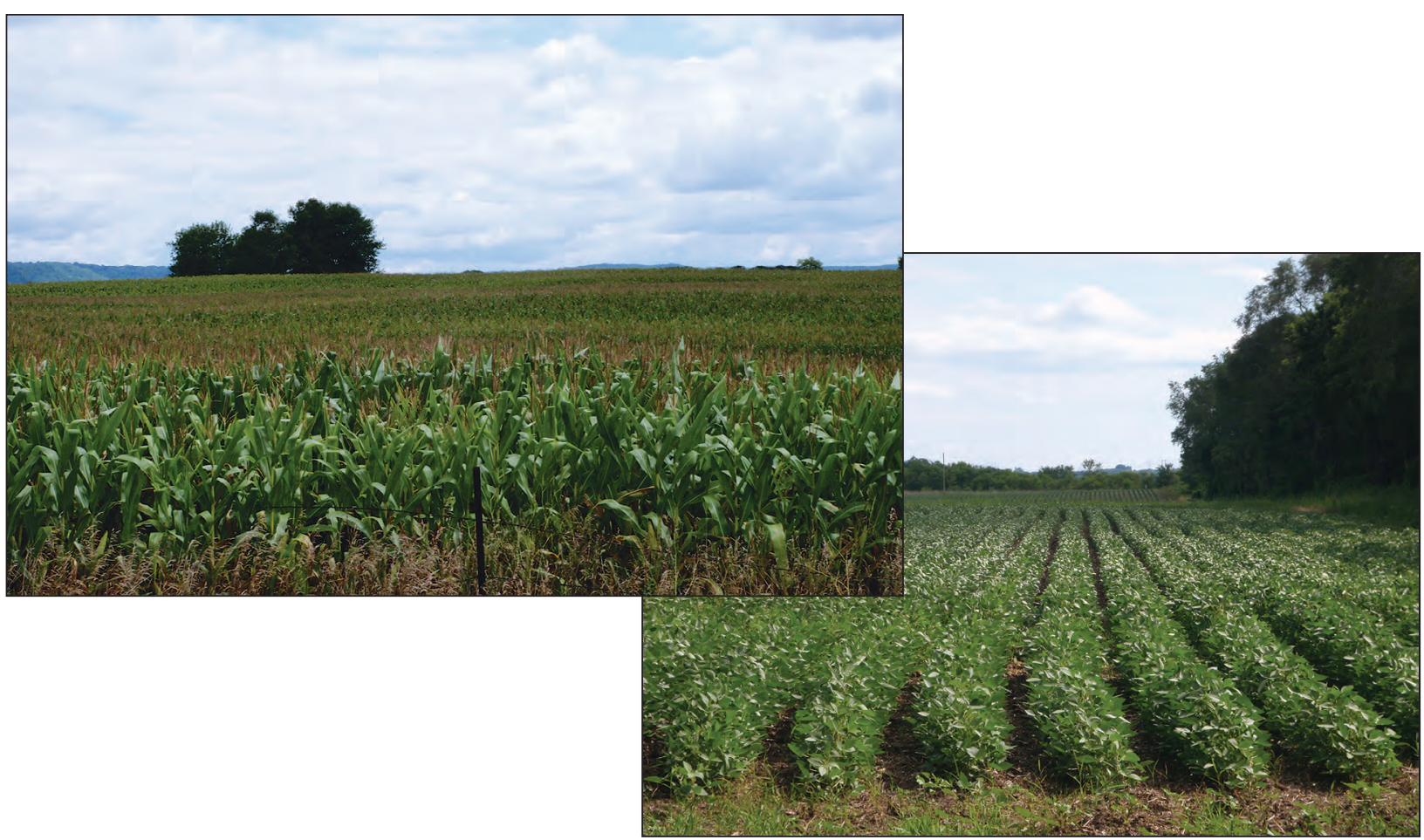

\section{Agriculture (AG)}

The Agriculture (AG) map class represents all fields obviously cultivated for crops. This map class may include transitional fallow fields that show evidence of tilling. Because of the large floodplain, vast agricultural areas are common in the southern reaches of the UMRS. Agriculture is generally considered infrequently flooded; however, it is not uncommon to find cultivated fields within seasonally or temporarily flooded areas.

Images $A$ and $B$ show examples of the Agriculture map class. The signature is generally uniform and smooth, and it ranges from white to red in color. In image $A$, the signature appears red - with obvious cultivation marks - and represents an actively cultivated area with standing crops. Image $B$ shows an agricultural area that has been left fallow for some time, but still shows signs of having been cultivated (till lines). Here the signature is uniform and grayish pink. The polygons with the attribute "GRD" to the south of the Agriculture field in image $B$ may have formerly been agricultural fields but have lost enough of the hallmarks of cultivation to be considered the more natural class of Grassland (GR). If the AG polygon in image $B$ continues to be left fallow, it will likely transition into the Grassland map class as well.

Images $A$ and $B$ were taken in August 2010.
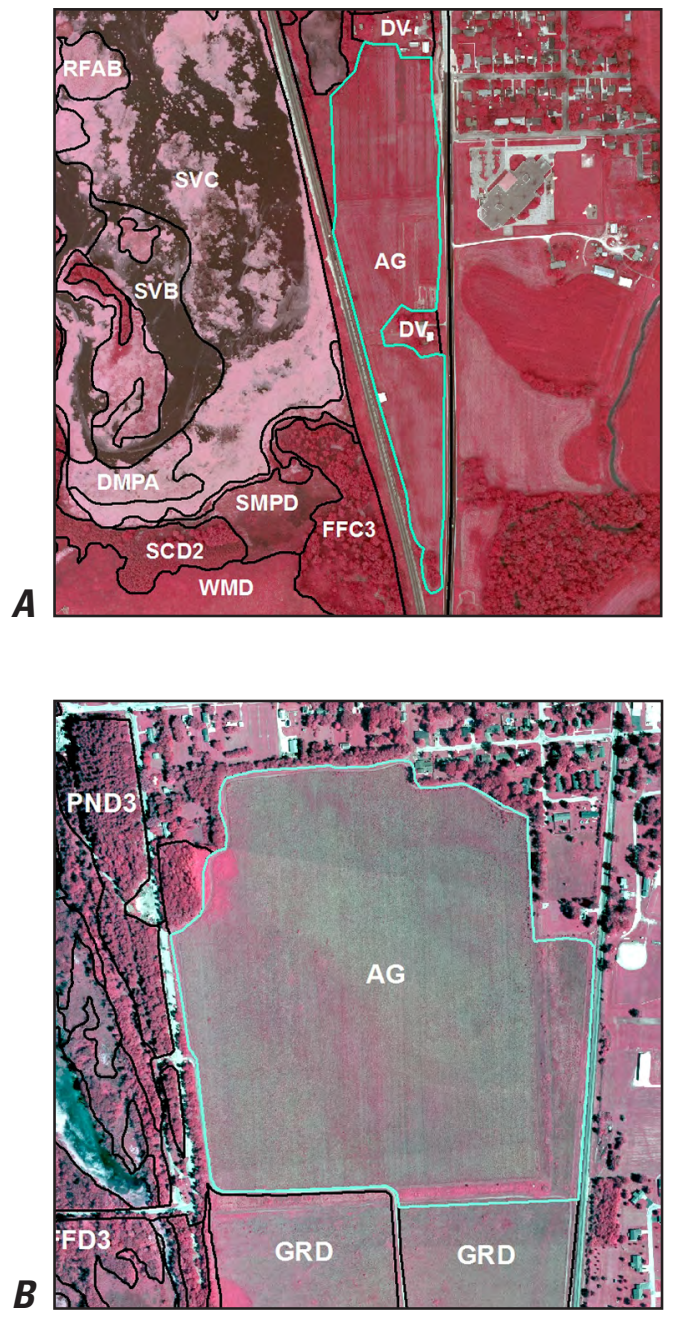


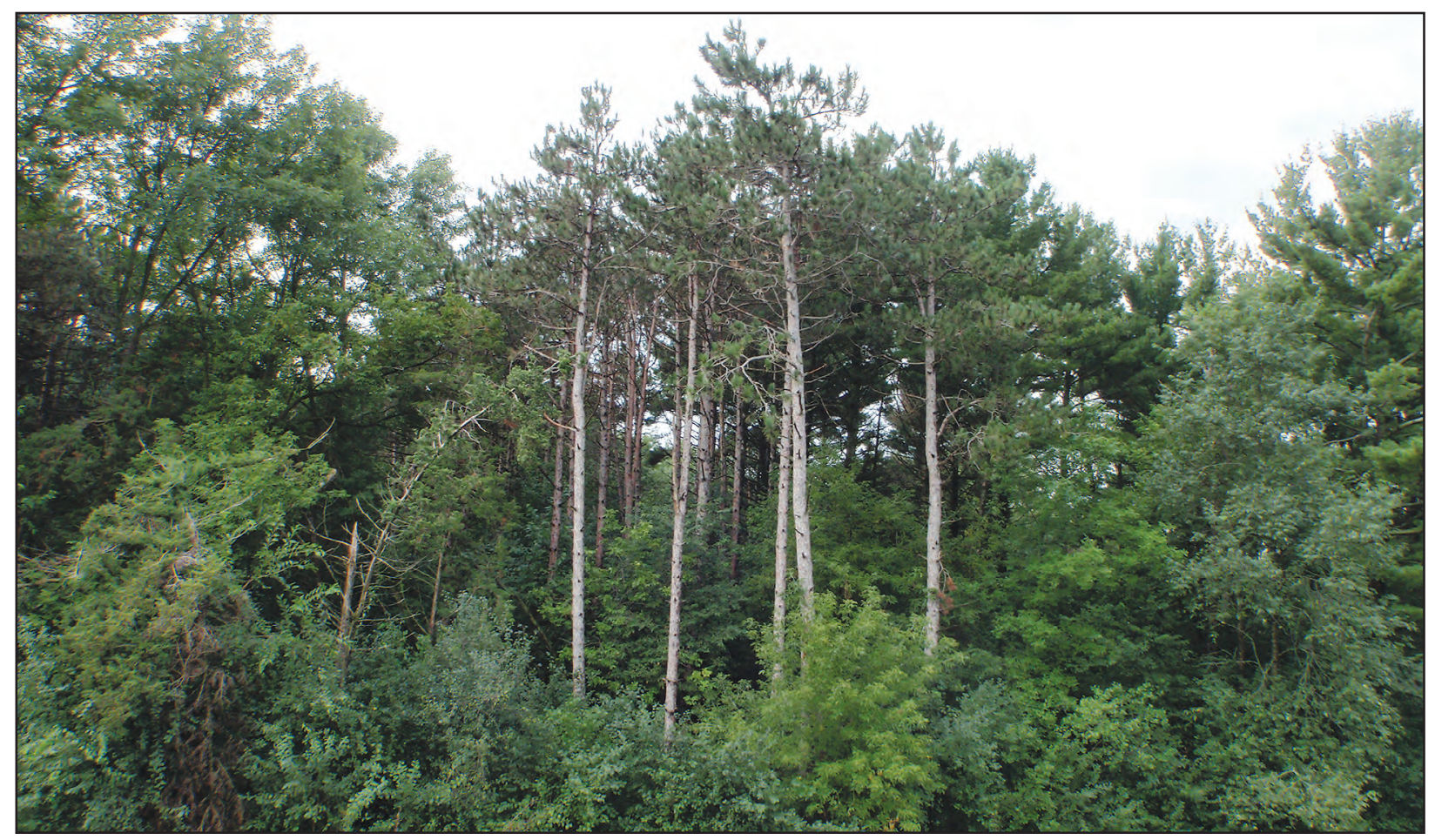

\section{Conifers (CN)}

The Conifer $(\mathrm{CN})$ map class represents forested areas that are $>10$ percent vegetated with natural or seminatural evergreen communities. Deciduous trees may also be present, but conifers make up $>50$ percent of the trees in the polygon. These communities are typically pine species (Pinus spp.) but may also include cedar (Juniperus spp.). This map class may also include former conifer plantations that are no longer actively managed. (The rows or patterns of planting have grown obscured, or there are other species growing among the planted conifers). This map class is infrequently flooded and is typically found in upland situations where the soils are well drained.

Images $A$ and $B$ show examples of the Conifer signature. In general, the signature appears dark red to brown. In image $A$, the conifers appear purplish brown. The conifers in image $A$ are cedars on a slope surrounded by areas of Grassland (GR), and among the cedars are a few pinkish shrubs. In image $B$, the conifers are mixed pines and cedars on a slope with some patches of red or pink deciduous trees interspersed. Here, the Conifer signature appears dark brownish red.

Images $A$ and $B$ were taken in August 2010.
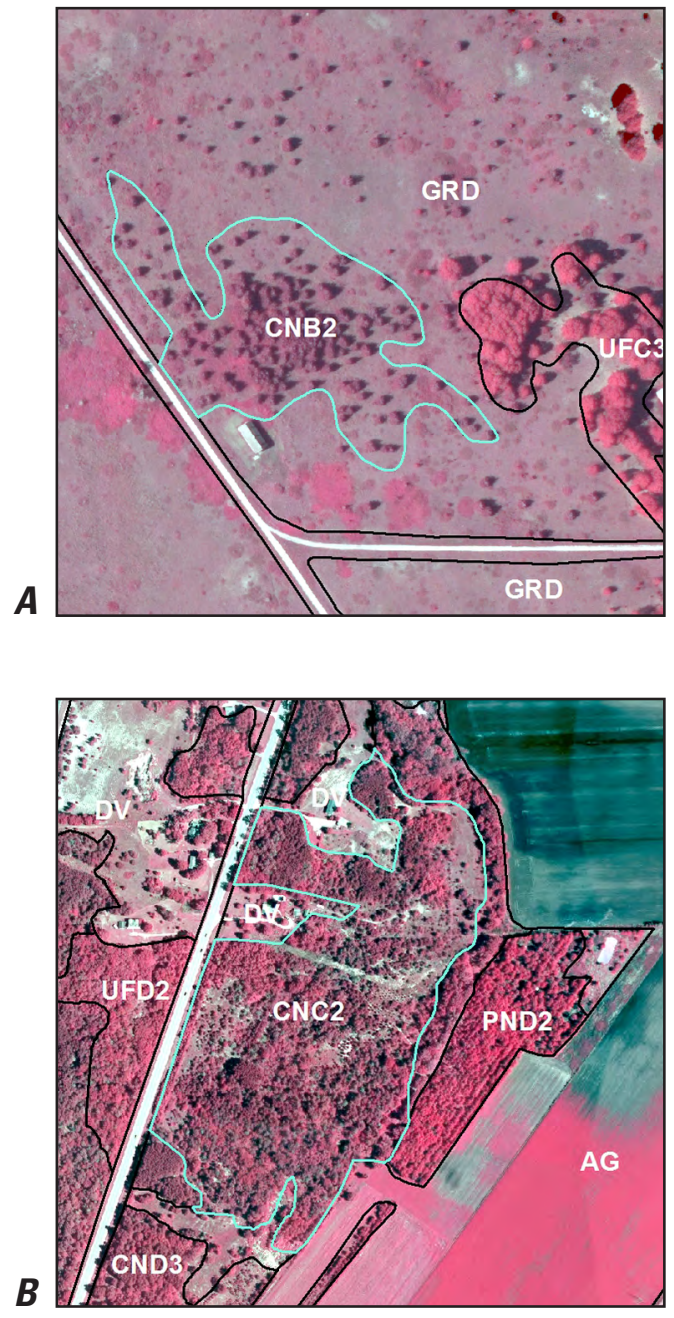


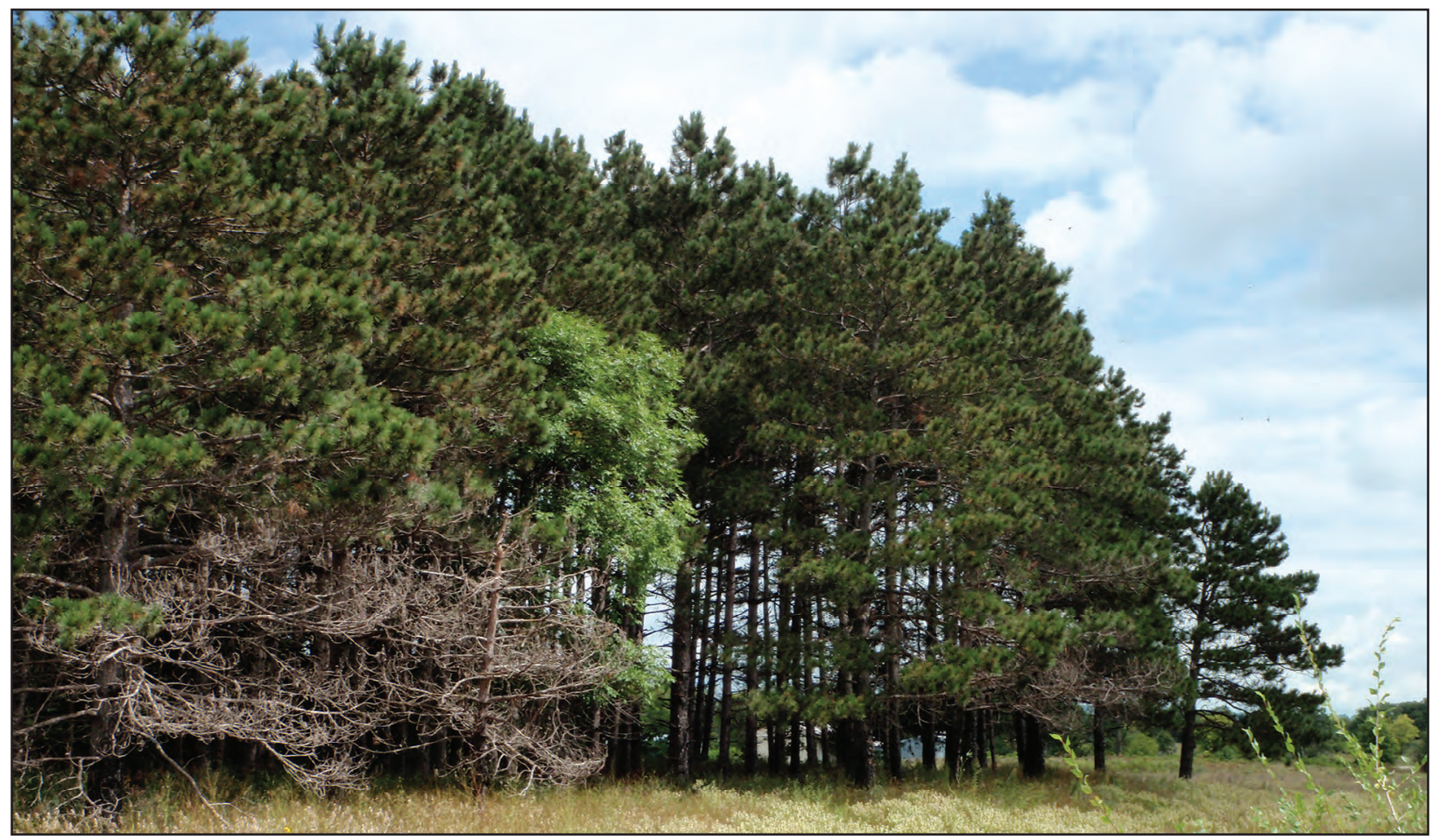

\section{Plantation (PN)}

The Plantation (PN) map class represents forested areas that are $>10$ percent vegetated with commercially grown evergreen plantations, large nurseries, or orchards. This map class typically consists of red pine (Pinus resinosa) or white pine (Pinus strobus) but may include other coniferous or deciduous trees. The Plantation map class is infrequently flooded and typically found in upland situations where the soils are well drained. In the lower UMRS, there are fairly extensive areas planted with typical Floodplain Forest (FF) species such as silver maple (Acer saccharinum), cottonwood (Populus deltoides), and green ash (Fraxinus pennsylvanica). Although these areas resemble a deciduous plantation with their regular rows and patterning, they are planted for noncommercial use and (or) habitat restoration and are therefore classified as Floodplain Forest and not Plantation.

Images $A$ and $B$ show examples of the Plantation signature. The signature visibly shows the trees growing in grids or rows. In general, the coniferous plantations appear dark red to brown but may sometimes appear lighter, whereas deciduous plantations appear pink or red. In image $A$, the trees are conifers. In image $B$, they are mixed; the trees on the left are planted conifers, but those on the lower right appear to be both conifers and deciduous trees planted together.

Images $A$ and $B$ were taken in August 2010.
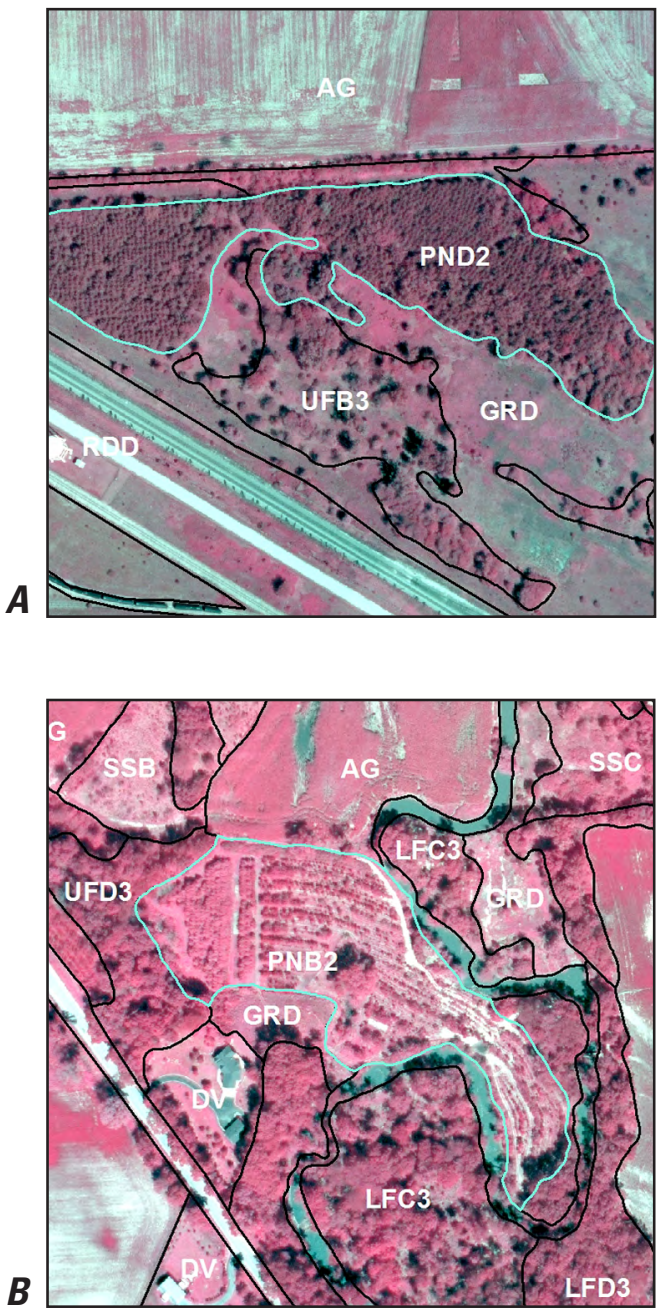


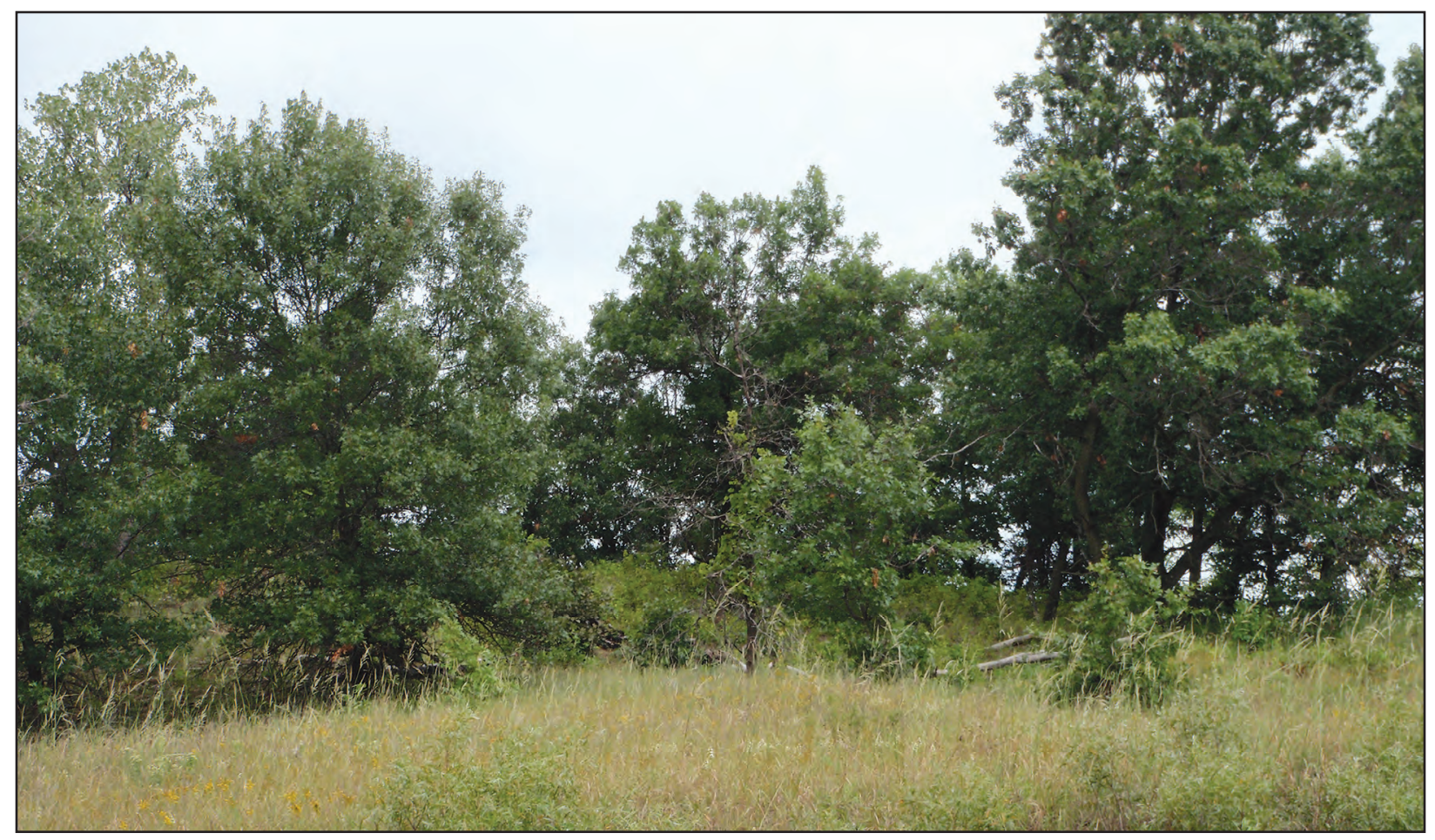

\section{Upland Forest (UF)}

The Upland Forest (UF) map class represents forested areas that are $>10$ percent vegetated with forests growing on hills near the edge of the floodplain or out of the floodplain. This map class typically consists of red oak (Quercus rubra) or white oak (Quercus alba), hickory (Carya spp.), elm (Ulmus spp.), and other deciduous trees. Upland Forest is infrequently flooded and is typically found in upland situations where soils are dry.

Images $A$ and $B$ show examples of the Upland Forest signature. In both images, the Upland Forest appears red to dark red. The Upland Forest in image $A$ is in the main channel of the river, but these trees receive little to no flooding because of the elevation of the sand island, and these sandy soils remain dry. In image $B$, the Upland Forest is close to the river but up a very steep incline, and this area experiences no flooding. In image $A$, the trees are mixed, including some oaks along with cottonwood (Populus deltoides), ash (Fraxinus spp.), and other trees that can grow in upland or lowland environments. The trees in image $B$ are predominantly oaks.

Images $A$ and $B$ were taken in August 2010.
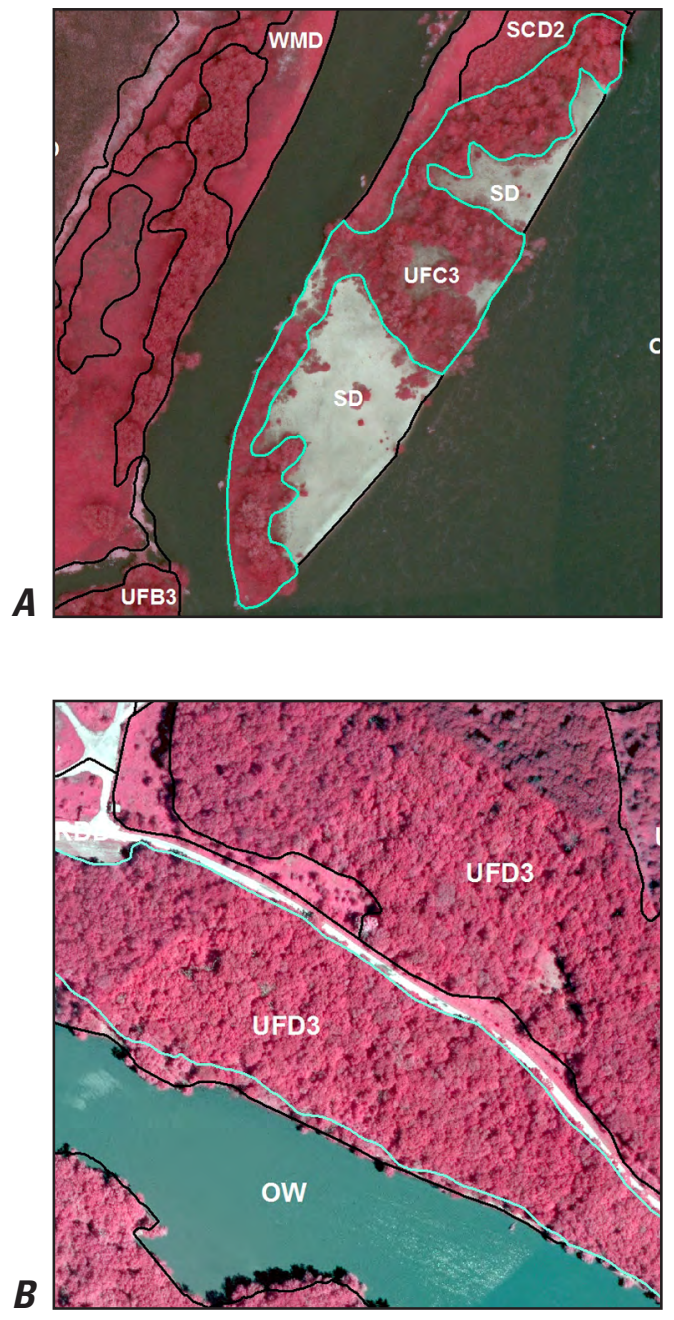


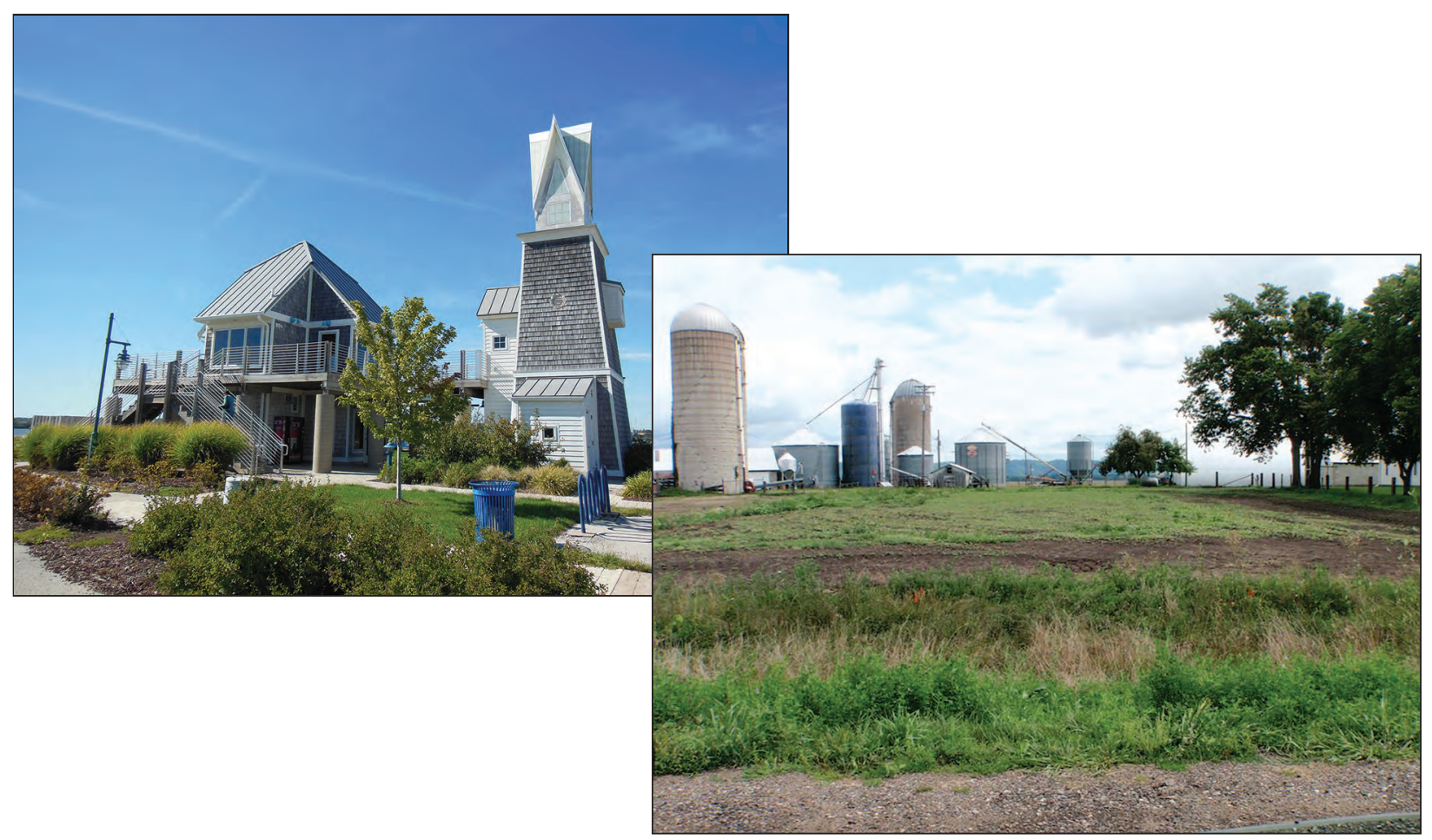

\section{Developed (DV)}

The Developed (DV) map class represents areas that are predominantly manmade. This map class includes residential homes in populated areas, homesteads in rural settings, farmsteads, industrial complexes, parks, locks and dams, marinas, boat launches, quarries, gravel pits, riprap, and newly constructed artificial islands. Most Developed areas are considered infrequently flooded; however, riprap and newly constructed artificial islands may be seasonally or temporarily flooded.

Images $A$ and $B$ show examples of two different types of the Developed map class. Image $A$ is an example of the edge of a town grading into a rural area. The large DV polygon at the top is delineating the many aggregated homes of the town, whereas the individual DV polygons below are picking out other developed areas such as a large civic building, some scattered residences, and a new subdivision area (highlighted polygon). Agricultural fields surround these more rural areas. Image $B$ shows a rural farmstead area adjoining a gravel pit.

Images $A$ and $B$ were taken in August 2010.
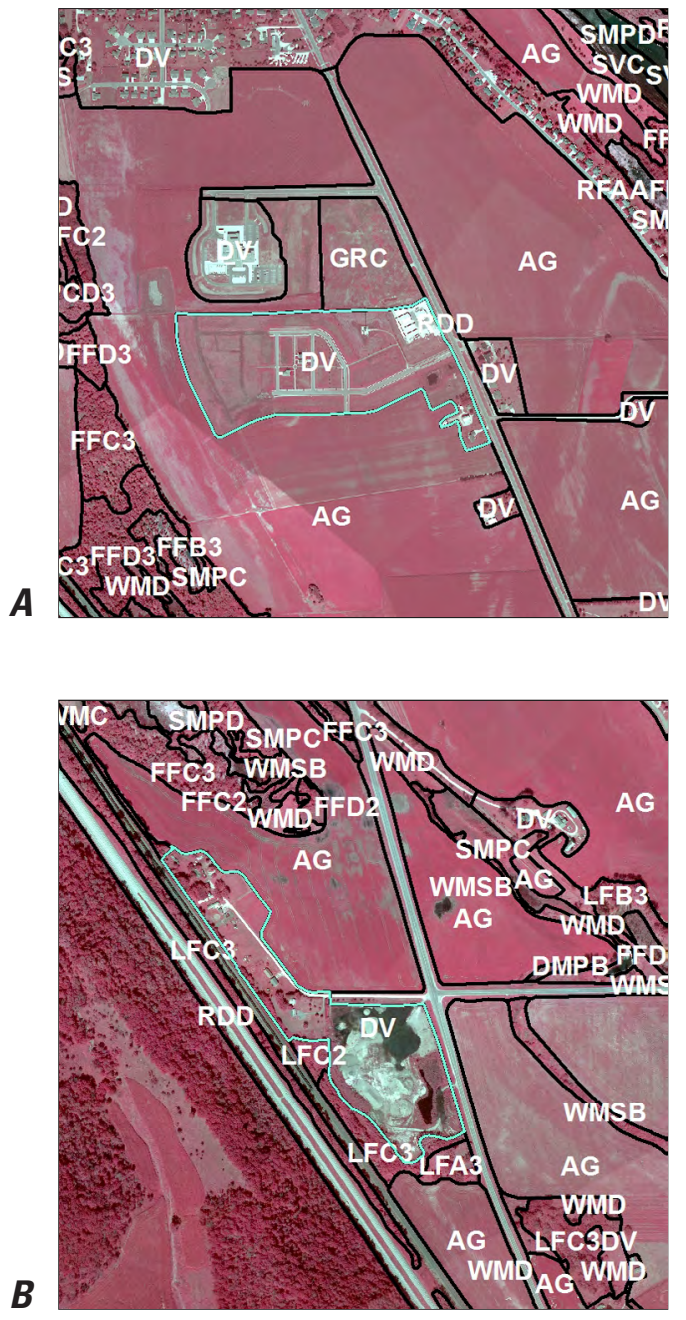


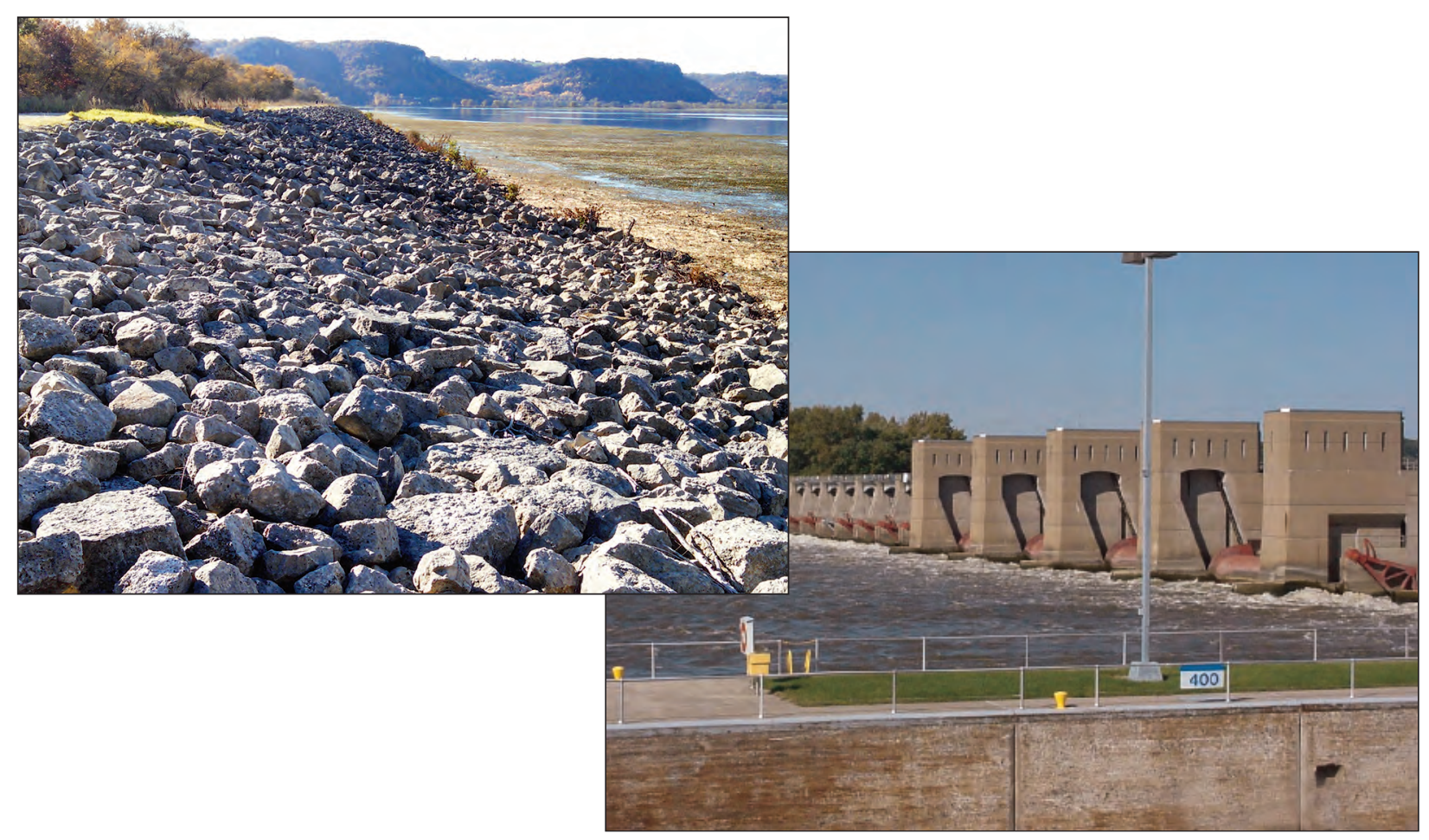

\section{Developed (DV)—Continued}

Image $C$ shows water treatment ponds, which are classified as Developed rather than Open Water (OW) because of their artificial construction. Image $D$ shows lock and dam structures.

Image $C$ was taken in August 2011, and image $D$ was taken in August 2010.
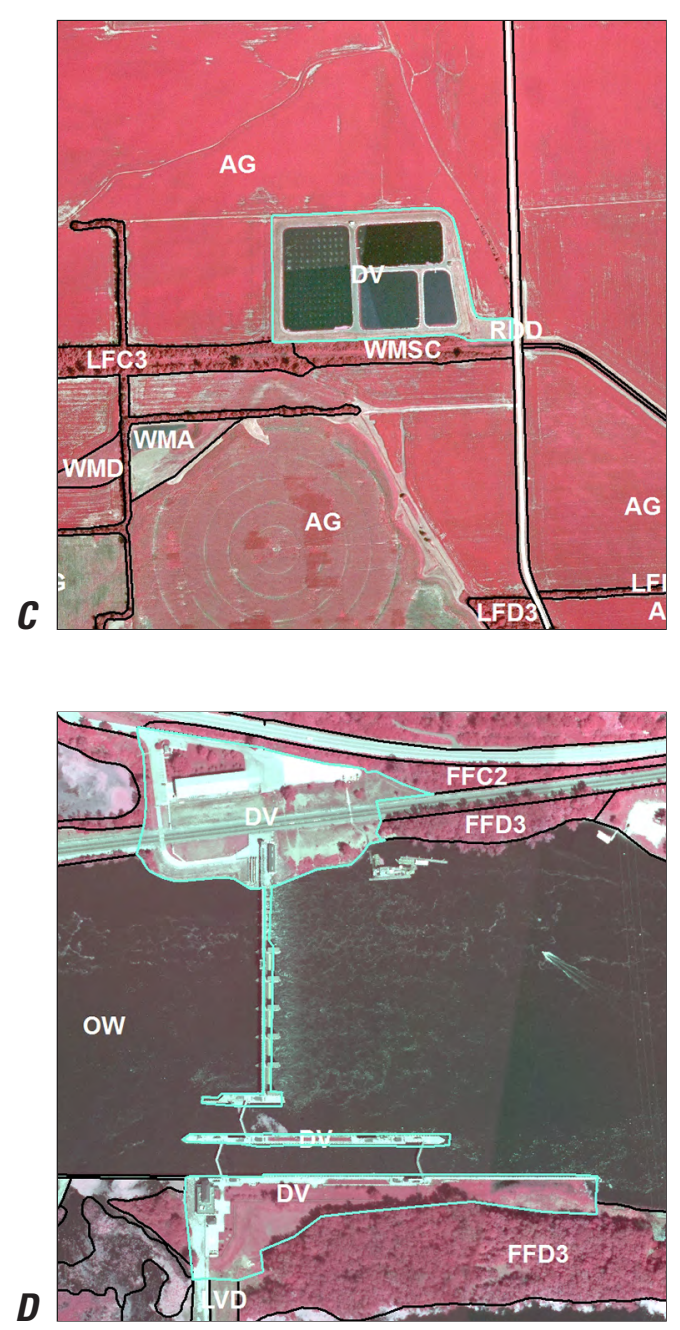


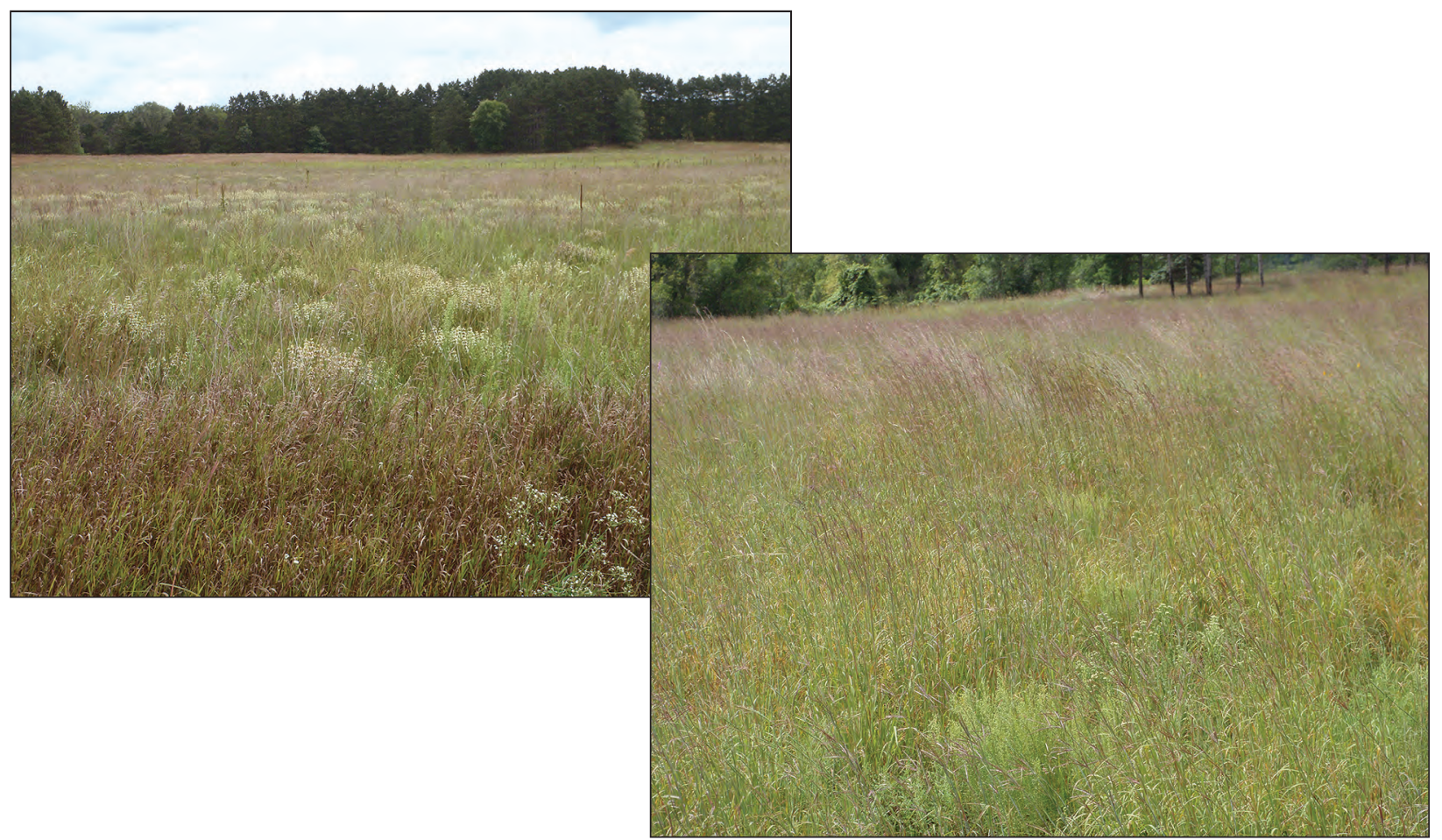

\section{Grassland (GR)}

The Grassland (GR) map class represents drier upland areas that are $>10$ percent vegetated with perennial grasses and forbs. This class can also be represented by lower areas that are subject to occasional, short-duration flooding, but the sandy substrate supports only drier adapted grasses and forbs. This map class may include fallow fields, sand prairies, and sandy islands, and it may contain $<25$ percent shrubby vegetation. It generally is near other upland map classes, such as Scrub-Shrub (SS) or Upland Forest (UF). Grassland is infrequently flooded and is typically found growing where soils are dry.

Images $A$ and $B$ show examples of the Grassland signature. It generally ranges from grayish green to pink. The Grassland in image $A$ is an example of a grassy area on a sand spoil island. Image $B$ depicts a large, upland sand-plain at the location of a former army ammunition depot. The area has intact areas of high-quality sand prairie (grayish) with large patches of invasive forbs (pink).

Images $A$ and $B$ were taken in August 2010.
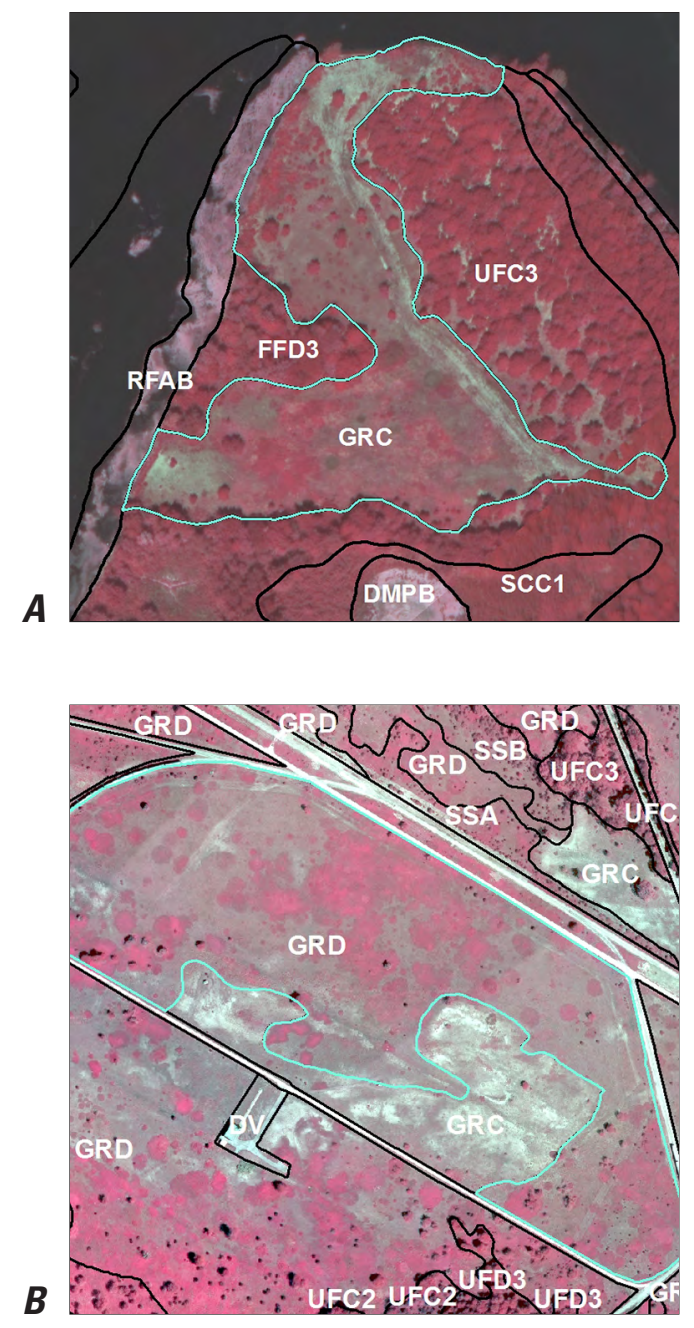


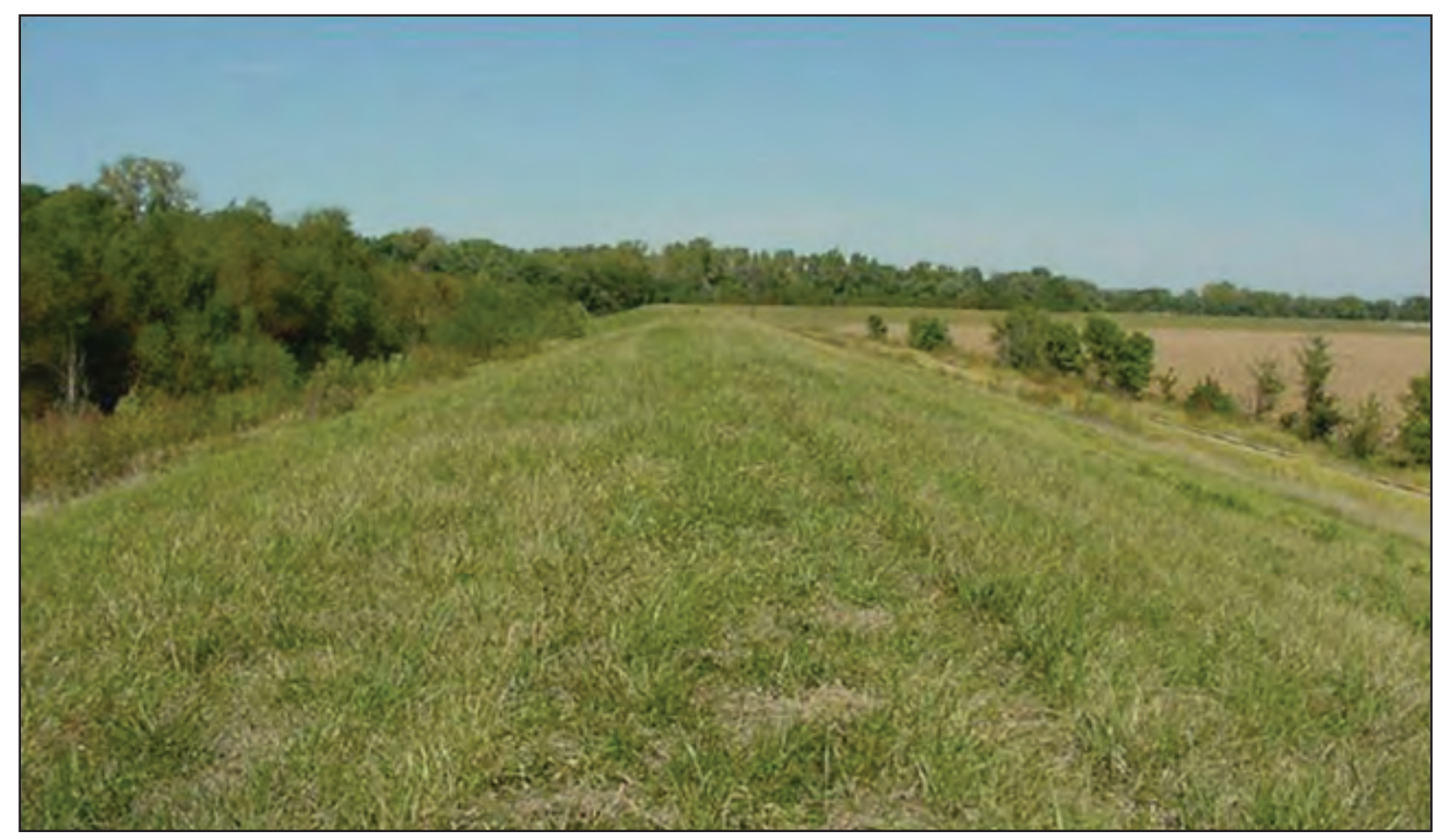

\section{Levee (LV)}

The Levee (LV) map class represents all continuous dikes or embankments designed for flood protection. This map class is elevated and is typically covered with a mix of perennial grasses and forbs. Occasionally, shrubs may grow along or on these structures. The Levee map class is more commonly found in the southern reaches of the UMRS, where levees often have roadways or paths running atop of or adjacent to them. The Levee map class is considered infrequently flooded.

Images $A$ and $B$ show examples of the Levee signature. It generally ranges from whitish gray to pink. In both images $A$ and $B$, the Levee appears pink. The white line running through the middle of the structure in image $A$ is a gravel path along the top of the levee. Commonly, levees are constructed to prevent water from entering agricultural land, as can be seen in image $B$.

Image $A$ was taken in August 2011, and image $B$ was taken in August 2010.
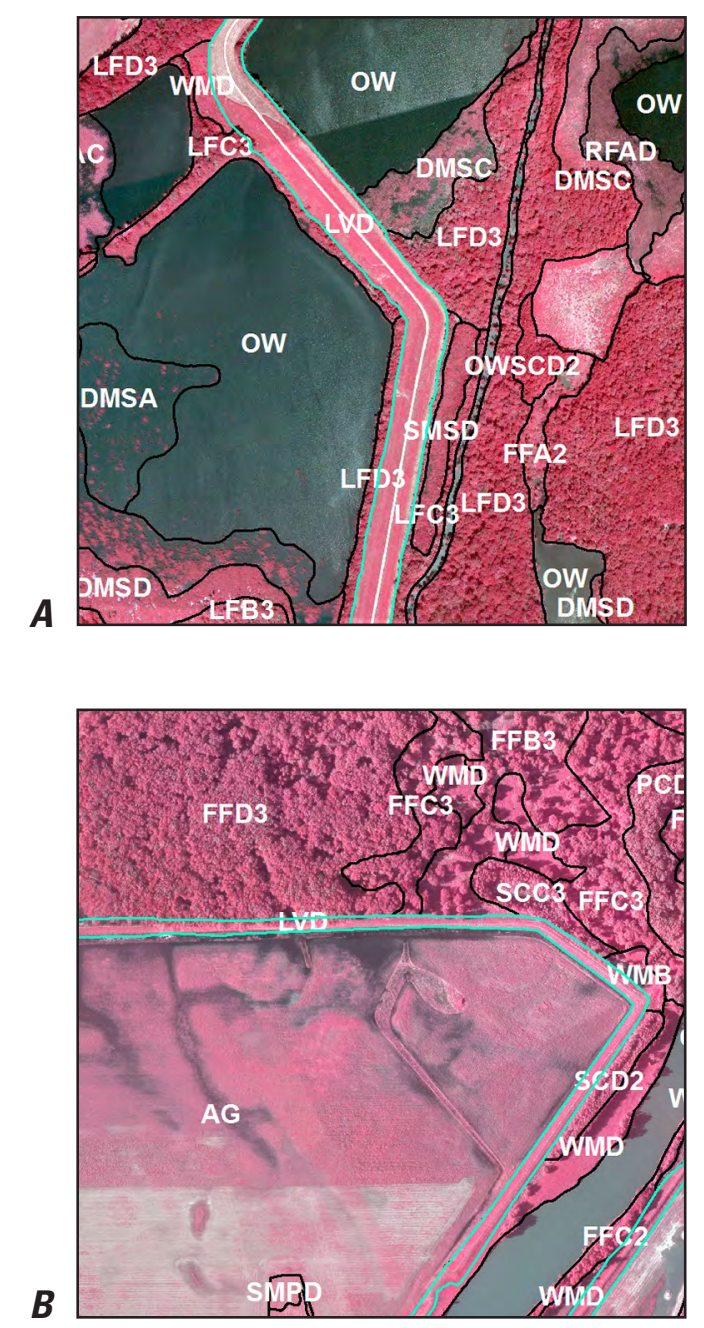


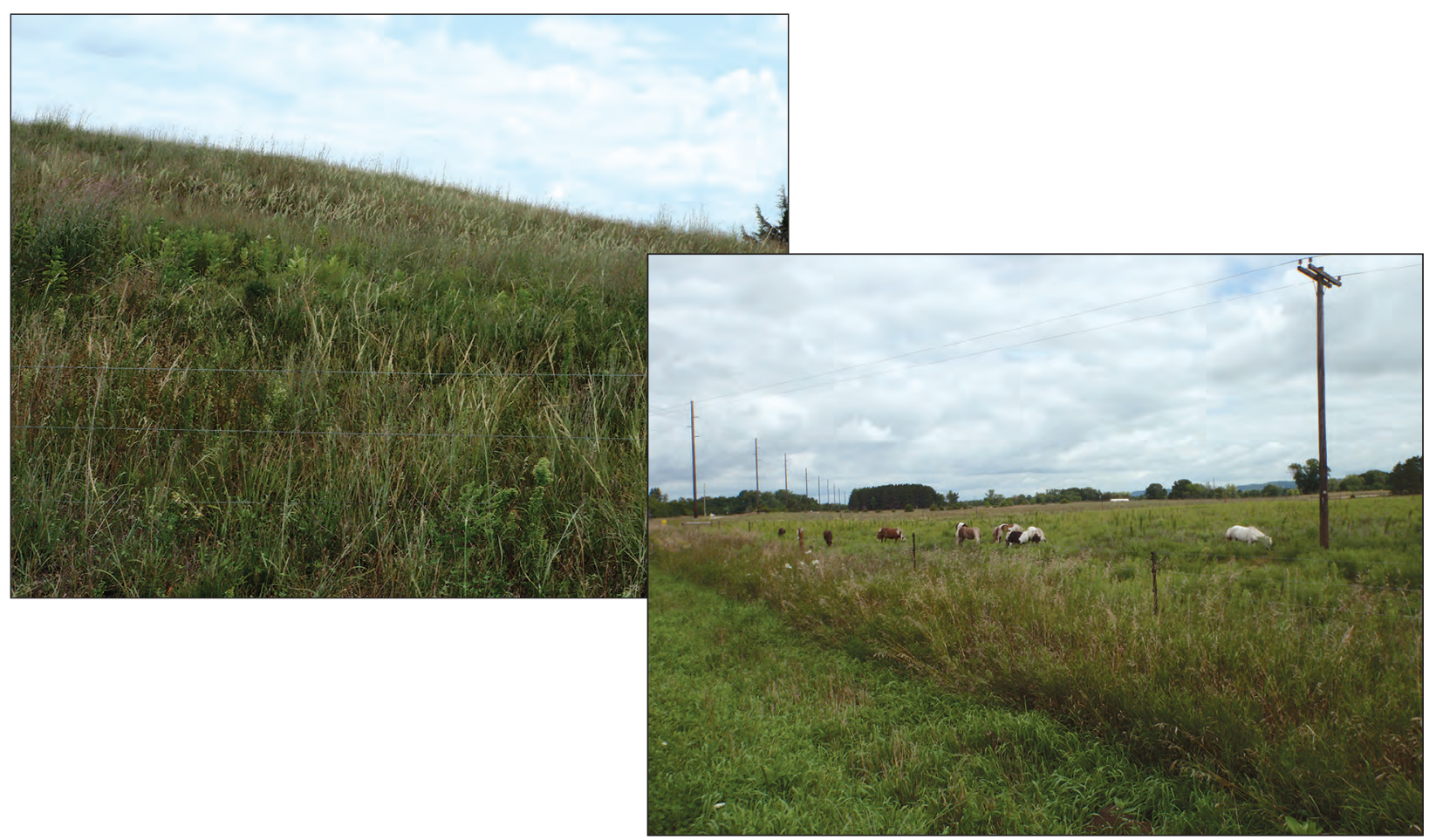

\section{Pasture (PS)}

The Pasture (PS) map class represents areas used for the production of livestock. This map class typically consists of a mix of perennial grasses and forbs used for pasturing. Grasses and forbs are generally grazed and are maintained relatively short. Some of these grasses and forbs may also be hayed. Scattered shrubs $(<25$ percent $)$ and trees $(<10$ percent $)$ may be present. The Pasture map class is considered infrequently flooded.

Images $A$ and $B$ show examples of the Pasture signature. It generally ranges from grayish green to pink and may appear mottled because of animal use. A fence line can often be seen surrounding the pastured area. In image $A$, the Pasture is adjacent to a farmstead and appears pinkish and mottled. In image $B$, the Pasture appears grayish pink and has mower lines from a recent haying but is fenced for horses. These Pasture polygons are just outside an urban area and are surrounded by agricultural fields.

Images $A$ and $B$ were taken in August 2010.
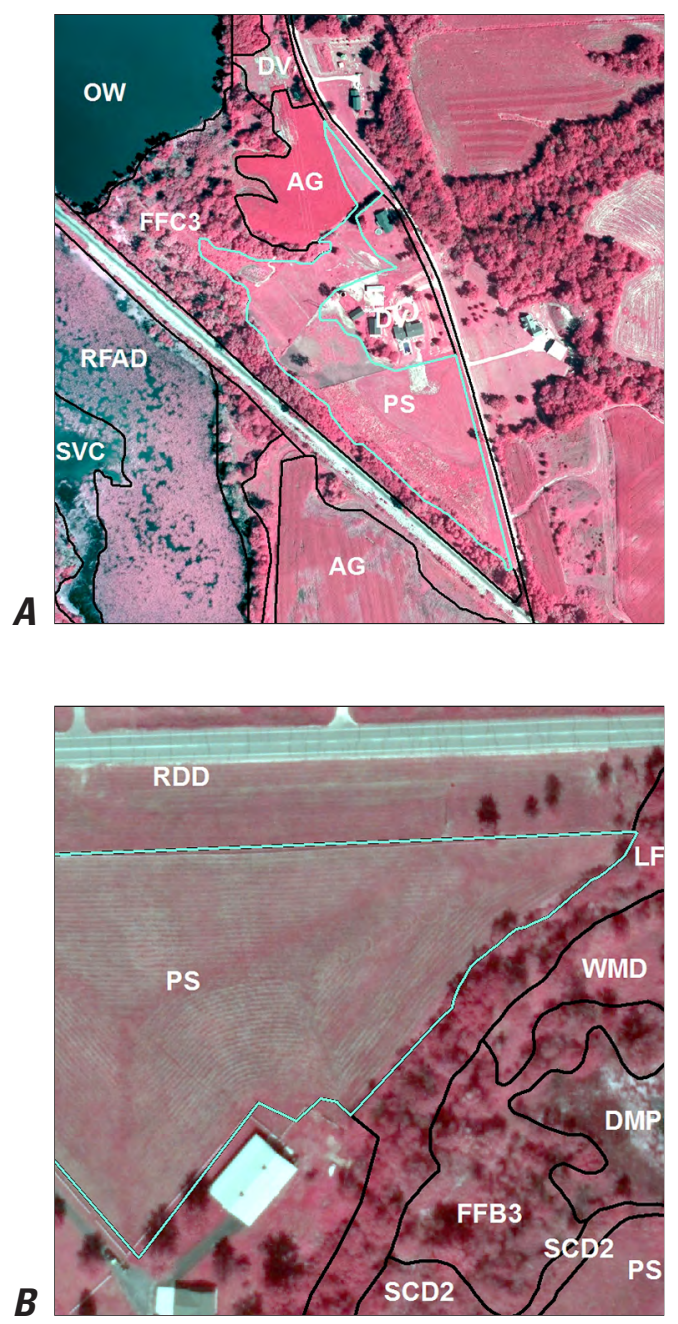


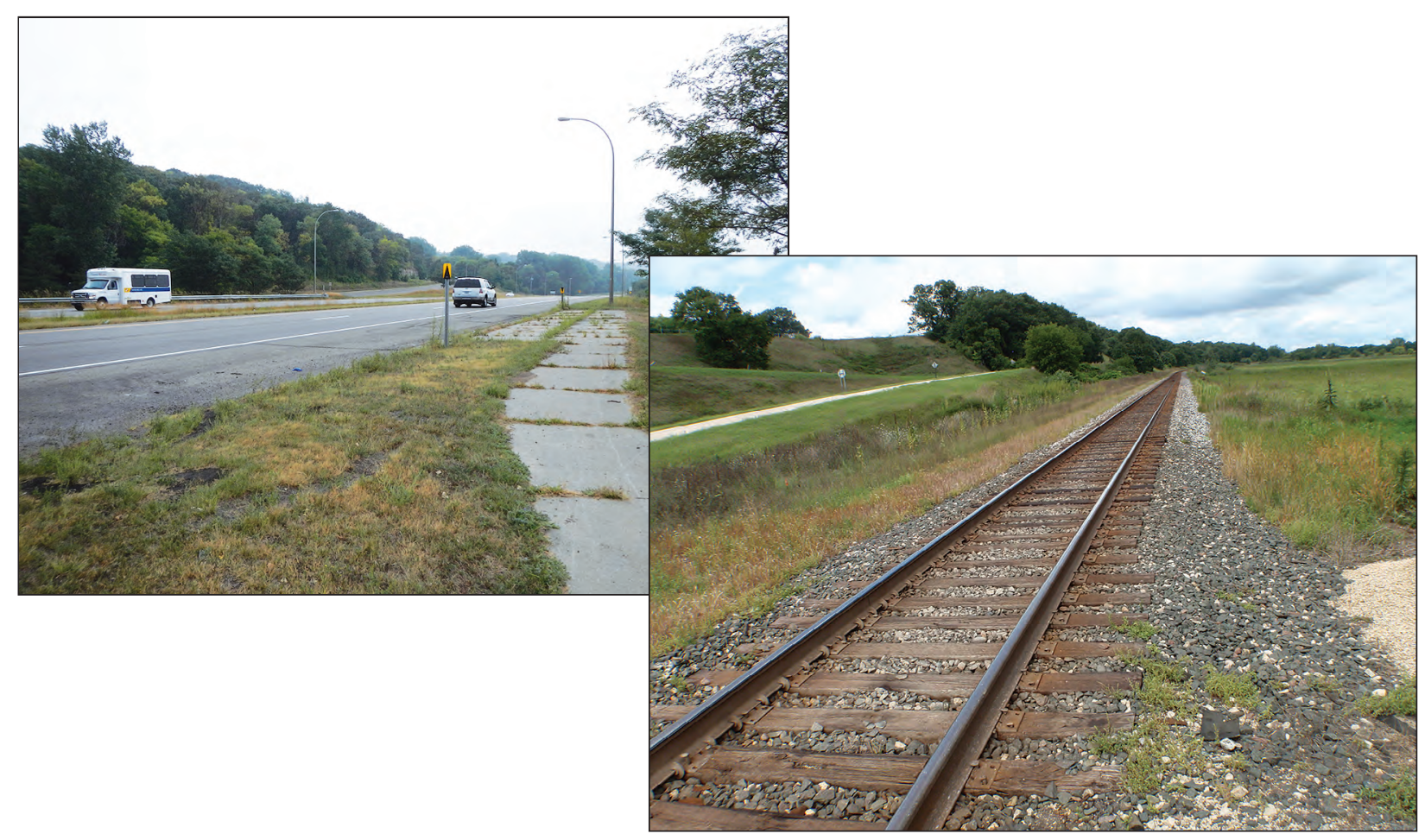

\section{Roadside (RD)}

The Roadside (RD) map class represents roads, highways, and railroads along with their respective rights-of-way. These rights-of-way are typically covered with a mix of perennial grasses and forbs. Shrubs $(<25$ percent of the total cover) and (or) scattered trees ( $<10$ percent of the total cover) also may be present. Typically, Roadside is used to classify only major rural roadways, leaving out small narrow roads and trails. Roads within developed areas are mapped as part of the Developed (DV) map class. The Roadside map class is considered infrequently flooded.

Images $A$ and $B$ show examples of the Roadside signature. The rights-of-way generally range from grayish green to pink and are adjacent to a road or railway, often bounded by fencing or crops. Image $A$ shows both a roadway (the roads show a wider, lighter paved surface with a wide right-of-way) and a thinner, darker-appearing railroad line with a narrow right-of-way. Image $B$ is an example of a highway with a parallel-running railroad line and wide median between the two that contains herbaceous vegetation (pink signature) and also small trees.

Image $A$ and $B$ were taken in August 2010.

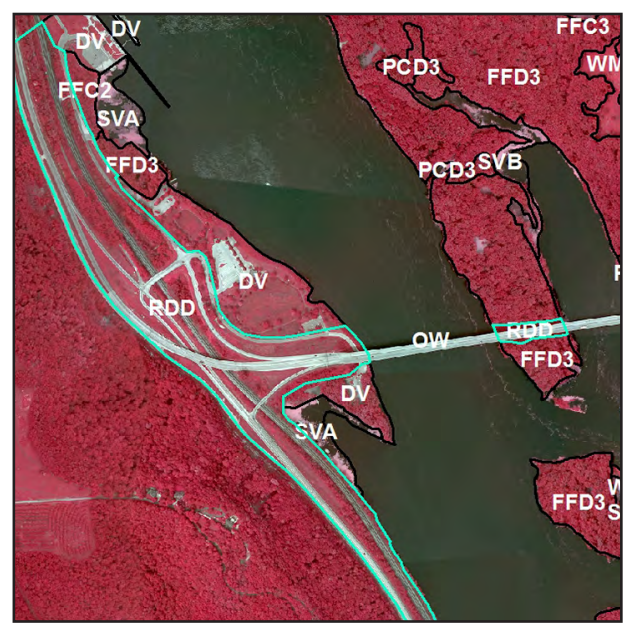



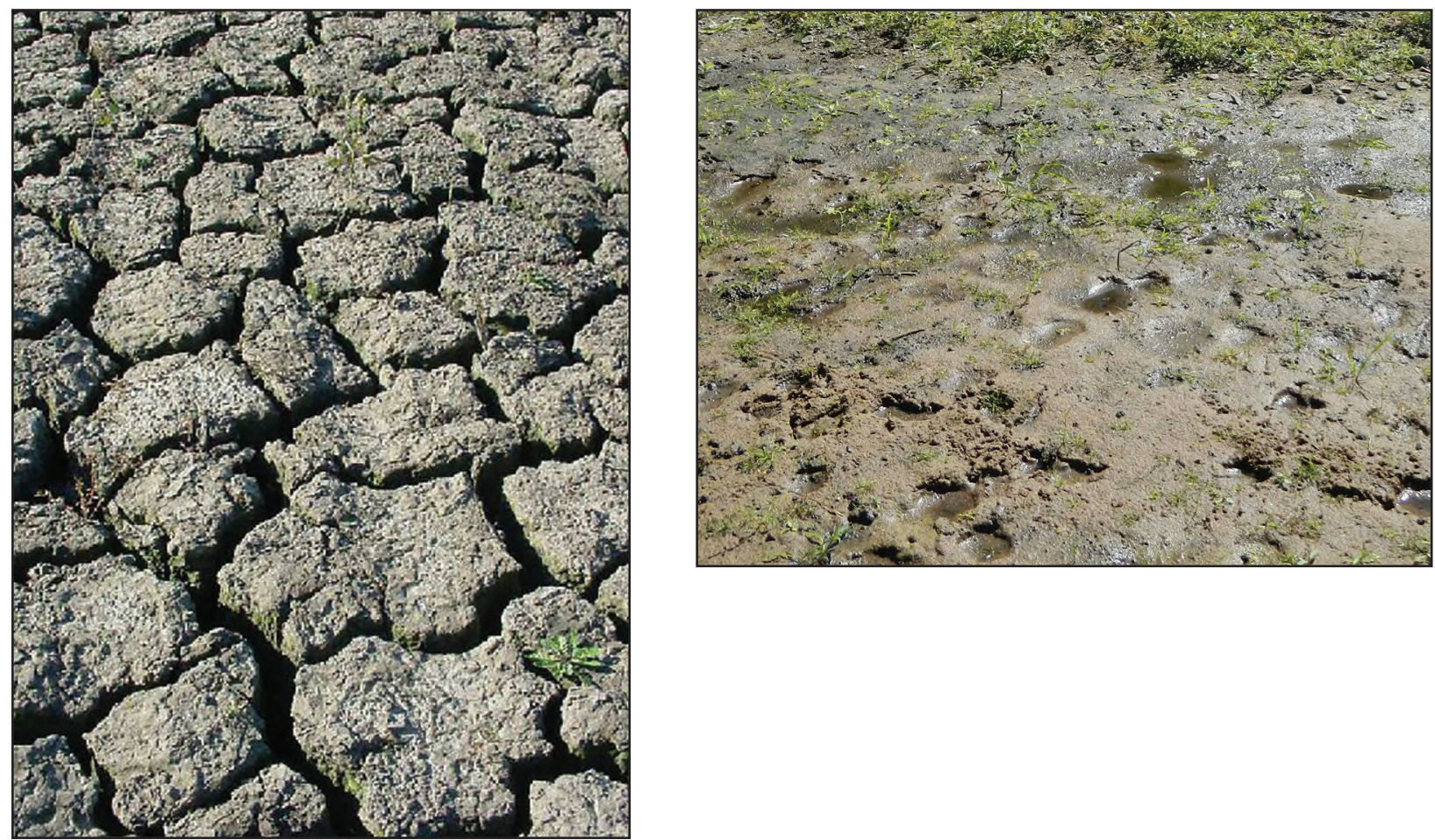

\section{Mudflat (MUD)}

The Mudflat (MUD) map class represents portions of lakes, ponds, backwaters, or shorelines that are seasonally flooded and where nonvegetated mud is exposed. This map class may have small inclusions ( $<10$ percent) of persistent or nonpersistent emergent vegetation, sedges, grasses, or forbs. If it is exposed long enough, a Mudflat that remains moist will usually transition into the Shallow Marsh Annual (SMA) map class.

Images $A$ and $B$ show examples of the Mudflat signature. It generally appears light to dark gray and smooth but may show a ripple effect from the movement of the water that formerly covered the mud. Small areas of standing water may remain within the Mudflat. Both images $A$ and $B$ are examples of Mudflat that appear smooth and light to dark gray, and both contain small areas of open water within them. Typically, Mudflat is mapped when the water recedes and nonpersistent emergent vegetation has not yet grown.

Images $A$ and $B$ were taken in August 2011.
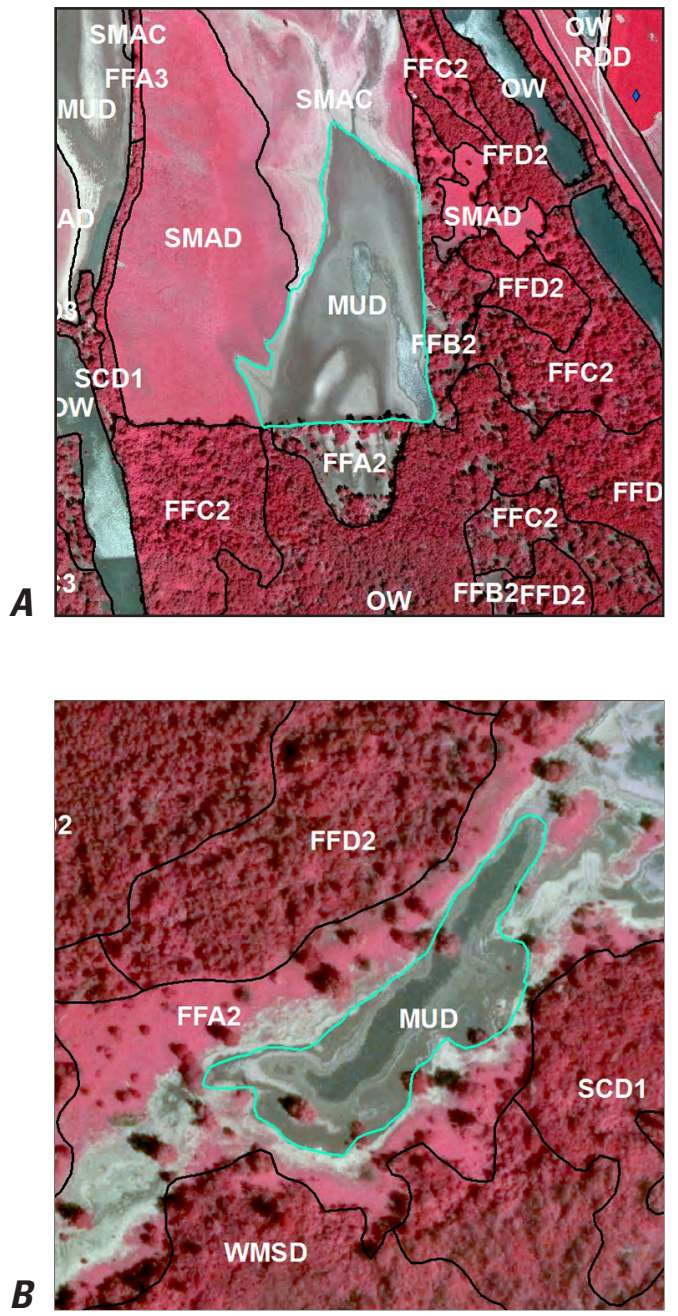


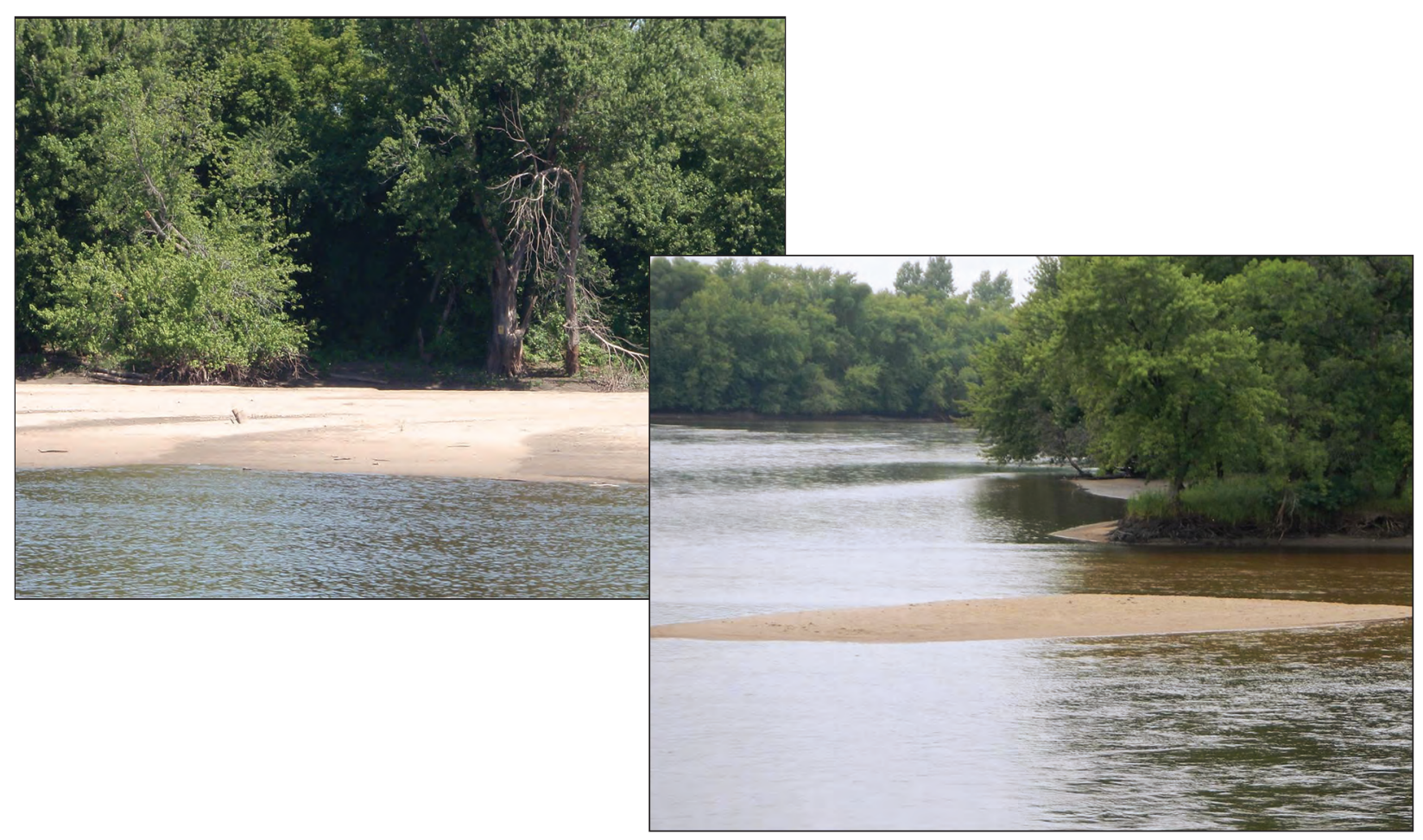

\section{Sand Bar (SB)}

The Sand Bar (SB) map class represents areas of exposed nonvegetated sand flats that are temporarily flooded throughout the year. They are typically found in or near the main channel and are often associated with wing dams, shorelines, and islands. This map class may have small inclusions of grasses and (or) forbs $(<10$ percent) or shrubs $(<25$ percent $)$ but usually does not support plant life.

Images $A$ and $B$ show examples of the Sand Bar signature. It generally appears white; when wetter, it may appear light gray. In image $A$, the Sand Bar is in the main channel north of an island and appears white. In image $B$, the shoreline Sand Bar has larger gray areas where the sand is still wet, and a ripple effect can be seen.

Images $A$ and $B$ were taken in August 2011.
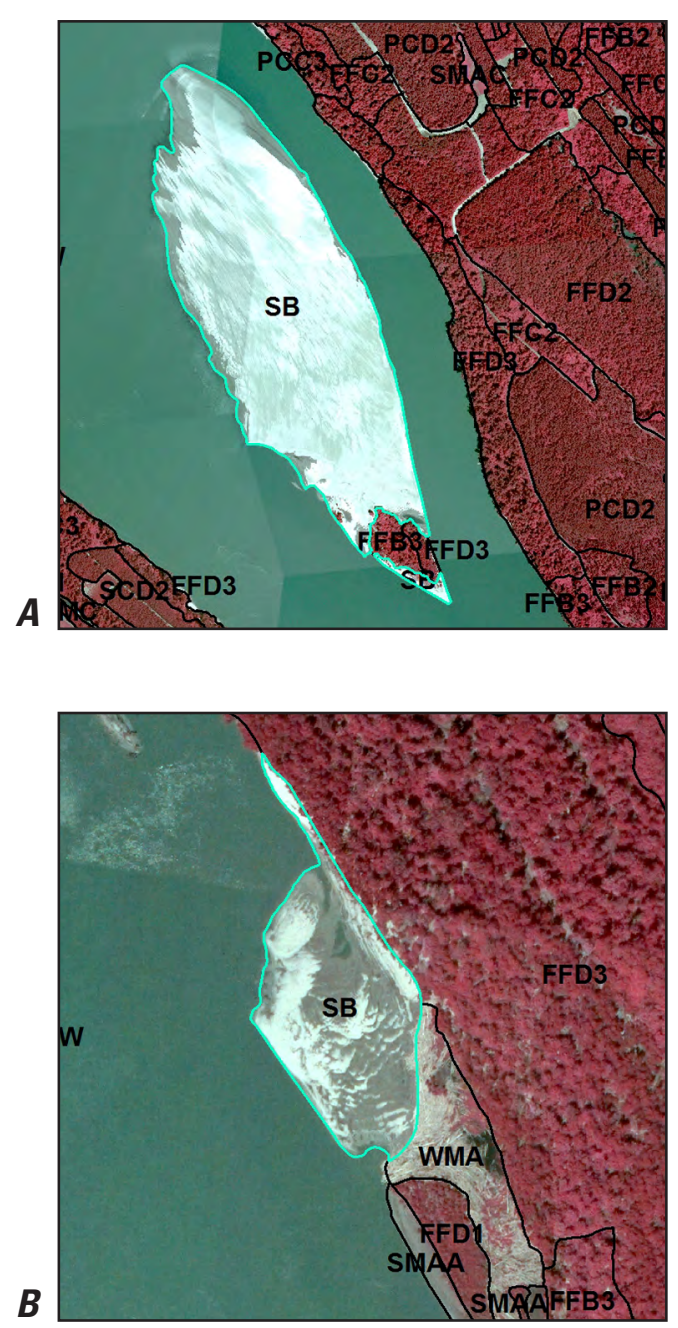


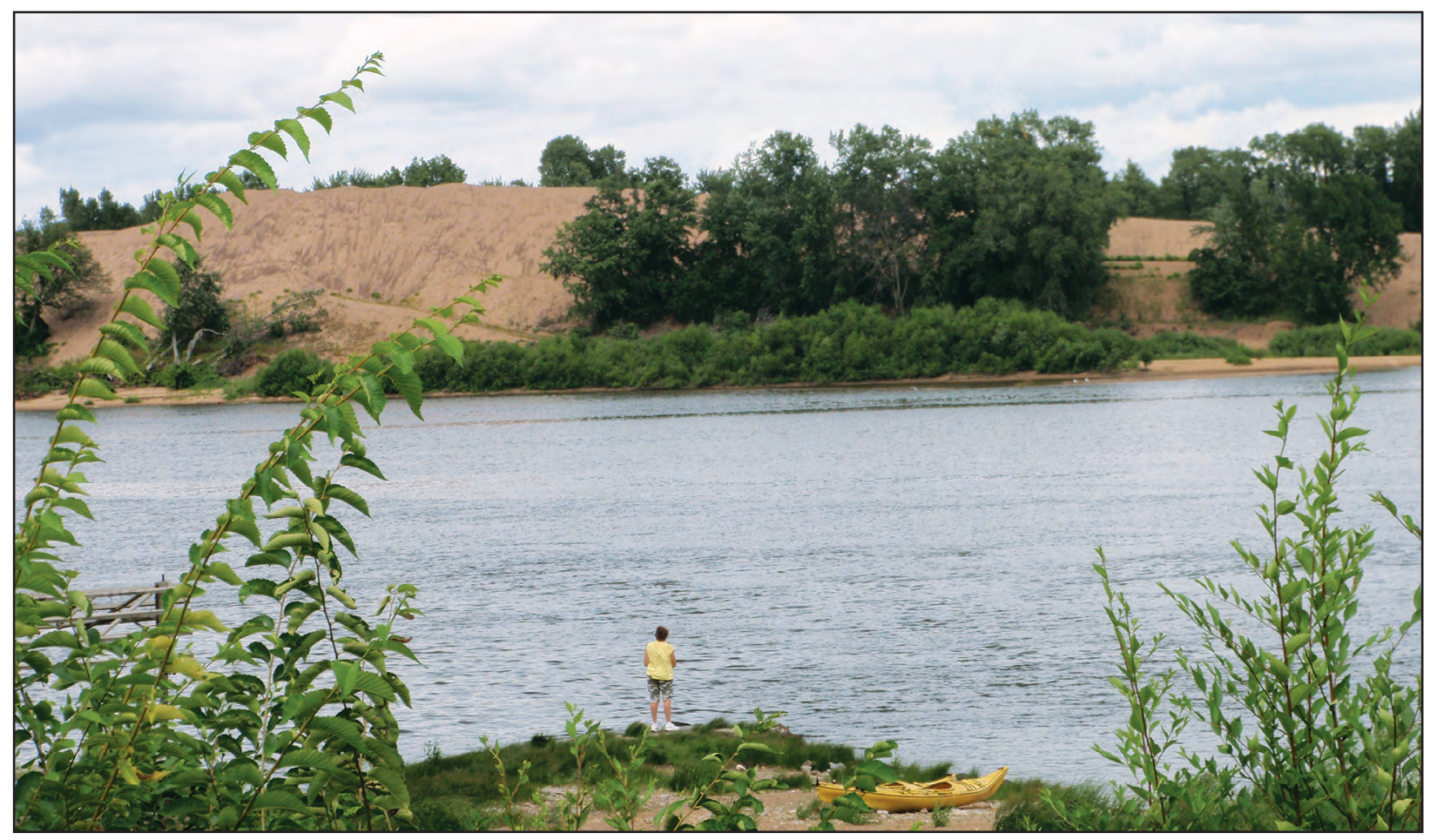

\section{Sand (SD)}

The Sand (SD) map class represents areas of dry, nonvegetated sand that is infrequently flooded. It typically includes sand spoil banks, beaches, and other sandy areas that are upland. This map class may have small inclusions of grasses and (or) forbs ( $<10$ percent), trees $(<10$ percent), or shrubs $(<25$ percent $)$.

Images $A$ and $B$ show examples of the Sand signature. It generally appears white and elevated. Image $A$ is a sand spoil bank. Image $B$ is a beach. Both appear elevated, indicating they would be infrequently flooded, and they display as white.

Images $A$ and $B$ were taken in August 2010.

\section{No Coverage (NC)}

The No Coverage (NC) map class represents a gap in the imagery coverage. This gap could be due to incomplete coverage of the study area by the flight plan or areas that are obscured by clouds or shadows. This map class is rarely used because supplemental imagery can often be found to fill in the gap. If no suitable imagery exists, however, the area will be attributed with NC.
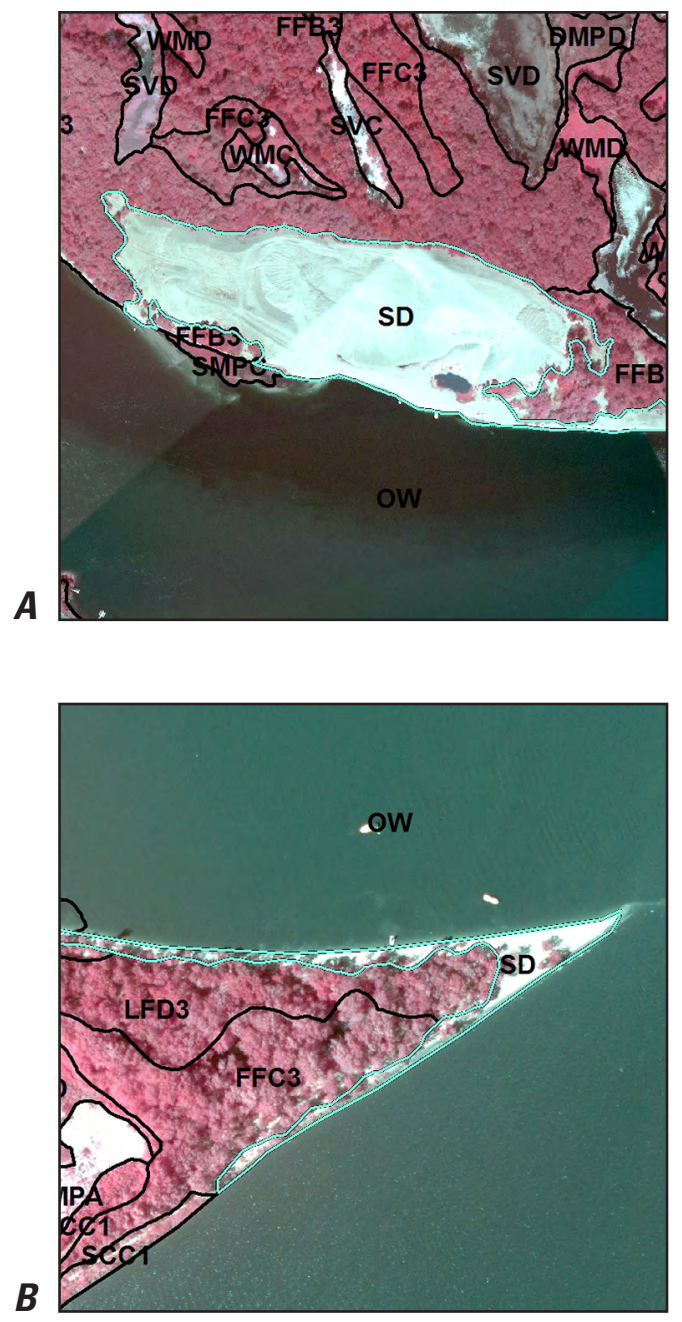


\section{Appendix 3. Classification Key for the General Wetland Vegetation Classification System}

$[<$, less than; $>$, greater than; $\%$, percent $]$

Dichotomous key for the General Wetland Vegetation Classification System.

General

code

1a Vegetation $<10 \%$ of the area 2

2a Aquatic - Open water, or Lemnaceae (duckweed) sparse enough to see $<10 \%$ submerged vegetation present, or Lemnaceae too dense to see submerged vegetation

$2 b \quad$ Terrestrial

3a Residential homes, homesteads in rural settings, farmsteads, industrial complexes, parks, locks, dams, marinas, boat launches,

3b Exposed mud or sand

4a Mudflat

$4 \mathrm{~b}$ Sand

$5 \mathrm{~b} \quad$ Sand dunes, sand spoil banks, beaches, and other sandy areas that are upland rip-rap, or newly constructed artificial islands

5a Sand bar

1b Vegetation $>10 \%$ of the area (not including Lemnaceae)

6a Includes residential homes, homesteads in rural settings, farmsteads, or parks

6b Does not include residential homes, homesteads in rural settings, farmsteads, or parks

7 a Shrub cover $<25 \%$ and tree cover $<10 \%$ of the area

8a Submerged vegetation $>10 \%$ of the vegetation; all other life forms $<10 \%$

$8 \mathrm{~b}$ At least one nonsubmerged species $>10 \%$ of the vegetation, submerged vegetation may be present or absent

9a Rooted-floating aquatics (that is Nelumbo, Nymphaea, Nuphar) $>50 \%$ of the vegetation

$9 \mathrm{~b}$ Annual or perennial emergents or perennial grasses and (or) forbs $>50 \%$ of the vegetation

10a Annual or perennial emergents $>50 \%$ of the vegetation

11a Rooted floating aquatics $>10 \%$

$11 \mathrm{~b}$ Rooted floating aquatics $<10 \%$

12a Deep marsh species (for example, Butomus, Pontederia, Sagittaria, Sparganium, Typha, Zizania) $>50 \%$ of the vegetation

13a Annuals (for example, Zizania)

13b Perennials (for example, Butomus, Pontederia, Sagittaria, Sparganium, Typha)

14 a One or two species; may include rooted-floating aquatics $>10 \%$ of the vegetation

$14 \mathrm{~b}$ One species $>50 \%$ of the vegetation and species other than rooted-floating or deep marsh $>10 \%$ of the vegetation; or three or more deep marsh species

$12 \mathrm{~b}$

Carex or shallow marsh species (for example, Bidens, Cyperus, Echinochloa, Eleocharis, Lythrum, Phragmites, Schoenoplectus) $>50 \%$ of the vegetation

15 a Carex $>50 \%$ of the vegetation

$15 \mathrm{~b}$ Shallow marsh species $>50 \%$ of the vegetation

16a Annuals (for example, Bidens, Cyperus, Echinochloa, Eleocharis)

16b Perennials (for example, Lythrum, Phragmites, Schoenoplectus)

17a Lythrum $>50 \%$ of the vegetation

18a Only Lythrum present

$18 \mathrm{~b}$ Lythrum and one or more species $>10 \%$ of the vegetation

17b Shallow marsh species other than Lythrum $>50 \%$ of the vegetation

$19 \mathrm{a}$ One species or a combination of species $>50 \%$ of the vegetation; except when

Phragmites $>50 \%$ of the vegetation and Phalaris $>10 \%$ of the vegetation

19b Phragmites $>50 \%$ of the vegetation and Phalaris $>10 \%$ of the vegetation
3

DV

4

MUD

5

SB

SD

OW$$
\text { V }
$$

6

DV

7

8

SV

9

RFA

10

11

DMP

12

13

DMA

14

DMP

SMP

15

SM

16

SMA

17

18

SMP

WM

19

SMP

WM 


\section{Appendix 3. Classification Key for the General Wetland Vegetation Classification System-Continued}

$[<$, less than; $>$, greater than; \%, percent $]$

Dichotomous key for the General Wetland Vegetation Classification System.

General

code

$10 \mathrm{~b}$ Perennial grasses or forbs $>50 \%$ of the vegetation

20

20a Landscape altered for human use

21a Areas for agricultural or livestock use

22a Cultivated fields for crops

22b Pastured area used for production of livestock

21b Areas not for agricultural or livestock use

23a Roads or railroads including grasses, forbs, or shrubs in rights-of-way RD

23b Levees (continuous dikes or embankments) LV

20b Landscape not altered for human use

24a Wet soils (for example, Amaranthus, Leersia, Phalaris, Solidago, Spartina)

24b Dry soils

$7 \mathrm{~b}$ Shrub cover $>25 \%$ of the area or tree cover $>10 \%$ of the area

$25 \mathrm{a}$ Shrub cover $>25 \%$ of the area and tree cover $<10 \%$ of the area

26 Salix $>50 \%$ of the vegetation

$26 \mathrm{~b}$ Other shrubs $>50 \%$ of the vegetation

27a Shrubs growing in standing water or with annual or perennial emergents

28a Shrubs (for example, Cephalanthus, Decodon) growing in standing water or with deep marsh species (for example, Butomus, Pontederia, Sagittaria, Sparganium, Typha, Zizania)

$28 \mathrm{~b}$ Shrubs growing with shallow marsh species (for example, Bidens, Cyperus, Echinochloa, Eleocharis, Lythrum, Phragmites, Schoenoplectus)

$27 \mathrm{~b}$ Shrubs growing with perennial grasses or forbs

DMS

SMS

29a Wet soils (for example, Alnus, Cornus, Sambucus)

29b Dry soils

$25 \mathrm{~b}$ Tree cover $>10 \%$ of the area

30a Cultivated areas (for example, orchards or pine plantations). Areas of deciduous lowland trees that appear as plantations, but are not planted for harvest but for restoration purposes are keyed through a noncultivated forest class (30b).

30b Noncultivated areas

31a Populus or Salix $>50 \%$ of the vegetation

32a Populus $>50 \%$ of the vegetation

$32 \mathrm{~b}$ Salix $>50 \%$ of the vegetation

$31 \mathrm{~b}$ Other trees $>50 \%$ of the vegetation

33a Coniferous trees $>50 \%$ of the vegetation (for example, Pinus, Juniperus) and not on saturated soils or in standing water

$33 \mathrm{~b}$ Deciduous trees and (or) coniferous trees on saturated soils or in standing water $>50 \%$ of the vegetation

34a Trees growing in standing water (for example, Taxodium, Nyssa)

$34 \mathrm{~b}$ Trees not growing in standing water

35a Trees growing on wet soils

36a Trees growing on alluvial soils; usually dominated by Acer

36b Trees growing on moist, well-drained soils; usually dominated by Quercus $\quad$ LF 


\section{Appendix 4. Representative Genera and Species and the Map Classes With Which They Are Commonly Associated}

[General codes for the map classes are in Appendix 3]

\begin{tabular}{|c|c|c|}
\hline Genera & Species & Map code \\
\hline Acer & A. negundo, A. rubrum, A. saccharinum & FF, LF, UF \\
\hline Alnus & A. glutinosa, A. incana & WMS \\
\hline Amaranthus & A. albus, A. tuberculatus & WM \\
\hline Amorpha & A. fruticosa & WMS \\
\hline Betula & B. nigra & $\mathrm{FF}, \mathrm{LF}$ \\
\hline Bidens & B. cernua, B. frondosa & SMA \\
\hline Butomus & B. umbellatus & DMP \\
\hline Carex & C. spp. ${ }^{1}$ & SM \\
\hline Carya & C. cordiformis, C. illinoinensis, C. ovata & LF, UF \\
\hline Cephalanthus & C. occidentalis & DMS, SMS \\
\hline Cornus & C. spp. ${ }^{1}$ & WMS, SS \\
\hline Cyperus & C. erythrorhizos, C. esculentus, C. odoratus, C. strigosus & SMA \\
\hline Decodon & D. verticillatus & DMS, SMS \\
\hline Echinochloa & E. crus-galli, E. muricata, E. walteri & SMA \\
\hline Eleocharis & E. acicularis, E. obtusa, E. palustris & SMA \\
\hline Fraxinus & F. nigra, F. pennsylvanica & WS, FF \\
\hline Juniperus & J. virginiana & $\mathrm{CN}$ \\
\hline Leersia & L. lenticularis, L. oryzoides, L. virginica & WM \\
\hline Lythrum & L. alatum, L. salicaria & SMP, WM \\
\hline Nelumbo & N. lutea & RFA \\
\hline Nuphar & N. lutea, & RFA \\
\hline Nymphaea & N. odorata, & RFA \\
\hline Nyssa & N. aquatica, $N$. sylvatica & WS \\
\hline Phalaris & P. arundinacea & WM \\
\hline Phragmites & P. australis & DMP, SMP, WM \\
\hline Pinus & P. resinosa, $P$. strobus & $\mathrm{CN}, \mathrm{PN}$ \\
\hline Platanus & P. occidentalis & FF, LF \\
\hline Polygonum & P. spp. ${ }^{1}$ & SMA, DMP, SMP, WM \\
\hline Pontederia & P. cordata & DMP \\
\hline Populus & P. deltoides & $\mathrm{PC}, \mathrm{FF}$ \\
\hline Quercus & Q. spp. ${ }^{1}$ & FF, LF, UF \\
\hline Sagittaria & S. latifolia, S. rigida & DMP, SMP \\
\hline Salix & S. interior, S. nigra & SC, SMS, WMS, FF \\
\hline Sambucus & S. canadensis & WMS \\
\hline Schoenoplectus & S. spp. ${ }^{1}$ & SMP \\
\hline Solidago & S. spp. ${ }^{1}$ & WM, GR \\
\hline Sparganium & S. eurycarpum & DMP, SMP \\
\hline Spartina & S. pectinata & WM \\
\hline Taxodium & T. distichum & WS \\
\hline Typha & T. angustifolia, T. latifolia, Typha $\times$ glauca & DMP, SMP \\
\hline Ulmus & U. americana, U. pumila, U. rubra & FF, LF, UF \\
\hline Zizania & Z. aquatica & DMA \\
\hline
\end{tabular}

${ }^{1}$ The abbreviation "spp." is used when more than four predominant species are present. 


\section{Appendix 5. Example Accuracy Assessment Contingency Table}

\begin{tabular}{|c|c|c|c|c|c|c|c|c|c|c|c|c|c|c|c|c|c|c|c|c|c|c|c|c|c|c|c|c|}
\hline \multirow{3}{*}{ 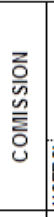 } & 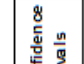 & 苨 & 前 & 善 & \%ั. & : & 厸 & 总 & है & 客 & 夢 & 兽 & \%̊. & 总 & કै & 参 & है & 㚐 & 糕 & 害 & 幽 & $\stackrel{\circ}{\%}$ & 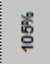 & & \multirow{4}{*}{\multicolumn{3}{|c|}{ 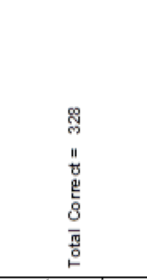 }} & \\
\hline & 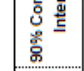 & $\stackrel{\circ}{\circ}$ & 总 & 鲾 & 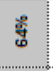 & 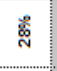 & : & 兽 & : & $\stackrel{\circ}{\stackrel{R}{*}}$ & 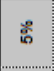 & \%ั. & : & $\frac{2}{\mathrm{~g}}$ & เั & 善 & $\stackrel{8}{\stackrel{2}{2}}$ & $\%$ & 兽 & 言 & 曾 & జ్. & \%ั & & & & & \\
\hline & 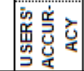 & $\frac{8}{8}$ & 善 & 商 & 总 & 总 & : & ${ }^{\circ}$ & : & 覾 & : & 卷 & 商 & 夢 & \%。ํำ & 亏 & $\frac{8}{9}$ & \%े & 龕 & s: & s: & s: & : & & & & & \\
\hline \multirow{23}{*}{ 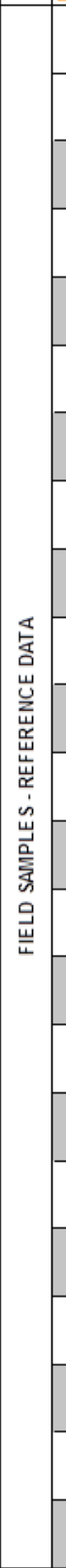 } & \begin{tabular}{|l|}
\multicolumn{1}{c}{} \\
5 \\
\end{tabular} & 2 & \& & $\bar{N}$ & $\mathscr{\sim}$ & 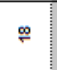 & \pm & $\stackrel{\circ}{\circ}$ & $\approx$ & m & $\infty$ & ন & $\approx$ & $\simeq$ & $=$ & $\bar{\pi}$ & $\sigma$ & $\mathscr{8}$ & $\approx$ & - & 的 & $\circ$ & ? & 罟 & & & & \\
\hline & 吕 & & & & & & & & & & & & & & & & & & & & & & ? & 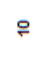 & : & 䍘 & $\stackrel{\circ}{\circ}$ & \\
\hline & ๓ & & & & & & & & & & & & & & & & & & & & & 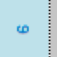 & & $\bullet$ & 영 & స్టి & : & 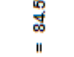 \\
\hline & 彦 & & & & & & & & & & & & & & & & & & & & "̊ & & & $\stackrel{\text { N }}{2}$ & $\stackrel{8}{8}$ & 产 & : & 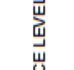 \\
\hline & $\stackrel{\infty}{a}$ & & & & & & - & & & & & & & & & & & & & - & & & & N & \% & \% & 旙 & \\
\hline & $\mathscr{8}$ & & & & & & $\bullet$ & & & & & & & & & - & & & 요 & & & & & $\tilde{n}$ & $\frac{2}{\dot{\alpha}}$ & 总 & \% & 总商 \\
\hline & 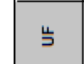 & & & & & & & & & & & & & & & & - & $\cong$ & & & & & & मे & 炎 & $\frac{2}{5}$ & 煎 & \\
\hline & za & & & & & & & & & & & & & & N & - & + & & & & & & & r & 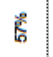 & $\stackrel{8}{\%}$ & \% & 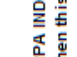 \\
\hline & z & & & & & & & & & & & & & & & 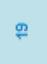 & N & & & & & & & $\bar{\pi}$ & s: & 染 & 前 & 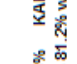 \\
\hline & د & & & & & & & & & & & - & & & $\omega$ & & & N & & & & & & $\infty$ & 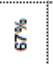 & 善 & \% & 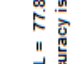 \\
\hline & 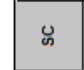 & & & & & & & - & $\infty$ & - & & & & r & & & & & & & & & & \pm & 害 & 㝵 & \%: & 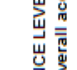 \\
\hline & : & & & & & & & & & & & & $\stackrel{2}{=}$ & N & & & - & & & & & & & ส & 曾 & $\stackrel{R}{2}$ & 홍 & 宸 \\
\hline & 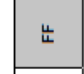 & & & & & & & & N & - & & $\bar{\pi}$ & + & N & $\infty$ & & & & & & & & & 8 & 敩 & 斝 & 总 & 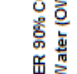 \\
\hline & 怘 & & & & & & & & & N & N & & & & & & - & & N & & & & & r & 总 & $\stackrel{\circ}{k}$ & 总 & 产 \\
\hline & $\sum_{s}^{\infty}$ & & & & & & & & & n & - & & & - & & & & & & & & & & $\infty$ & 总 & 尊 & : & 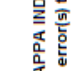 \\
\hline & $\stackrel{n}{5}$ & & & & N & & & - & $=$ & - & & & & & & & & & & & & & & \% & 䟫 & 善 & \% & 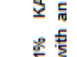 \\
\hline & $\stackrel{\text { s. }}{\frac{0}{2}}$ & & & & & & & 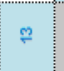 & & & & & & & & & & & & & & & & 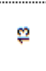 & : & 总 & 总 & 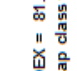 \\
\hline & इ & & & & & $\sim$ & r & & & - & & & & & & & & & & & & & & 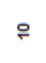 & s & $\frac{8}{4}$ & 券 & $\frac{x}{0}$ \\
\hline & $\frac{0}{5}$ & & & - & - & 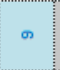 & & & - & & & & & & & & & & & & & & & $\cong$ & 善 & 害 & : & 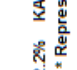 \\
\hline & 言 & & & & ส & & & & $m$ & & & & & & & & & & & & & & & 果 & 总 & \%。․․ & 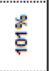 & ב" \\
\hline & 高 & & & 8 & & r & & & & & & & & & & & & & & & & & & $\pi$ & $\frac{2}{2}$ & : & 今。 & 总 \\
\hline & $\begin{array}{l}\text { 菨 } \\
\end{array}$ & & $\hat{\mathrm{N}}$ & & & & & & & & & & & & & & & & & & & & & N & $\frac{8}{6}$ & 兽 & 윰 & 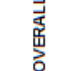 \\
\hline & के & 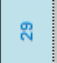 & N & & $m$ & & & & & & & & & & & & & & & & & & & मे & 总 & $\stackrel{8}{2}$ & 疍 & \\
\hline & 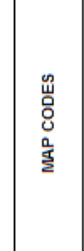 & के & 咅 & 言 & 言 & $\frac{0}{\bar{n}}$ & $\underline{\underline{s}}$ & 訔 & $\sum_{n=0}^{n}$ & 䁬 & s & 岌 & $\because$ & 只 & ت & z & za & 岂 & $\frac{\alpha}{0}$ & is & 号 & Ф & s & 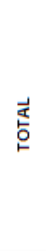 & 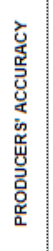 & 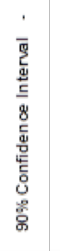 & 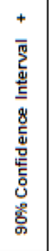 & \\
\hline & & & & & & & & & & & Iran & ૦Шગ & c日add & & & & & & & & & & & & & ISSIW & & \\
\hline
\end{tabular}





\section{3 inc}

Q.

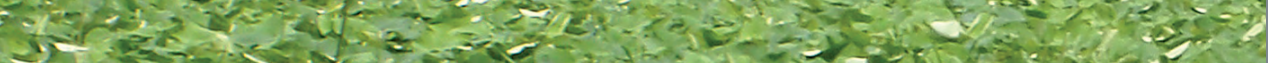

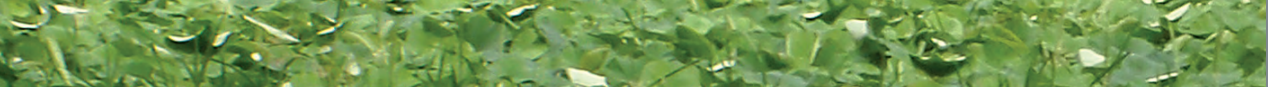

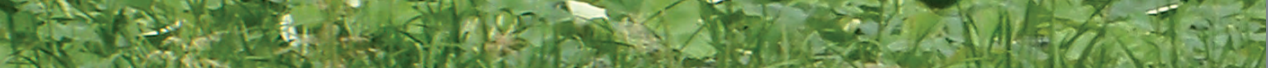

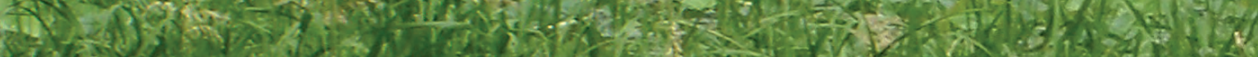

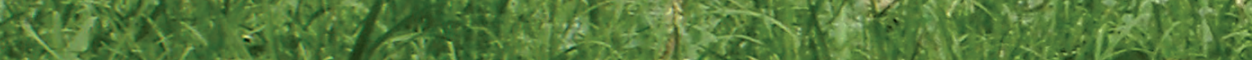
al

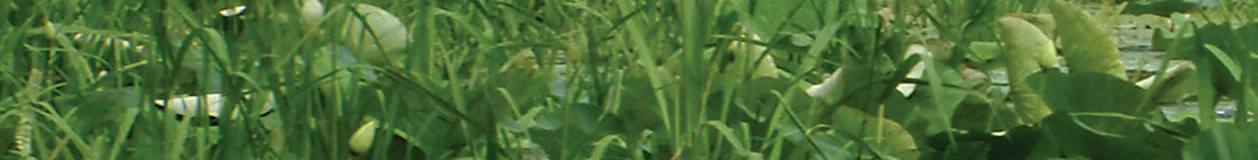
$\frac{1}{2}$

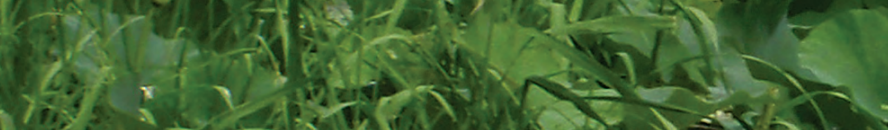

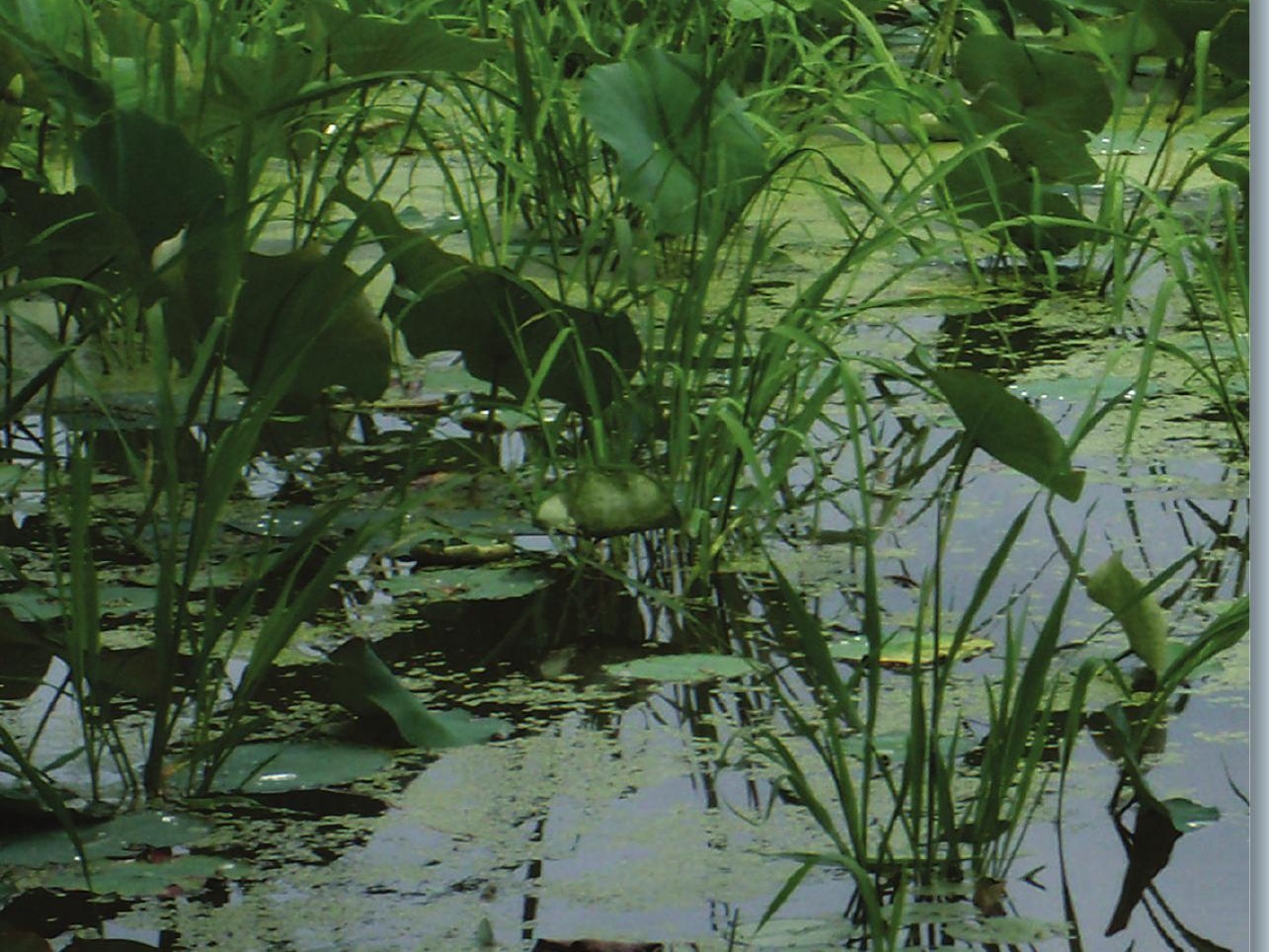

